BIBLIOTECA

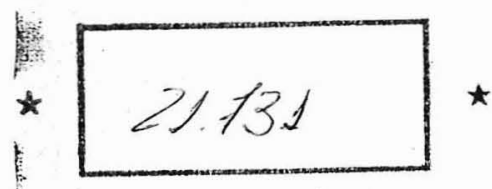

\title{
"Complexos de Vanádio como Miméticos de Peroxidases e Catalisadores de Oxidação: síntese e caracterização espectroscópica."
}

\author{
Joelson de Souza
}

Dissertação de Mestrado

Profa. Dra . Ana Maria da Costa Ferreira

Orientadora

São Paulo - SP

2006 


\section{"Complexos de vanádio como miméticos de peroxidases e catalisadores de oxidação: síntese e caracterização espectroscópica "}

\section{JOELSON DE SOUZA}

Dissertação de Mestrado subłnetida ao Instituto de Química da Universidade de São Paulo como parte dos requisitos necessários à obtenção do grau de Mestre em Química - Área: Químiça Inorgânica.

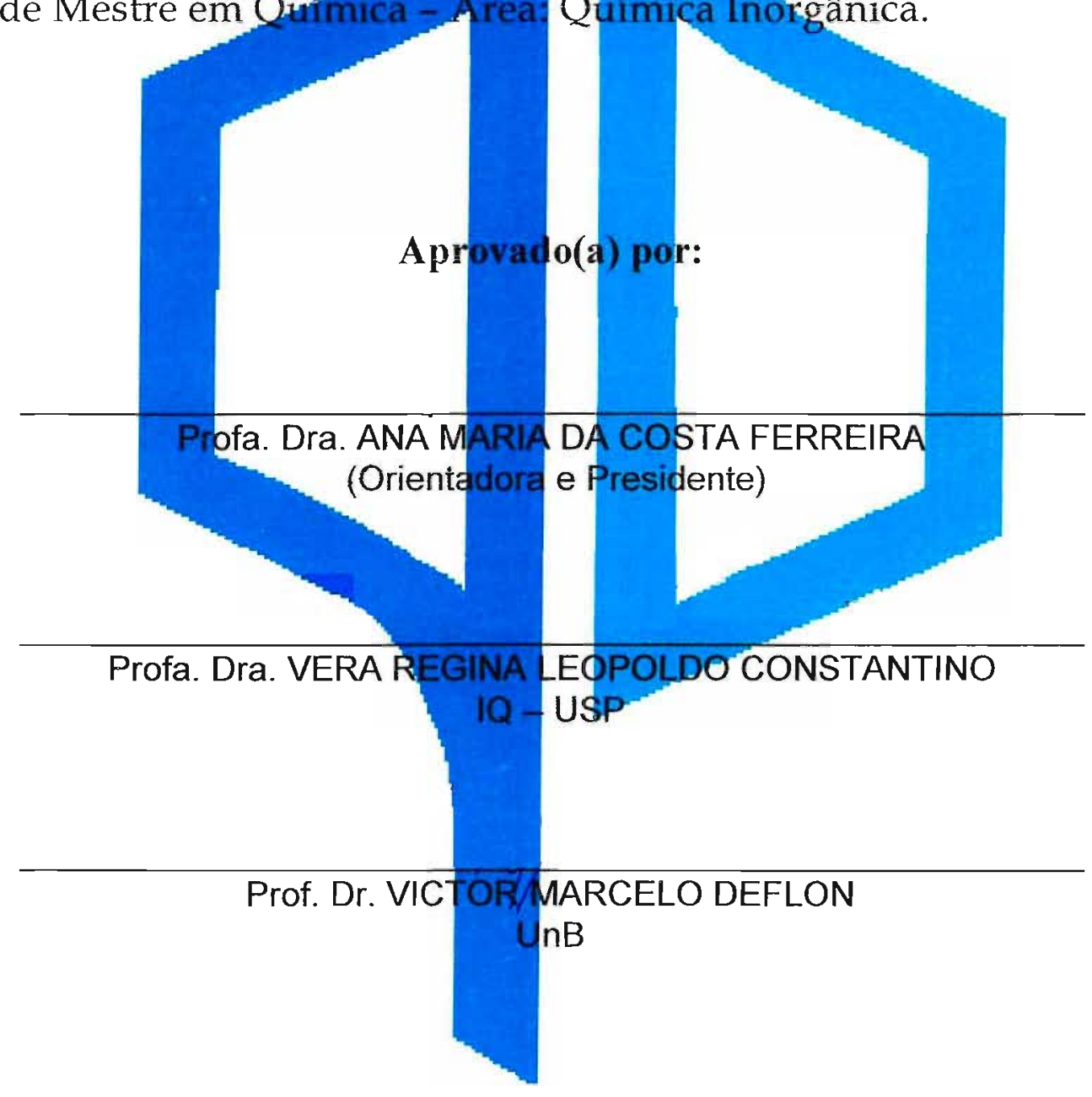

SÃO PAULO

25 DE SETEMBRO 2006 
If I have the gift of prophecy and can fathom all mysteries and all knowledge, but have not love, I am nothing.

I Corinthians 13-2 
Ao Pai das luzes, Regente maior do Universo e criador de todas as coisas. Pelo seu amor, vida, força energia e entendimento que tenho que lutar sempre sem olhar para as adversidades e nunca desistir.

Pela grande oportunidade de crescimento espiritual.

Por ser meu amigo incondicional em todas as horas.

Te amo Senhor de todo meu coração. 
Dedico este trabalho ao meu pai José e minha mãe Vera(in memorian) sempre guerreira dando sempre seu melhor, a minha querida e mais do que tia Liu, pelo seu cuidado e amor, nem só comigo mais com todos meus irmãos, aos meus irmãos Joselito, Jaílton e Joeme(in memorian) que apesar da distância estão sempre dispostos a ajudar, aos meus sobrinhos Rhu e Bruninho e minhas cunhadas, Néa e Glória. 
À profa. Dr ${ }^{\mathrm{a}}$ Ana Maria da Costa Ferreira pela paciência, amizade $\mathrm{e}$ grande precisão na orientação. Me ensinou a crescer tanto como profissional como ser humano. 


\section{AGRADECIMENTOS}

Ao grupo de pesquisa em Bioinorgânica do qual eu faço parte: Mariana, Vivian, Saulo, Bruno, Kelly, e Magaly, pela amizade e o convívio.

À técnica Maria Aparecida, sempre prestativa.

Aos colegas da salinha: Karina, Otávio, André e agregados.

Ao grupão Ana Lùcia, Vanessa, Renatinha, Cláudia, Marcos, RenataTorres, e Geise.

Às professoras Vera Regina Leolpodo Constantino e Denise de Oliveira Silva, pelas discussões nas reuniões de grupo.

Ao professor Jivaldo do Rosário Matos, pelas Análises Termogravimétricas.

Á dona Ivone, pelas conversas e sábios conselhos.

To my English teacher Adriene Zigaib and my classmates Ana Digianatalli, Carly Haaka and Flavinha, for friendly.

Aos colegas do AP-309 Francisco e José, pela amizade, descontrações, pizzas e cocacola.

Á professora Rosenira Serpa da Cruz da UESC, pelo incentivo.

À Wedilla, pelo seu carinho e amizade e por ter sempre confiado em mim.

Aos amigos da SNT Franklin, Moisés e Marco Antônio, pela amizade e orações.

Aos amigos ganduenses Paulo, Nely, Luciano (Polar) e Murilo, pela amizade e incentivo.

À Fapesp, pelo apoio financeiro na compra de reagentes e materläls.

Ao CNPq, pela bolsa concedida. 


\section{Índice}

Resumo

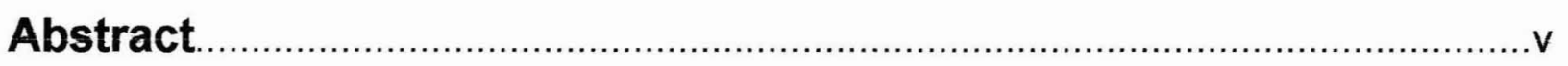

Lista de abreviaturas

i. Estrutura das Iminas e dos Complexos de Vanádio preparados..................vi

ii. Estrutura dos principais precursores dos compostos preparados................

iii. Terminologia empregada ..........................................................................

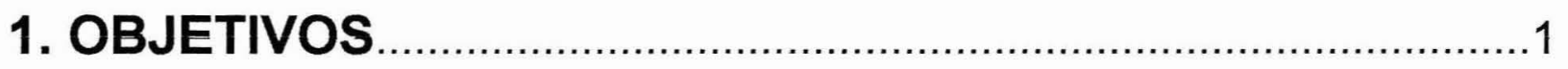

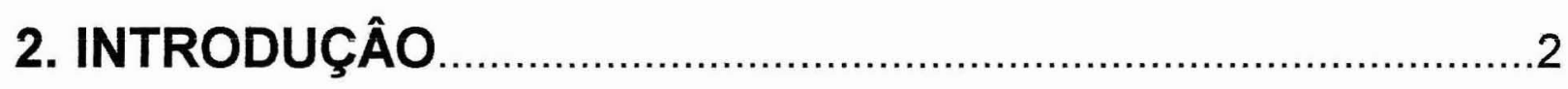

2.1. A Química do Oxovanádio................................................................

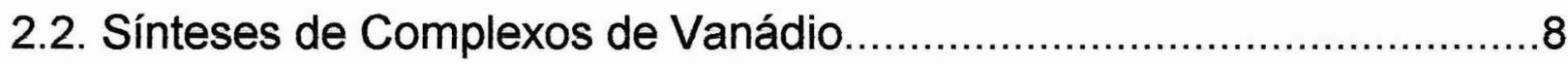

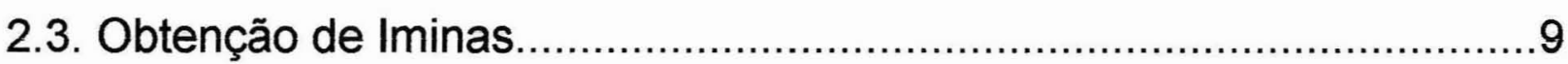

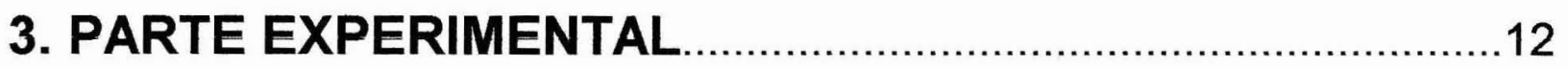

3.1. Reagentes e solução............................................................. 12

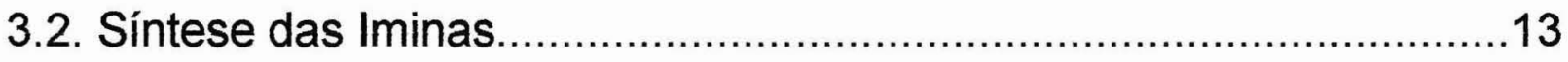

3.3. Síntese dos Complexos de Vanádio(IV) ........................................15

3.4. Instrumentos e Técnicas Experimentais.........................................19 


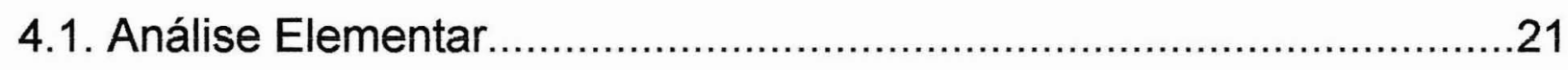

4.2. Espectroscopia na região do Ultravioleta e Visível.............................25

4.3. Espectroscopia na região do Infravermelho...................................49

4.4. Análise Termogravimétrica.......................................................59

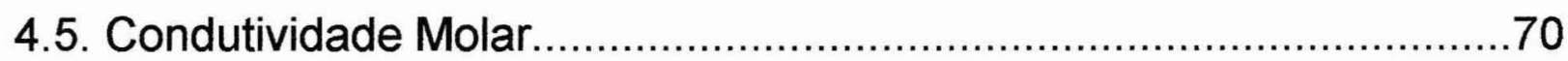

4.6. Espectroscopia de Ressonância Paramagnética Eletrônica...............72

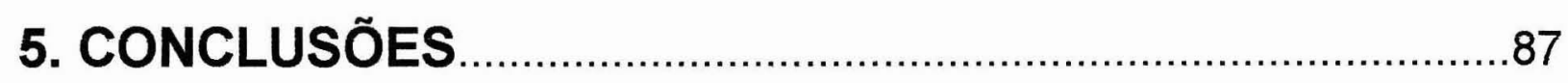

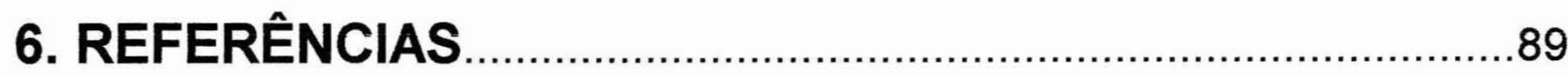




\section{Resumo}

Quatro novos complexos mononucleares e um dinuclear de vanádio(IV) contendo ligantes do tipo imínico e carboxilato foram sintetizados e caracterizados através de diferentes técnicas espectroscópicas, UV/Vis, FT/IR e EPR, além de análise elementar, medidas de condutividade molar e, para alguns deles, análise termogravimétrica. Alguns deles foram obtidos como espécies neutras e outros, contendo grupos carboxilatos, foram isolados como espécies aniônicas, com contra-íons $\mathrm{Na}^{+}$ou $\mathrm{NH}_{4}^{+}$.

Os complexos clássicos da literatura, largamente estudados e caracterizados, $\left[\mathrm{V}^{\mathrm{IV} O} \mathrm{O}(\mathrm{acac})_{2}\right]$ e $\left[\mathrm{V}^{\mathrm{IV}} \mathrm{O}(\right.$ salen)], também foram sintetizados e caracterizados, a fim de comparar suas propriedades com aquelas dos novos complexos de vanádio(IV) sintetizados.

Através das técnicas espectroscópicas, as principais bandas de transição e os principais grupos funcionais existentes nos complexos puderam ser verificados, bem como a simetria da estrutura geométrica e a confirmação do estado de oxidação do metal nos complexos. Além disso, através de medidas de condutividade molar e análise térmica foram confirmadas as razões estequiométricas ligante: metal em cada complexo, verificando-se, por exemplo, a natureza dimérica proposta para o complexo

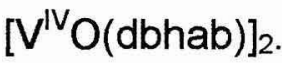




\begin{abstract}
Some new vanadyl complexes, including four mononuclear and one dimeric species, were isolated and characterized by different spectroscopic techniques (UVNis, IR and EPR), in addition to elemental analysis, molar conductivity and, for a few ones, thermal analysis. Two of them were obtained as neutral compounds, and the others, with carboxylate ligands, as anionic species with sodium or ammonium as counter-ions.

Additionally, the classical examples of vanadium complexes, [ $\left.\mathrm{V}^{\mathrm{IV}} \mathrm{O}(\mathrm{acac})_{2}\right] \mathrm{e}$ $\left[\mathrm{V}^{\mathrm{IV}} \mathrm{O}\right.$ (salen)], already extensively studied in the literature, were prepared for comparison purposes.

The main absorption bands in the UVNis and the characteristic ones at the IR spectra permitted the identification of the various complexes, while EPR spectroscopic data allowed to verify the oxidation state and the geometrical arrangements of the ligands around the metal center. Molar conductivity measurements and thermal analysis curves helped to determine the stoichiometric ratio ligand to metal, specially for the $\left[\mathrm{V}^{\mathrm{IV}} \mathrm{O}(\mathrm{dbhab})\right]_{2}$ complex.
\end{abstract}




\section{Lista de Abreviaturas}

i. Estrutura das Iminas e dos Compostos de Vanádio preparados

\section{Estruturas das Iminas}

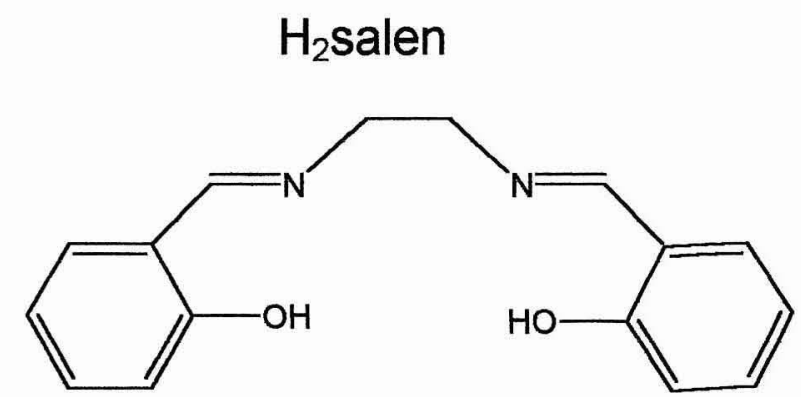

$\mathrm{H}_{2} \mathrm{dbhab}$

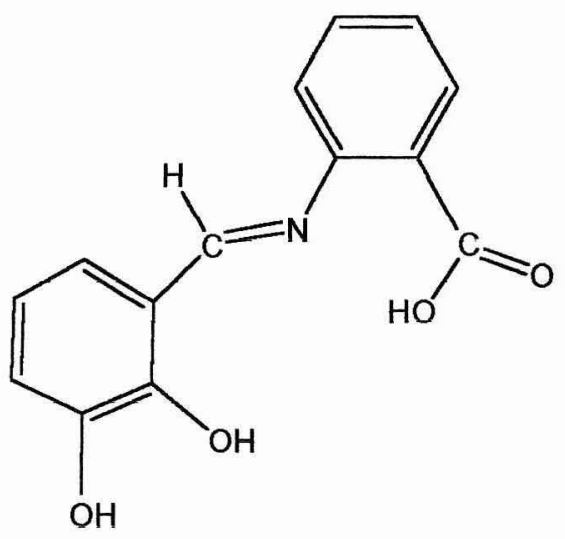

Hdbhbal

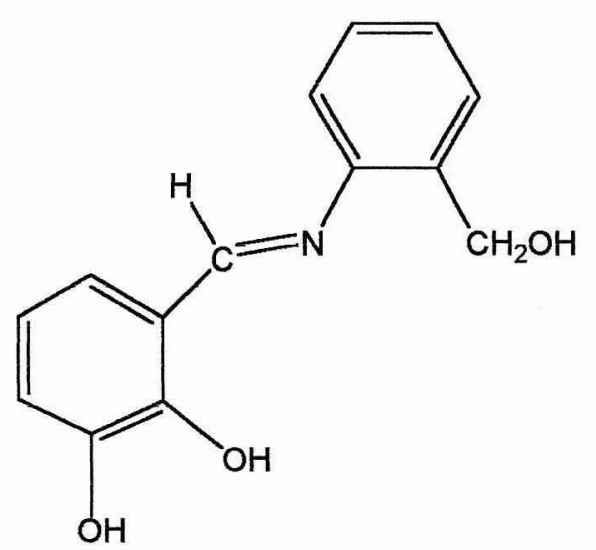


Estrutura dos Complexos de Vanádio(IV) Preparados

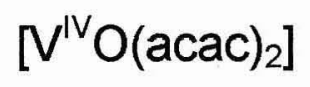<smiles>CC1=C[PH]2(=O)(OC(C)=C1)OC(C)=CC(C)=[O+]2</smiles>

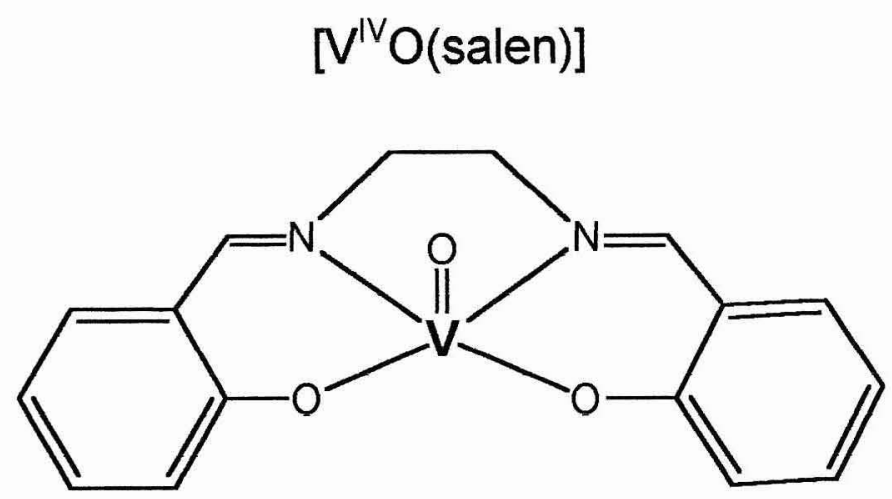

$\left[\mathrm{V}^{\mathrm{V} \mathrm{O}}(\mathrm{dbhbal})_{2}\right]$

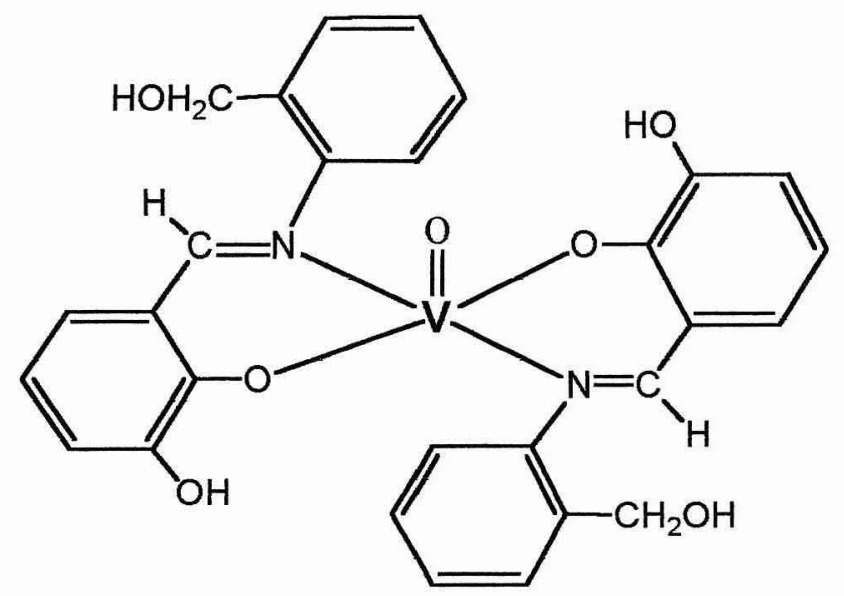


$\left[\mathrm{V}^{\mathrm{IV}} \mathrm{O}(\mathrm{dbhab})\right]_{2}$

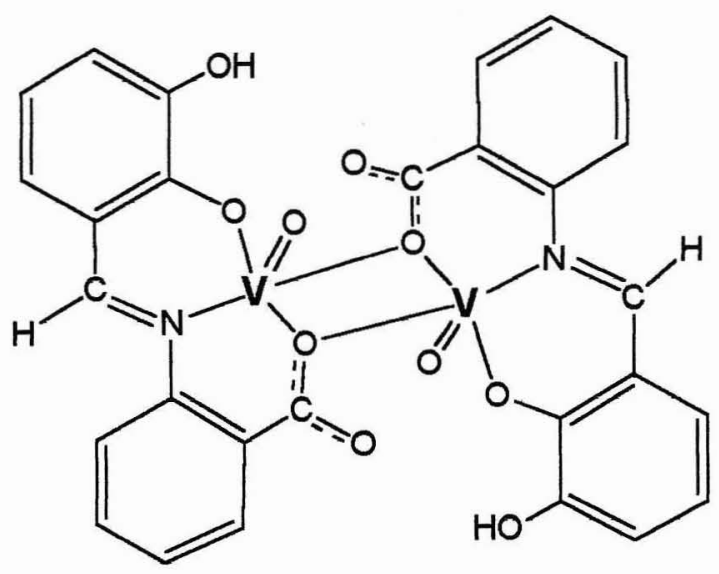

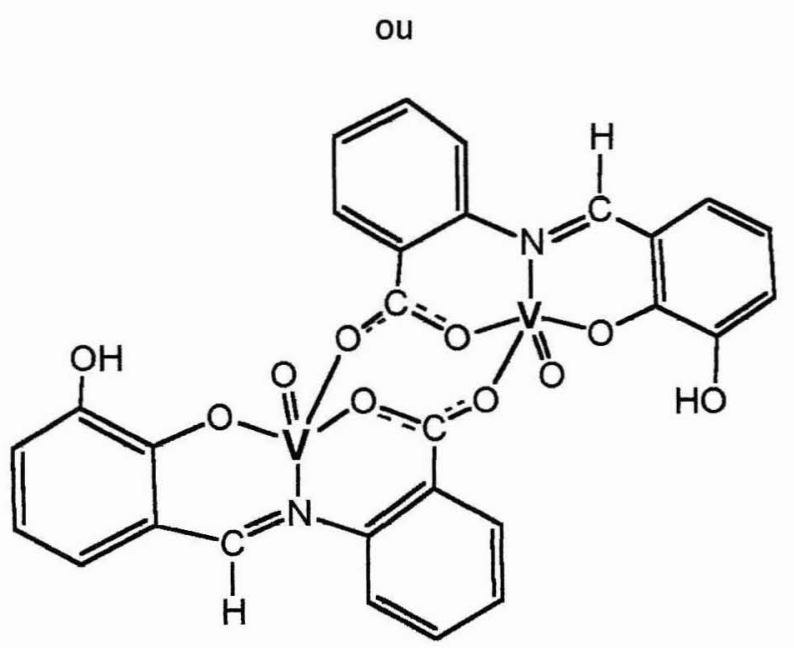

$\mathrm{NH}_{4}\left[\mathrm{~V}^{\mathrm{IV}} \mathrm{O}_{2}\right.$ (dbhab)]<smiles></smiles> 


\section{$\left.\mathrm{Na}_{2}\left[\mathrm{~V}^{\mathrm{IV}} \mathrm{O} \text { (cetoglut) }\right)_{2}\right] \cdot 2 \mathrm{H}_{2} \mathrm{O}$}

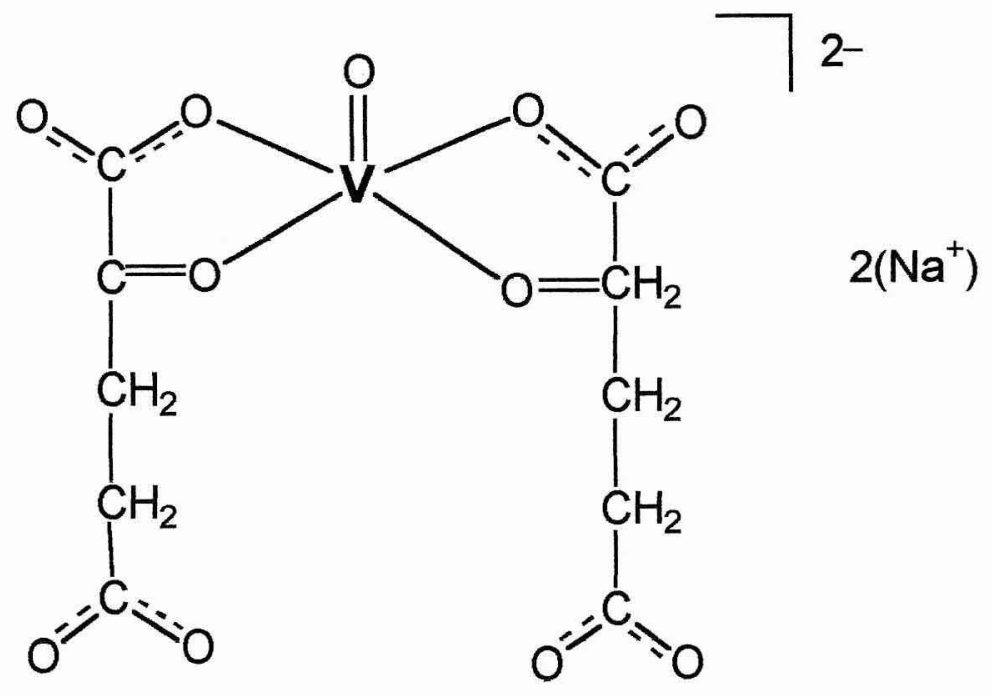

$\left(\mathrm{NH}_{4}\right)_{3}\left[\mathrm{~V}^{\mathrm{IV}} \mathrm{O}_{2}\right.$ (cetoglut) ${ }_{2}$<smiles>O=C(O)CCC1=C(CCC(=O)O)O[PH]2(=O)(OC(=O)C(CCC(=O)O)O2)O1</smiles> 
ii. Estrutura dos principais precursores dos compostos preparados

Abreviatura

$\mathrm{dbh}$<smiles>O=Cc1cccc(O)c1O</smiles>

$a b$<smiles>Nc1ccccc1C(=O)O</smiles>

bal<smiles>Nc1ccccc1CO</smiles>

sal<smiles>O=Cc1ccccc1O</smiles>

Nome

2,3-dihidroxibenzaldeído

Ácido 2-aminobenzóico ou ácido antranílico

Álcool 2-aminobenzílico 
cetoglut

$\left[\mathrm{VO}\left(\mathrm{H}_{2} \mathrm{O}\right)_{5}\right] \mathrm{SO}_{4}[]^{2+}$<smiles>O=C(O)CCC(=O)C(=O)O</smiles>

Ácido $\alpha$-cetoglutárico

Sulfato de Vanadila<smiles></smiles>

Bis(acetilacetonato)oxovanádio(IV)

$\mathrm{NH}_{4}\left[\mathrm{~V}^{\mathrm{V}} \mathrm{O}_{3}\left(\mathrm{H}_{2} \mathrm{O}\right)_{2}\right]$<smiles>O=S(=O)(O)O[Na]</smiles>

Metavanadato de amônio 


\section{iii. Terminologia empregada}

sal= salicilaldeído

en= etilenodiamina

acac $=$ acetilacetona

$\mathrm{dbh}=2$,3-dihidroxibenzaldeído

ab= ácido 2-aminobenzóico ou ácido antranílico

bal= álcool 2-aminobenzílico

cetoglut= ácido $\alpha$-cetoglutárico

ATP $=$ adenosina tri-fosfato

t.a. $=$ temperatura ambiente

$\mathrm{UV}=$ ultravioleta

Vis= visível

IV= infravermelho

$\mathrm{NC}=$ número de coordenação

$\mathrm{IL}=$ intraligante

LMCT $=$ transição do ligante para o metal

DMSO= Dimetilsulfóxido

$\mathrm{TG}=$ termogravimetria 


\section{OBJETIVOS}

a) Sintetizar complexos de vanádio(IV) com ligantes contendo grupos carboxilatos e imínicos, obtidos por reação de condensação entre aldeídos e aminas primárias, seguida de metalação;

b) Caracterizar os compostos obtidos, utilizando diferentes técnicas, como: Análise Elementar, Espectroscopia UVNisível, Espectroscopia no Infravermelho (FT/IR), Espectroscopia de Ressonância Paramagnética Eletrônica (EPR), medidas de Condutividade Molar e Análise Termogravimétrica (TG). 


\section{INTRODUÇÃO}

Em 1801, Andrés Manuel Del Rio afirmou ter descoberto o novo elemento químico de número atômico 23 , ainda não conhecido, em minérios no México. Por causa de sua cor vermelha e dos sais produzidos por acidificação, ele foi chamado de eritrônio. Em 1830 o elemento foi "redescoberto" por Nils Gabriel Sefström em minérios de ferro na Suécia. Devido à riqueza e as variedades de cores encontradas em seus compostos, ele o chamou de vanádio, em referência à beleza da deusa escandinava, cujo nome era Vanadis [1].

O vanádio tem sido detectado com uma concentração de aproximadamente 136 ppm (isto é $0,0136 \%$ ) em rochas da crosta terrestres. É o $19^{\circ}$ elemento em ordem de abundância (entre $\mathrm{Zr}, 162 \mathrm{ppm}, \mathrm{e} \mathrm{Cl}, 126$ ppm), sendo o $5^{\circ}$ metal de transição mais abundante, depois do $\mathrm{Fe}, \mathrm{Ti}, \mathrm{Mn}$, e $\mathrm{Zr}$ [2]. O vanádio também tem sido encontrado em alguns materiais fósseis, como óleo cru, carvão, em rochas betuminosas, sedimentos carbonáceos e carbonato de cálcio, muitas vezes na forma de porfirinas de vanádio. Os principais minérios de vanádio são: patronita $\left[\mathrm{VS}_{4}\right]$, vanadinita $\left[\mathrm{Pb}\left(\mathrm{VO}_{4}\right)_{3} \mathrm{Cl}\right]$ que é isomorfa da apatita $\left[\mathrm{Ca}_{5}\left(\mathrm{PO}_{4}\right)_{3} \mathrm{Cl}\right]$, e a carnitita $\left[\mathrm{K}\left(\mathrm{UO}_{2}\right) \mathrm{VO}_{4}\right] \cdot 3 / 2 \mathrm{H}_{2} \mathrm{O}[3]$.

No oceano, o vanádio está diretamente ligado à vida, onde sua concentração é de 50 $n$ mol. $\mathrm{L}^{-1}$. Alguns organismos aquáticos acumulam vanádio, entre os quais estão muitos membros da família dos tunicatos, as Ascídias, que concentram vanádio na ordem de $0,15 \mathrm{~mol} . \mathrm{L}^{-1} \mathrm{em}$ células especializadas, que são chamadas de vanadócitos. A habilidade de acumular vanádio não é restrita a organismos de vida marinha; foram descobertos em certos liquens metaloenzimas com centro ativo de vanádio [4]. O vanádio está presente nas células de plantas e animais com uma concentração de $10-20$ nmol. $\mathrm{L}^{-1}$, porém em seres humanos, ainda não foi descoberto como elemento essencial, onde sua 
concentração é estimada em 100-200 $\mu \mathrm{g}$ [5], presente no núcleo e nas mitocôndrias das células do fígado, baço e dos rins.

A importância biológica do vanádio foi reconhecida em 1904, pelo seu efeito fungostático em leveduras. Porém, só recentemente o vanádio tornou-se interessante para a Química Bioinorgânica, quando ficou evidente que ele está presente no sítio ativo de várias enzimas [4]. As principais enzimas que possuem vanádio em seu centro ativo são: haloperoxidases, presentes em algas marinhas vermelhas e marrons, fungos terrestres e liquens, V-nitrogenases nas bactérias fixadoras de nitrogênio, cujo centro ativo enzimático é mostrado na Figura 1, e amavadina, um composto de vanádio de baixo peso molecular, obtido da Amanita Muscaria [6] e cujo sítio ativo é esquematicamente mostrado na Figura 2.

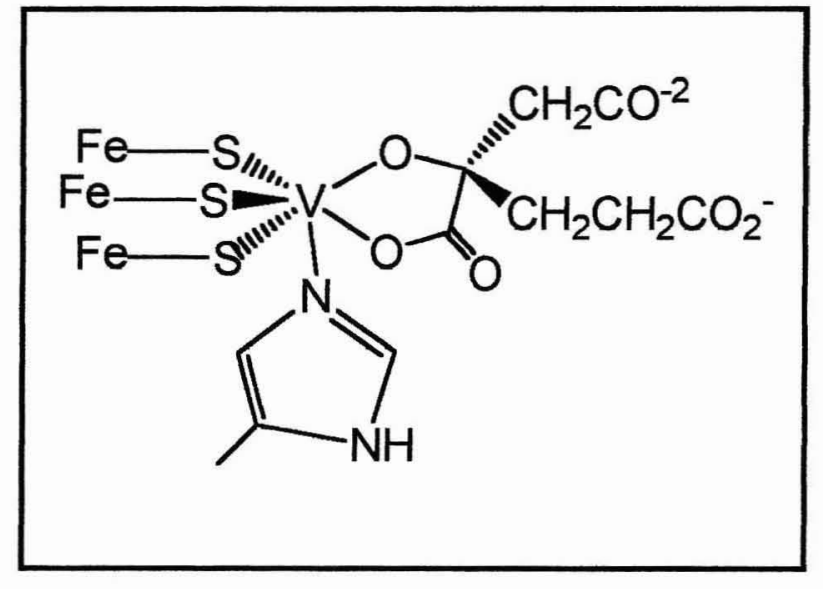

Figura 1. Sítio ativo da V-nitrogenase.

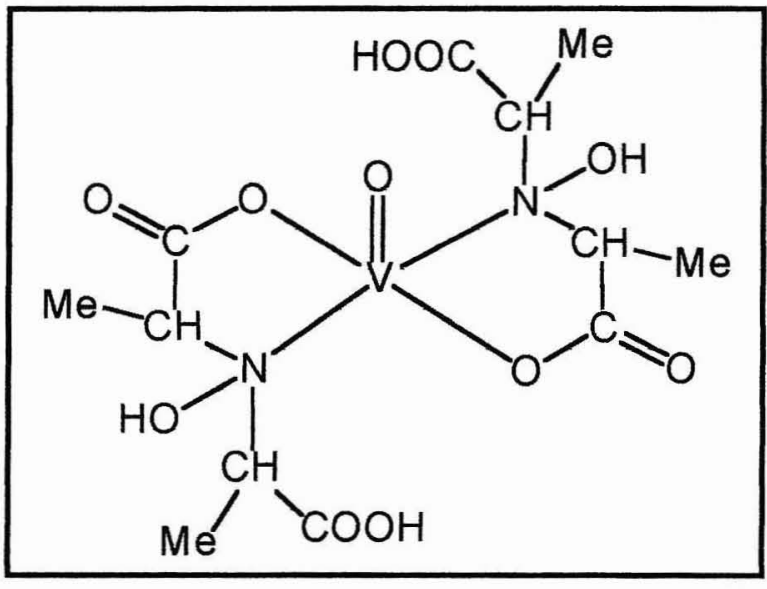

Figura 2. Sítio ativo da Amavadina.

Similarmente ao molibdênio, o vanádio assume uma posição excepcional entre os biometais, em que ambas as formas, catiônica e aniônica, podem participar de processos biológicos.

A forma aniônica do vanádio, vanadato( $\mathrm{V})$ presente como $\left[\mathrm{H}_{2} \mathrm{VO}_{4}\right]^{-} \mathrm{em}$ pH fisiológico, pode ser facilmente reduzida, preferencialmente às formas catiônicas de vanádio(III) e (IV), podendo apresentar numero de coordenação 5, 6, e 7. Assim, a química deste metal 
envolve mudanças estruturais apreciáveis, aumentando seu interesse do ponto de vista químico [7].

Em comum com outros metais, o vanádio pode se apresentar em vários estados de oxidação em seus compostos, de -3 a +5 , sendo +4 e +5 os mais estáveis [8]. Em meio biológico, o vanádio é encontrado predominantemente nos estados de oxidação $\mathrm{V}^{+5}$ (vanadato), como $\mathrm{H}_{2} \mathrm{VO}_{4}^{-}$, que se assemelha ao fosfato, $\mathrm{e} \mathrm{V}^{+4}$ como $\mathrm{VO}^{2+}$ (vanadila), que se assemelha ao $\mathrm{Mg}^{2+}$. No plasma em organismos marinhos, o vanádio se apresenta em ambos os estados de oxidação, sendo que aproximadamente $90 \%$ está ligado a proteinas (predominantemente na transferrina) [9].

No século XIX, o uso de vanádio em humanos foi recomendado como agente terapêutico em estados patológicos, tais como: desnutrição, anemia, tuberculose e diabetes. Lyonnet e Martin [10] observaram em 1889 que pacientes tratados com vanadato de sódio excretavam pouca glicose em sua urina.

Entre os anos de 1975 e 1980, um interesse renovado pelo vanádio surgiu entre bioquímicos e biólogos celulares, atribuído à eficácia do vanadato em inibir fosfohidrolases em quantidades micromolares. Exemplos de tais enzimas são as $\mathrm{Na}^{+}$e $\mathrm{K}^{+}-$ ATPases. Estas enzimas facilitam a manutenção do próprio balanço iônico por bombeamento de íons, utilizando a rica energia da adenosina-trifosfato (ATP). A eficácia do vanadato em inibir $\mathrm{Na}^{+}$e $\mathrm{K}^{+}$-ATPases é historicamente ligada ao descobrimento da ação insulino-mimética de sais de vanádio [10].

Algumas investigações biológicas têm sido realizadas com complexos relevantes de vanádio. Estudos recentes $[11,12,13]$ demonstram que compostos do tipo peroxovanádio como ○ $\left.[\mathrm{VO} \text { (malto })_{2}\right], \mathrm{NH}_{4}\left[\mathrm{VO}\left(\mathrm{O}_{2}\right)_{2}\right.$ (phen)], com os ligantes maltolato (malto) e fenantrolina (phen), têm alta atividade insulino-mimético, sugerindo que eles podem ser uma alternativa oral para a insulina. Complexos de oxovanádio também têm 
sido propostos como agentes antitumoral e antileucêmico [14], entretanto eles podem causar danos ao DNA [15], induzindo o crescimento de células, e são conhecidos como potentes agentes tóxicos e carcinogênicos [16], podendo ser ativos na geração de radicais hidroxil.

Por outro lado, nosso interesse neste trabalho concentra-se na síntese e caracterização de complexos de vanádio(IV) com ligantes contendo grupos carboxilatos e imínicos, que possam atuar como miméticos de peroxidases e sejam capazes de catalisar reações de oxidação de substratos escolhidos como, por exemplo, o ciclohexano [17].

Haloperoxidases são enzimas dependentes de vanádio que catalisam a oxidação de haletos, levando à halogenação de substratos nucleófilos receptores ou que, na ausência desses substratos apropriados, promovem a oxidação de peróxido de hidrogênio a oxigênio singleto $\left({ }^{1} \mathrm{O}_{2}\right)$ e água [18], como mostrado no Esquema 1. Têm sido também apresentadas como bons catalisadores de bromação de vários substratos orgânicos [19].

$$
\begin{aligned}
& \mathrm{X}^{-}+\mathrm{H}_{2} \mathrm{O}_{2}+\mathrm{R}-\mathrm{H}+\mathrm{H}^{+} \longrightarrow \longrightarrow \mathrm{R}-\mathrm{X}+2 \mathrm{H}_{2} \mathrm{O} \\
& \mathrm{X}^{-}+\mathrm{H}_{2} \mathrm{O}_{2} \longrightarrow \mathrm{O}_{2}+2 \mathrm{H}_{2} \mathrm{O}+\mathrm{X}^{-}
\end{aligned}
$$

Esquema 1. Reações de halogenação de substratos nucleófilos receptores.

Existem vários tipos de haloperoxidases, como a iodoperoxidase (catalisa a oxidação do iodeto), bromoperoxidase (catalisa a oxidação de brometo e iodeto) e cloroperoxidase (catalisa a oxidação de cloreto, brometo e iodeto) [18]. Em 1996, Messerschmidt e Wever determinaram por raios-X a estrutura da enzima V-cloroperoxidase no fungo Curvularia inaequalis [20]. Estas enzimas contêm um íon vanadato $\left(V^{V}\right)$ em seu sítio ativo e têm como ligantes aminoácidos do tipo doadores de oxigênio, como serina, treonina, 
ácido glutâmico, ácido aspártico ou outros doadores, como a histidina, [21], Figura 3. Portanto, complexos de vanádio com ligantes imínicos e oxigenados (carboxilatos) tritetradentados podem constituir bons miméticos deste sítio ativo.

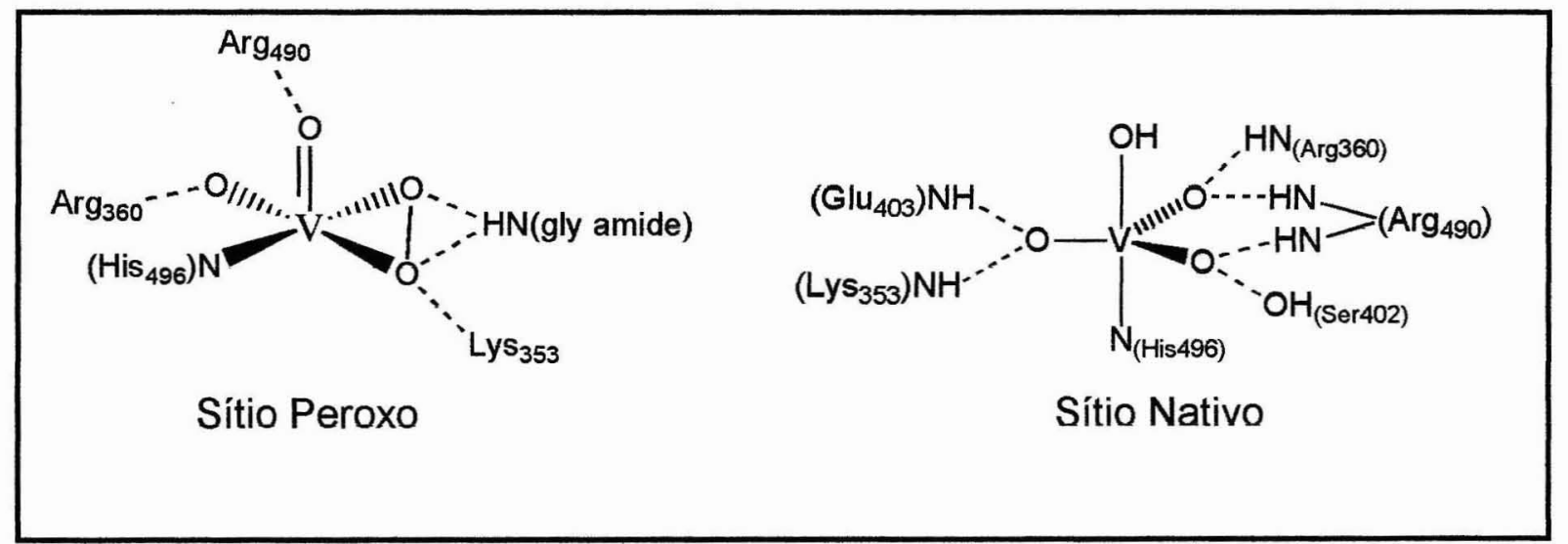

Figura 3. Sítio nativo e sítio vanádio-peroxo em cloroperoxidase V-CIPO [20, 22].

Recentemente, muitos complexos de vanádio(IV) e (V) com os mais variados tipos de ligantes, têm sido estudados como modelos estrutural e funcional de Vhaloperoxidases, sendo utilizados como catalisadores em diversos tipos de reações, como a de epoxidação de olefinas [23], oxidação de sulfetos a sulfitos [24] e oxidação de hidrocarbonetos tanto em fase homogênea [25] como heterogênea [26], imobilizado em diversas matrizes.

Iniciamos este trabalho com a finalidade de preparar novos compostos de vanádio que apresentassem alguma atividade catalítica, por exemplo, frente ao ciclohexano como substrato e peróxido de hidrogênio como agente oxidante. A oxidação desta espécie leva a obtenção de produtos de grande aplicação industrial [27], como álcoois (ciclohexanol), cetonas (ciclohexanona) e ciclohexilhidroperóxido como mostrado no Esquema 2, sendo que o ciclohexilhidroperóxido se decompõe em ciclohexanol e ciclohexanona. O peróxido de hidrogênio é muito utilizado por ser um reagente barato, além de gerar apenas água como subproduto de reação. 
Assim devido à relevância científica e econômica desta reação, vários estudos têm sido realizados no sentido de desenvolver novos catalisadores mais ativos e seletivos.

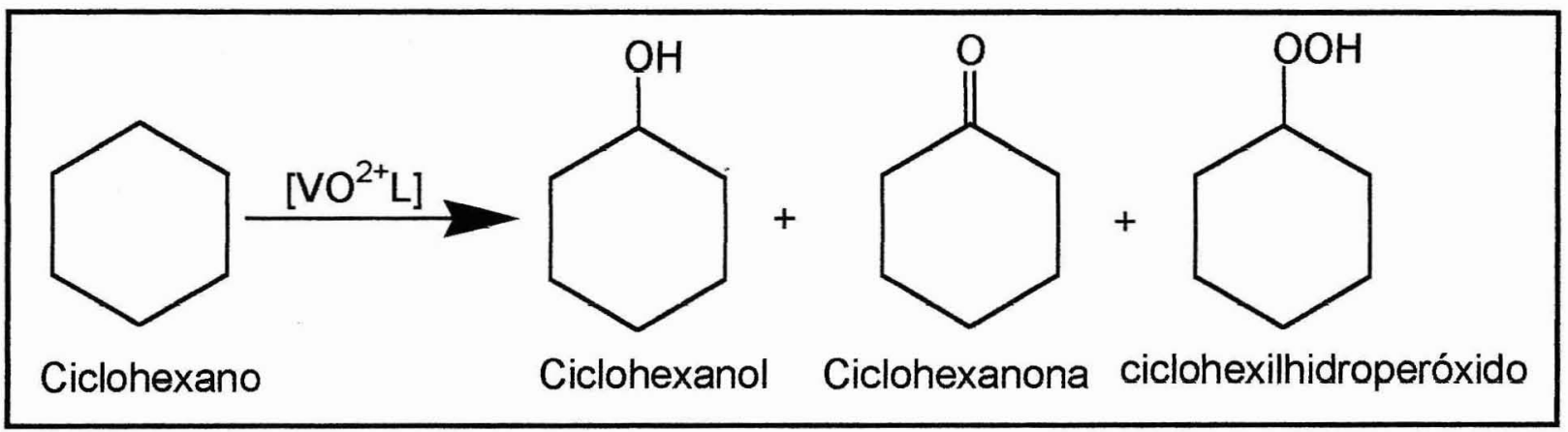

Esquema 2. Reação de oxidação de Ciclohexano.

Devido ao pouco tempo disponível, infelizmente não foram possíveis estudos cinéticos sobre a atividade catalítica dos vários compostos preparados.

\subsection{A Química do Oxovanádio}

Como o titânio, a química do vanádio está diretamente ligada ao oxigênio, pelo fato de o oxigênio estar prontamente disponível em meio aquoso, na atmosfera e como átomo doador em moléculas orgânicas. Como o vanádio forma íons pequenos e pouco polarizáveis, estes são classificados como ácidos duros, segundo a notação de R. G. Pearson, e, portanto, têm grande afinidade por ligantes do tipo O-doadores [28].

Ligantes orgânicos têm um papel muito especial na química do vanádio. O ligante oxo possui a habilidade de estabilizar os estados de oxidação do vanádio(IV) e (V). Um outro ponto importante é a relação do ligante oxo e aquo no equilíbrio ácido-base, e a relação do ligante oxo aos ligantes que são isoeletrônicos com eles.

A formação de espécies com ligante oxo ao invés do ligante aquo é favorecida em $\mathrm{pH}$ e estados de oxidação altos, onde predomina as espécies $\mathrm{V}^{\mathrm{lV}} \mathrm{O}^{2+} \mathrm{e} \mathrm{V}^{\mathrm{V}} \mathrm{O}_{2}{ }^{+}$, enquanto que 
em baixo $\mathrm{pH}$ e estado de oxidação, há o predomínio de espécies $\left[V^{\|}\left(\mathrm{H}_{2} \mathrm{O}\right)_{6}\right]^{2+}$ e $\left[\mathrm{V}^{\prime \prime \prime}\left(\mathrm{H}_{2} \mathrm{O}\right)_{6}\right]^{3+}$, onde o ligante $\mathrm{H}_{2} \mathrm{O}$ pode ser eliminado formando polioxometalatos.

Os oxigênios na posição apical nos íons vanadila e metavanadato situam-se aproximadamente a $0,035-0,055 \AA$ acima do plano definido pelos ligantes equatoriais e possui um comprimento de ligação de 157-169 pm [29].

Os pares solitários do oxigênio axial são doados ao vanádio central, com sobreposição $\pi$ dos orbitais d-p envolvidos nas ligações múltiplas, como mostra a Figura 4 [28]. Em espectros vibracionais, a espécie oxovanádio apresenta um estiramento $v(V=0)$ que geralmente é observado entre 938 e $1010 \mathrm{~cm}^{-1}$. Esta é uma característica importante dos complexos oxovanádio, sendo sensível à natureza do ligante coordenado $[30,62]$.

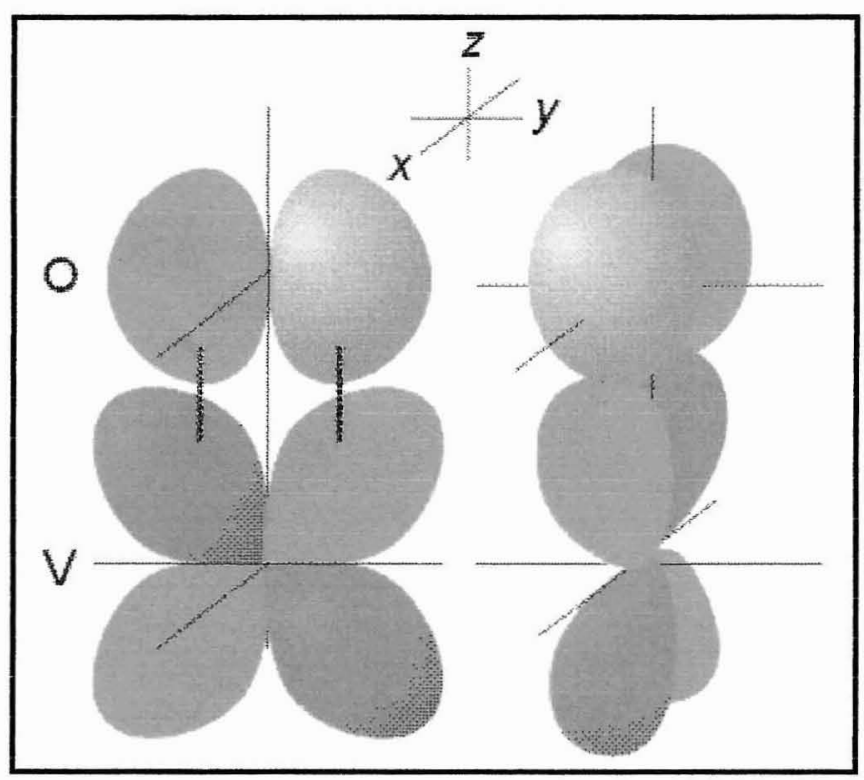

Figura 4. Interação do orbital $p$ do oxigênio com o orbital d do vanádio.

\subsection{Sínteses de Complexos de Vanádio}

Compostos de vanádio(IV) e (V) com ligantes contendo grupos e carboxilatos e imínicos, têm sido muito estudado nos últimos anos $[31,32,33,34,35]$, devido às mais 
variadas aplicações desses complexos. Várias rotas sintéticas foram utilizadas, principalmente pelo comportamento versátil do vanádio e a influência de diferentes fatores, como a natureza dos ligantes, solvente, $\mathrm{pH}$ e reação e meio reacional.

Como precursor ou fonte de vanádio utiliza-se comumente, [VO(acac $\left.)_{2}\right]$, $\left[\mathrm{VO}\left(\mathrm{H}_{2} \mathrm{O}\right)_{5}\right] \mathrm{SO}_{4}$ e vanadatos. A escolha do precursor depende do tipo de material que se pretende obter. $\mathrm{O}\left[\mathrm{VO}(\mathrm{acac})_{2}\right]$ é considerado um bom precursor, pois, seus ligantes são lábeis e sofrem facilmente substituição por ligantes orgânicos [36].

Complexos de oxovanádio(IV) usualmente se formam em condições anidras [37, 38, 39]. Sob condições aeróbicas eles são oxidados e reagem com ligantes orgânicos, podendo ser oxidado estabilizando complexos de vanádio(V). Complexos de vanádio(IV) obtidos por estes processos usualmente contêm apenas um ligante oxo coordenado e estabilizam-se como $[\mathrm{VO}]^{2+}$, enquanto os complexos mais oxidados são associados a um ou dois ligantes oxo coordenados e se estabilizam como $[\mathrm{VO}]^{3+},\left[\mathrm{VO}_{2}\right]^{+}$e $\left[\mathrm{V}_{2} \mathrm{O}_{3}\right]^{4+}$. Outros precursores, tais como os íons metavanadato $\mathrm{VO}_{3}^{-}$, só são adequados para ligantes solúveis em água, enquanto $\left[\mathrm{VO}\left(\mathrm{H}_{2} \mathrm{O}\right)_{5}\right] \mathrm{SO}_{4}$ pode ser usado em meio aquoso ou não aquoso [ 40, 41, 42].

Os complexos de vanádio(IV) e (V) têm tipicamente geometria piramidal-quadrada ou octaédrica e configuração eletrônica $d^{1}$ e $d^{0}$, respectivamente. O íon vanadila $\left(\mathrm{VO}^{2+}\right)$ nos complexos de vanádio absorve no UV-Vis, na região de comprimento de onda de $\sim 600$ a $800 \mathrm{~nm}$ e possui spin nuclear de $7 / 2$ dando sinais com até 16 linhas no espectro de EPR [43]. Por outro lado, o íon metavanadato $\left(\mathrm{VO}_{3}{ }^{-}\right)$não possui absorção nesta região, uma vez que sua estrutura eletrônica não possui elétrons para efetuar as transições d-d, e seu espectro de EPR é silencioso. 


\subsection{Obtenção de Iminas}

Os aldeídos ou as cetonas reagem com as aminas primárias $\left(\mathrm{RNH}_{2}\right)$ formando compostos com dupla ligação carbono-nitrogênio, chamados iminas $(\mathrm{RCH}=\mathrm{NR}$ ou $\mathrm{R}_{2} \mathrm{C}=\mathrm{NR}$ ) Esquema 3. A reação é catalisada por ácidos.

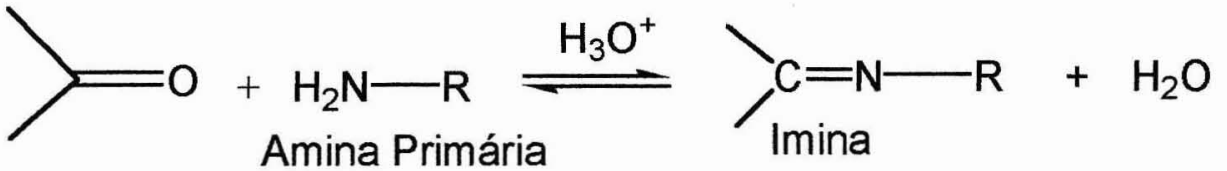

$$
\begin{aligned}
& \text { Aldeído ou } \\
& \text { cetona }
\end{aligned}
$$

Esquema 3. Reação de formação da Imina.

A formação da imina é lenta em pH muito baixo ou muito alto e em geral é mais rápida entre $\mathrm{pH} 4$ e 5 . Podemos entender a necessidade do catalisador ácido se analisarmos o mecanismo proposto para a formação da imina. A etapa mais importante é a etapa na qual um aminoálcool protonado perde moléculas de água e se transforma em um ín imínio. Pela protonação do grupo álcool, o ácido converte um grupo retirante fraco (o grupo-OH) num grupo retirante forte (o grupo $-\mathrm{OH}_{2}{ }^{+}$), Esquema 4. [44]

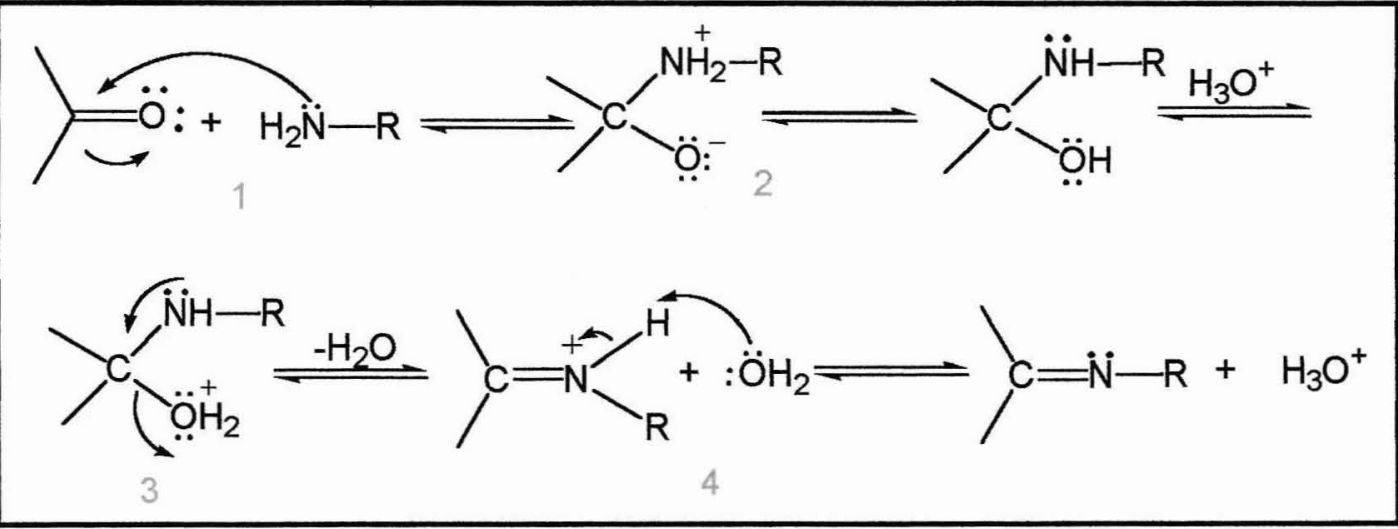

Esquema 4. Mecanismo de síntese das Iminas. 
1) A imina adiciona-se ao grupo carbonila e forma uma espécie intermediária tetraédrica dipolar.

2) Um próton, transferido do nitrogênio para o oxigênio, produz um aminoálcool.

3) A protonação do oxigênio provoca a formação de um grupo fortemente retirante. A perda de uma molécula de água leva ao íon imínio.

4) A transferência de um próton para a água produz a imina e regenera o íon hidrônio.

A reação é mais lenta se a concentração do íon hidrônio for muito elevada, pois ocorre, em boa medida, a protonação da própria amina; o que tem o efeito de diminuir a concentração do nucleófilo indispensável na primeira etapa. Se a concentração do íon hidrônio for muito baixa, a reação se torna mais lenta, pois a concentração do aminoálcool protonado também fica mais baixa. $\mathrm{O} \mathrm{pH}$ entre 4 e 5 parece corresponder a uma condição de compromisso eficaz.

A formação de iminas ocorre em muitas reações bioquímicas, pois as enzimas usam, freqüentemente, o grupo $-\mathrm{NH}_{2}$ para reagir com aldeídos ou cetonas. A formação da ligação imínica é importante, por exemplo, numa etapa das reações que se passam durante o processo da visão [45] e durante o processo de glicoxidação de proteínas [46]. 


\section{PARTE EXPERIMENTAL}

\subsection{Reagentes e soluções}

Os reagentes: salicilaldeído, 2,3-dihidroxibenzaldeído, sulfato de vanadila, álcool 2aminobenzílico, metavanadato de amônio, ácido $\alpha$-cetoglutárico, assim como um dos solventes utilizados, acetonitrila, foram de procedência da Aldrich Chemical Co. Este solvente foi destilado sob $\mathrm{CaH}_{2}$ em um balão acoplado com coluna de Vigreaux, de 15 $\mathrm{cm}$, e tratado com peneira molecular $(4 \AA)$, de acordo com metodologia descrita na literatura [47]. O ácido antranílico foi obtido da Reagen Co.

Os solventes utilizados, tais como: álcool etílico (96\%), álcool etílico absoluto (99\%), acetona, álcool metílico absoluto e DMSO; assim como os reagentes acetilacetona, etilenodiamina e ácido clorídrico foram de procedência da Merck Chemical Co. O solvente éter etílico (98\%) foi obtido da Synth.

A água para preparo de todas as soluções foi deionizada, em aparelho Barnstead, modelo D470. O sistema desionizador é formado por um conjunto em circuito de 4 filtros cilíndricos, contendo resina de troca iônica para captura de íons e carvão ativado para captura de material orgânico. 


\subsection{Síntese das Iminas}

As iminas foram sintetizadas a partir da condensação de um composto carbonílico (neste trabalho, aldeídos) com uma amina primária, de acordo com procedimentos gerais descritos na literatura $[48,49]$. Modificações adequadas foram feitas em cada caso, dependendo do ligante desejado de ser obtido.

\subsubsection{Síntese da Imina $\mathrm{H}_{2}$ salen}

Dissolveu-se a etilenodiamina $(7 \mathrm{mmol}, 0,464 \mathrm{~g})$ em $15 \mathrm{~mL}$ de acetona. Sob agitação constante, adicionou-se lentamente gota a gota o salicilaldeído ( $7 \mathrm{mmol}, 0,976$ g), previamente dissolvido em $10 \mathrm{~mL}$ de acetona. Após 30 minutos de agitação constante à temperatura ambiente, observou-se a formação de um precipitado amarelo-alaranjado. Este precipitado foi filtrado em funil de placa porosa, lavado com acetona e éter etílico gelados e secado a pressão reduzida, por $2 \mathrm{~h}$. Rendimento: $85 \%$

\subsubsection{Sintese da Imina $\mathrm{H}_{2} \mathrm{dbhab}$}

Dissolveu-se 2,3-dihidroxibenzaldeído ( $5 \mathrm{mmol}, 0,690 \mathrm{~g}$ ) em $10 \mathrm{~mL}$ de etanol. Após completa dissolução, adicionou-se sob agitação constante e gota a gota o ácido antranílico (5 mmol, 0,686 g), previamente dissolvido em $10 \mathrm{~mL}$ de etanol. A solução, que era amarela, tornou-se vermelha após completa adição da solução de ácido antranílico. A solução foi agitada por mais 30 minutos e reduziu-se seu volume à metade em um evaporador rotatório, sob pressão reduzida. Deixou-se em banho de gelo por $5 \mathrm{~h}$, verificando-se a formação de um precipitado vermelho, que foi filtrado em funil de placa porosa, lavado com álcool e éter etílico gelados e secado em um dessecador, sob pressão reduzida, durante $3 \mathrm{~h}$. Rendimento: $78 \%$ 


\subsubsection{Síntese da Imina Hdbhbal}

Dissolveu-se o 2,3-dihidroxibenzaldeído ( $5 \mathrm{mmol}, 0,690 \mathrm{~g}$ ) em $10 \mathrm{~mL}$ de etanol e adicionou-se sob agitação constante e gota a gota o álcool 2-aminobenzílico ( $5 \mathrm{mmol}$, $0,686 \mathrm{~g}$ ), previamente dissolvido em $10 \mathrm{~mL}$ de etanol. A solução que era amarela tornou-se laranja intenso, após completa adição da solução de álcool 2-aminobenzílico. Deixou-se a solução sob agitação por mais 30 minutos, reduzindo seu volume à metade em um evaporador rotatório, sob pressão reduzida. Após banho de gelo por 5 h, houve a formação de um precipitado vermelho, que foi filtrado em funil de placa porosa, lavado com álcool e éter etílico gelados e secado em um dessecador a baixa pressão, por 3h. Rendimento: $73 \%$ 


\subsection{Síntese dos Complexos de Vanádio(IV)}

\subsubsection{Síntese do complexo $\left[\mathrm{V}^{\mathrm{IV}} \mathrm{O}(\mathrm{acac})_{2}\right]$}

Esse complexo foi sintetizado segundo metodologia já conhecida [50]. Sulfato de vanadila $(10,0 \mathrm{mmol}, 1,630 \mathrm{~g})$ foi dissolvido em $20 \mathrm{~mL}$ de etanol, sob agitação constante, e juntou-se acetilacetona $(20,0 \mathrm{mmol}, 2,002 \mathrm{~g})$, quando a cor da solução inicial, que era azul, ficou verde, após o final da mistura. Em seguida, neutralizou-se esta solução com uma solução de carbonato de sódio, deixando-se a mistura em agitação por $1 \mathrm{~h}$, quando se observou a formação de precipitado. Deixou-se a solução na geladeira por $3 \mathrm{~h}$, para crescimento do precipitado. Após esse período o precipitado foi filtrado a pressão reduzida, lavado com etanol e éter etílico gelados e secado em um dessecador a baixa pressão, por $4 \mathrm{~h}$. Rendimento: $75 \%$

\subsubsection{Síntese do complexo [ $\mathrm{V}^{\mathrm{IV}} \mathrm{O}($ salen)]}

Esse complexo foi sintetizado segundo metodologia já descrita na literatura [51]. Dissolveu-se a imina $\mathrm{H}_{2}$ salen $(5,0 \mathrm{mmol}, 1,341 \mathrm{~g})$ em $10 \mathrm{~mL}$ de acetona, sob agitação constante, obtendo-se solução de coloração amarelo-alaranjada. Em seguida adicionou-se lentamente, gota a gota, $\mathrm{VOSO}_{4}(5 \mathrm{mmol}, 0,815 \mathrm{~g})$ previamente dissolvido em $10 \mathrm{~mL}$ de água, quando se observou, que a solução foi se tornando verde. Após 30 minutos de agitação, à temperatura ambiente, houve a formação de precipitado verde. Filtrou-se este precipitado em placa porosa, lavou-se com acetona e éter etílico gelados e secou-se a vácuo, por $2 \mathrm{~h}$. Rendimento: $56 \%$ 


\subsubsection{Síntese do complexo $\left[\mathrm{V}^{\mathrm{IV}} \mathrm{O}(\mathrm{dbhab})\right]_{2}$}

Este complexo novo foi sintetizado segundo metodologia já descrita [32], com algumas modificações. Dissolveu-se o ligante $\mathrm{H}_{2} \mathrm{dbhab}(2,5 \mathrm{mmol}, 0,943 \mathrm{~g})$ em $70 \mathrm{~mL}$ de $\mathrm{CH}_{3} \mathrm{CN}$, à temperatura de $35-40^{\circ} \mathrm{C}$. Adicionou-se então, lentamente, gota a gota, [ $\left.\mathrm{V}^{\mathrm{IV}} \mathrm{O}(\mathrm{acac})_{2}\right](2,5 \mathrm{mmol}, 0,680 \mathrm{~g})$ previamente dissolvido em $25 \mathrm{~mL}$ de $\mathrm{CH}_{3} \mathrm{CN}$, sob agitação constante e em atmosfera inerte de $\mathrm{N}_{2}$. Após a completa mistura dos reagentes, a solução tornou-se marrom escura, quando anteriormente era vermelha. Fez-se refluxo por $4 \mathrm{~h}$ e deixou-se a solução em repouso por $12 \mathrm{~h}$, sob atmosfera inerte. Após esse tempo observou-se a formação de precipitado marrom escuro. Em seguida, reduziu-se o volume da reação à metade, em um evaporador rotatório a baixa pressão, e deixou-se em repouso por $10 \mathrm{~h}$, à temperatura ambiente, para precipitação. $\mathrm{O}$ precipitado formado foi filtrado em um funil de placa porosa, lavado com $\mathrm{CH}_{3} \mathrm{CN}$ e secado em um dessecador, a baixa pressão. Rendimento: $65 \%$.

\subsubsection{Síntese do complexo $\left[\mathrm{V}^{\mathrm{IV}} \mathrm{O}(\mathrm{dbhbal})_{2}\right]$}

Este novo complexo também foi sintetizado segundo metodologia já estabelecida [32], com algumas modificações. Dissolveu-se Hdbhbal $(2,5 \mathrm{mmol}, 0,608 \mathrm{~g})$ em $20 \mathrm{~mL}$ de $\mathrm{CH}_{3} \mathrm{CN}$, à temperatura de $35-40{ }^{\circ} \mathrm{C}$, e adicionou-se, lentamente, gota a gota,

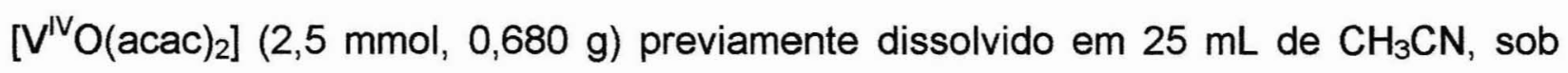
agitação constante e em atmosfera inerte de $\mathrm{N}_{2}$. Após a mistura dos reagentes, a solução tornou-se marrom avermelhada, sendo que anteriormente era laranja intenso. Fez-se refluxo por $1 \mathrm{~h}$, e deixou-se a solução em repouso por $24 \mathrm{~h}$, à temperatura ambiente e em atmosfera inerte, para precipitação. A solução tornou-se marrom mais intenso. O precipitado marrom avermelhado formado foi filtrado em um funil de placa 
porosa, lavado com $\mathrm{CH}_{3} \mathrm{CN}$, e secado em dessecador, a baixa pressão. Rendimento: $74 \%$.

\subsubsection{Sintese do $\mathrm{NH}_{4}\left[\mathrm{~V}^{\mathrm{lV}} \mathrm{O}_{2}(\mathrm{dbhab})\right]$}

Esse complexo foi sintetizado de acordo com metodologia anteriormente descrita [52], com algumas modificações. Dissolveu-se a imina $\mathrm{H}_{2} \mathrm{dbhab}(3,0 \mathrm{mmol}, 0,743 \mathrm{~g})$ em $60 \mathrm{~mL}$ de etanol absoluto sob agitação constante e adicionou-se, aos poucos, metavanadato de amônio $(3,0 \mathrm{mmol}, 0,360 \mathrm{~g})$ no estado sólido. À medida que o metavanadato de amônio se dissolvia, a cor da solução vermelha tornava-se escura e, ao fim da dissolução, a solução tinha uma cor preta intensa. Fez-se em seguida refluxo por $3 \mathrm{~h}$; após esse tempo filtrou-se a solução à quente e reduziu-se o volume da reação à metade, em um evaporador rotatório a baixa pressão, e deixou-se a solução em repouso por 3 dias, para formação de precipitado. O precipitado preto foi filtrado em funil de placa porosa, lavado com etanol e éter etílico gelados e secado em dessecador a baixa pressão, por $4 \mathrm{~h}$. Rendimento: $38 \%$.

\subsubsection{Síntese do complexo $\mathrm{Na}_{2}\left[\mathrm{~V}^{\mathrm{V}} \mathrm{O}\right.$ (cetoglut) $\left.{ }_{2}\right] \cdot 2 \mathrm{H}_{2} \mathrm{O}$}

Dissolveu-se o ácido $\alpha$-cetoglutárico $(10,0 \mathrm{mmol}, 1,461 \mathrm{~g})$ em $10 \mathrm{~mL}$ de metanol. Sob atmosfera inerte de nitrogênio $\left(\mathrm{N}_{2}\right)$ adicionou-se lentamente, gota a gota, o sulfato de vanadila ( $5 \mathrm{mmol}, 0,815 \mathrm{~g}$ ), previamente dissolvido em $20 \mathrm{~mL}$ de metanol. A solução que era incolor tornou-se azul-esverdeada. Após 10 minutos de agitação, adicionou-se estequiométricamente e gota a gota $2,5 \mathrm{~mL}$ de $\mathrm{NaOH} 2 \mathrm{~mol} \cdot \mathrm{L}^{-1}$. A solução tornou-se verde e observou-se a formação de um precipitado branco, que foi removido por filtração. Deixou-se a solução a baixa temperatura por cinco dias, com adições sucessivas de etanol absoluto e após esse tempo observou-se a formação de um 
precipitado verde. Este precipitado foi filtrado a baixa pressão em um funil de placa sinterizada, e lavado com etanol absoluto e éter etílico gelados e secado em um dessecador a baixa pressão, por $3 \mathrm{~h}$. Rendimento: $41 \%$.

\subsubsection{Síntese do complexo $\left.\left(\mathrm{NH}_{4}\right)_{3}\left[\mathrm{~V}^{\mathrm{lV}} \mathrm{O}_{2} \text { (cetoglut }\right)_{2}\right]$}

Dissolveu-se o ácido $\alpha$-cetoglutárico $(10,0 \mathrm{mmol}, 1,461 \mathrm{~g})$ em $5 \mathrm{ml}$ de água. Em seguida adicionou-se o metavanadato de amônio no estado sólido e adicionou-se mais $30 \mathrm{~mL}$ de água. A solução que era incolor foi-se tornando azul à medida que o metavanadato ia-se dissolvendo. A temperatura foi aumentada vagarosamente, até $80^{\circ} \mathrm{C}$. Deixou-se em refluxo por 5 minutos, em seguida filtrou-se a baixa pressão. Deixou-se esfriar até a temperatura ambiente e, em seguida, colocou-se a solução na geladeira. Depois de 8 dias observou-se a formação de um fino precipitado azul. Este precipitado foi filtrado a baixa pressão e lavado com etanol e éter gelados e secado em um dessecador a baixa pressão, por $4 \mathrm{~h}$. Rendimento $43 \%$. 


\subsection{Instrumentos e Técnicas Experimentais}

\subsubsection{Análise Elementar}

As análises elementares foram realizadas na Central Analítica do Instituto de Química da USP, usando um analisador elementar CHN Perkin-Elmer 240, que permite a determinação de porcentagens de carbono, hidrogênio, e nitrogênio com precisão de $0,01 \%$

\subsubsection{Espectroscopia na região do UV-Vis}

Os espectros de absorção na região do visível e ultravioleta foram obtidos em espectrofotômetro UV-Visível modelo 1650, da Shimadzu, a partir de soluções etanólica, aquosa, metanólica ou em DMSO dos compostos, em concentração de $10^{-3}$ a $10^{-5} \mathrm{~mol} . \mathrm{L}^{-1}$, utilizando cubetas de quartzo de caminho ótico de $1,00 \mathrm{~cm}$.

\subsubsection{Espectroscopia na região do Infravermelho}

Os espectros de absorção na região do infravermelho foram obtidos em um espectrômetro MB 102, da ABB Bomem, por reflectância difusa, na região de 4000 a $400 \mathrm{~cm}^{-1}$. As amostras foram maceradas em $\mathrm{KBr}$, previamente seco a $120^{\circ} \mathrm{C}$.

\subsubsection{Análise Termogravimétrica}

As análises termogravimétricas foram realizadas em aparelho da Shimadzu, modelo TGA-50. As amostras foram aquecidas em um cadinho de platina, sob atmosfera de ar sintético, com fluxo de gás de $50 \mathrm{~mL} \cdot \mathrm{min}^{-1}$, à razão de aquecimento de $10^{\circ} \mathrm{C} \cdot \mathrm{min}^{-1}$, partindo de uma massa de $5,113 \mathrm{mg}$, a partir da temperatura ambiente até $900^{\circ} \mathrm{C}$. 


\subsubsection{Condutividade Molar}

As medidas de condutividade molar foram realizadas no condutivímetro Digimed DM-31, usando solução padrão de $\mathrm{KCl}$ 10,0 mmol.L-1 (condutividade específica: 1412,0 $\mu \mathrm{S} \mathrm{cm}^{-1}$, a $25^{\circ} \mathrm{C}$ ). Os solventes utilizados para o preparo das soluções foram secos em peneira molecular de $(4 \AA)$. As soluções contendo as amostras tinham concentrações de $10 \mathrm{mmol} \cdot \mathrm{L}^{-1}$.

\subsubsection{Espectroscopia de Ressonância Paramagnética Eletrônica}

Os espectros de EPR foram registrados no espectrômetro EPR da BRUKER, modelo EMX, operando na banda $X(v=9,33 \mathrm{GHz})$ com potência de $20 \mathrm{~mW}$, equipado com uma cavidade Dewar para baixas temperaturas (77 K), usando tubos de quartzo, da marca Wilmad, de $4 \mathrm{~mm}$ de diâmetro interno. As medidas dos compostos de vanádio foram feitas a baixas temperaturas $(77 \mathrm{~K})$ no estado sólido e em etanol, DMSO ou em solução de DMSO/ $\mathrm{H}_{2} \mathrm{O}(3,5: 1,5 \mathrm{v} / \mathrm{v})$. 


\section{RESULTADOS E DISCUSSÃO}

\subsection{Análise Elementar}

As Iminas e os Complexos de Vanádio(IV) isolados foram caracterizados inicialmente através da análise elementar, determinando-se os teores de $\mathrm{C}, \mathrm{H}$ e $\mathrm{N}$, cujos resultados são apresentados na Tabela 1, a seguir. Dois dos compostos, [ $\left.\mathrm{V}^{\mathrm{IV} O}(\mathrm{acac})_{2}\right]$ e [ $V^{\mathrm{IV}} \mathrm{O}($ salen)], são exemplos clássicos da literatura e foram preparados com a finalidade de estudos comparativos.

Analisando os dados contidos na Tabela 1, observa-se que os valores experimentais estão muito próximos dos valores esperados e obtidos através de cálculos, considerando as fórmulas mínimas indicadas (vide Esquema 5). Dados de condutividade molar, análise térmica e espectroscópicos, obtidos na caracterização de cada um dos compostos isolados e discutidos nas seções posteriores, corroboraram estes resultados. Assim, parece que as sínteses foram bem sucedidas e os compostos sintetizados correspondem provavelmente às estruturas propostas, tanto para as iminas isoladas, como para os complexos de vanádio. 
Tabela 1. Resultados da Análise Elementar das Iminas e dos Complexos de Vanádio(IV) preparados.

\begin{tabular}{|c|c|c|c|}
\hline Compostos & $\begin{array}{c}\% \mathrm{C} \\
\text { calculado } \\
\text { obtido }\end{array}$ & $\begin{array}{c}\% \mathrm{H} \\
\text { calculado } \\
\text { obtido }\end{array}$ & $\begin{array}{c}\% \mathrm{~N} \\
\text { calculado } \\
\text { obtido }\end{array}$ \\
\hline $\mathrm{H}_{2}$ salen & 71,62 & 6,01 & 10,44 \\
\hline $\mathrm{C}_{16} \mathrm{H}_{16} \mathrm{~N}_{2} \mathrm{O}_{2} ; \mathrm{MM}=268,31 \mathrm{~g} \cdot \mathrm{mol}^{-1}$ & 71,47 & 5,93 & 10,38 \\
\hline $\mathrm{H}_{2} \mathrm{dbhbal}$ & 69,12 & 5,38 & 5,75 \\
\hline $\mathrm{C}_{14} \mathrm{H}_{13} \mathrm{NO}_{3} ; \mathrm{MM}=243,26 \mathrm{~g} \cdot \mathrm{mol}^{-1}$ & 69,13 & 5,26 & 5,88 \\
\hline Hdbhab & 65,36 & 5,44 & 4,30 \\
\hline $\mathrm{C}_{14} \mathrm{H}_{11} \mathrm{NO}_{4} ; \mathrm{MM}=256,23 \mathrm{~g} \cdot \mathrm{mol}^{-1}$ & 65,06 & 5,71 & 4,27 \\
\hline$\left[\mathrm{V}^{\mathrm{N}} \mathrm{O}(\mathrm{acac})_{2}\right]$ & 45,29 & 5,32 & - \\
\hline $\mathrm{C}_{10} \mathrm{H}_{14} \mathrm{O}_{5} \mathrm{~V} ; \mathrm{MM}=265,16 \mathrm{~g} \cdot \mathrm{mol}^{-1}$ & 45,10 & 5,24 & 0,31 \\
\hline$\left[\mathbf{V}^{\mathrm{IV}} \mathrm{O}(\right.$ salen$\left.)\right]$ & 57,67 & 4,23 & 8,40 \\
\hline $\mathrm{C}_{16} \mathrm{H}_{14} \mathrm{~N}_{2} \mathrm{O}_{3} \mathrm{~V} ; \mathrm{MM}=333,23 \mathrm{~g} \cdot \mathrm{mol}^{-1}$ & 57,64 & 3,98 & 8,20 \\
\hline $\left.\mathrm{N}^{\mathrm{IV}} \mathrm{O}(\mathrm{dbhbal})_{2}\right]$ & 60,98 & 4,39 & 5,08 \\
\hline $\mathrm{C}_{28} \mathrm{H}_{24} \mathrm{~N}_{2} \mathrm{O}_{7} \mathrm{~V} ; \mathrm{MM}=551,45 \mathrm{~g} \cdot \mathrm{mol}^{-1}$ & 60,14 & 4,45 & 5,38 \\
\hline$\left[V^{I V} O(d b h a b)\right]_{2}$ & 51,98 & 3,12 & 4,33 \\
\hline $\mathrm{C}_{28} \mathrm{H}_{20} \mathrm{~N}_{2} \mathrm{O}_{10} \mathrm{~V}_{2} ; M M=646,35 \mathrm{~g} \cdot \mathrm{mol}^{-1}$ & 51,44 & 3,38 & 4,71 \\
\hline $\mathrm{NH}_{4}\left[\mathrm{~V}^{\mathrm{IV}} \mathrm{O}_{2}(\mathrm{dbhab})\right]$ & 47,07 & 3,95 & 7,84 \\
\hline $\mathrm{C}_{14} \mathrm{H}_{14} \mathrm{~N}_{2} \mathrm{O}_{6} \mathrm{~V} ; \mathrm{MM}=357,21 \mathrm{~g} \cdot \mathrm{mol}^{-1}$ & 47,49 & 3,78 & 7,01 \\
\hline $\mathrm{Na}_{2}\left[\mathrm{~V}^{\mathrm{IV}} \mathrm{O}(\text { cetoglut })_{2}\right] \cdot 2 \mathrm{H}_{2} \mathrm{O}$ & 27,48 & 2,76 & - \\
\hline $\mathrm{C}_{10} \mathrm{H}_{12} \mathrm{O}_{13} \mathrm{~V} ; \mathrm{MM}=437,11 \mathrm{~g} \cdot \mathrm{mol}^{-1}$ & 27,50 & 3,45 & 0,15 \\
\hline$\left(\mathrm{NH}_{4}\right)_{3}\left[\mathrm{~V}^{\mathrm{IV}} \mathrm{O}_{2}\right.$ (cetoglut) $\left.{ }_{2}\right]$ & 28,18 & 4,96 & 9,85 \\
\hline $\mathrm{C}_{10} \mathrm{H}_{21} \mathrm{~N}_{3} \mathrm{O}_{12} \mathrm{~V} ; \mathrm{MM}=426,23 \mathrm{~g} \cdot \mathrm{mol}^{-1}$ & 28,48 & 4,57 & 9,23 \\
\hline
\end{tabular}

Alguns dos compostos foram preparados esperando-se obter o correspondente composto de vanádio(V), mas resultados de sua caracterização (especialmente dados de espectroscopias EPR e de UVNis) demonstraram que se tratava na verdade de compostos de vanádio(IV). Isto ocorreu com os compostos: $\mathrm{NH}_{4}\left[\mathrm{~V}^{\mathrm{IV}} \mathrm{O}_{2}\right.$ (dbhab)] e $\left.\left(\mathrm{NH}_{4}\right)_{3}\left[\mathrm{~V}^{\prime \mathrm{V}} \mathrm{O}_{2} \text { (cetoglut) }\right)_{2}\right]$. 
Provavelmente, a redução do metavanadato, $\mathrm{VO}_{3}{ }^{-}$ocorreu com oxidação dos ligantes carboxílicos a $\mathrm{CO}_{2}$ e água, conforme as reações abaixo:

Reação de formação do complexo $\mathrm{NH}_{4}\left[\mathrm{~V}^{\prime \mathrm{V}} \mathrm{O}_{2}(\mathrm{dbhab})\right]$

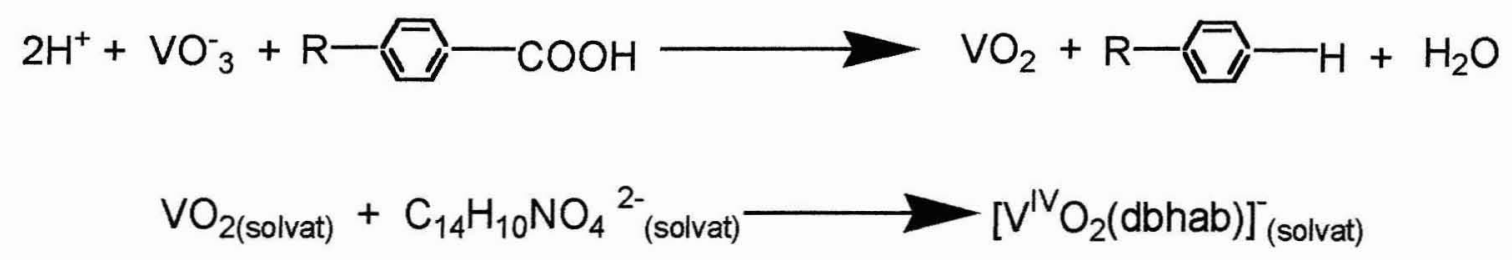

Reação de formação do complexo $\left.\left(\mathrm{NH}_{4}\right)_{3}\left[\mathrm{~V}^{\mathrm{IV}} \mathrm{O}_{2} \text { (cetoglut }\right)_{2}\right]$

$$
\begin{gathered}
2 \mathrm{H}^{+}+\mathrm{VO}_{3}^{-}+\mathrm{R}^{\prime}-\mathrm{COOH} \longrightarrow \mathrm{R}^{\prime} \longrightarrow \mathrm{H}+\mathrm{CO}_{2}+\mathrm{VO}_{2}+\mathrm{H}_{2} \mathrm{O} \\
\mathrm{VO}_{2(\mathrm{aq})}+2 \mathrm{C}_{5} \mathrm{H}_{6} \mathrm{O}_{5}{ }^{3-}{ }_{\text {(aq) }} \longrightarrow\left[\mathrm{V}^{\mathrm{IV}} \mathrm{O}_{2} \text { (cetoglut) }{ }_{2}\right]_{(\text {(aq) }}^{3-}
\end{gathered}
$$



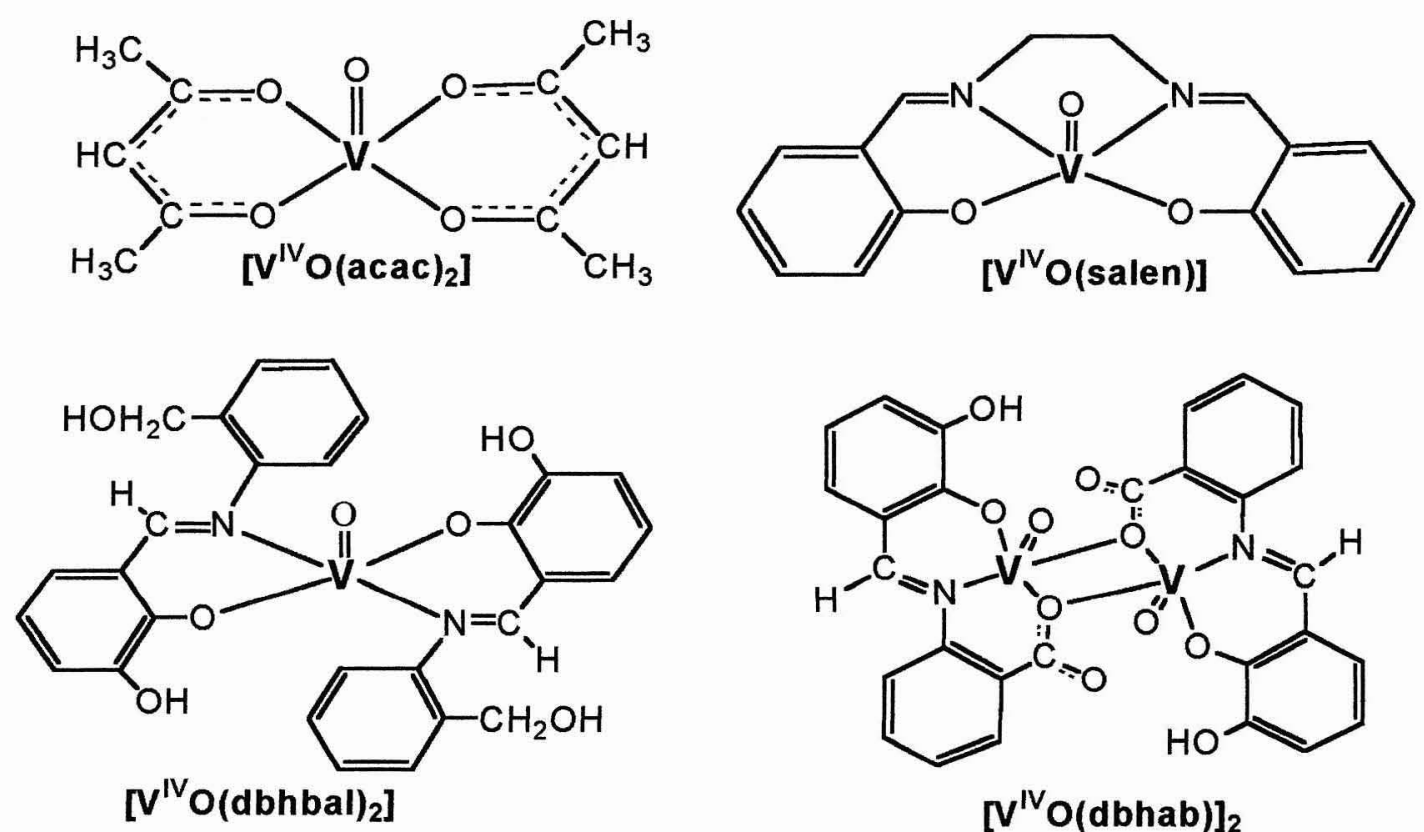

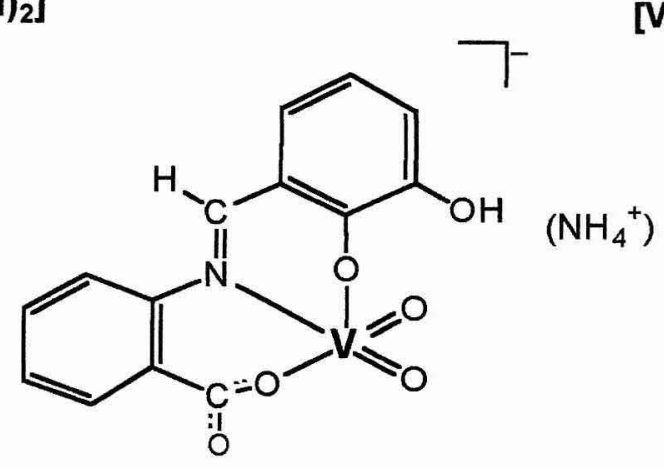

$\left[V^{I V} O(d b h a b)\right]_{2}$

$$
\mathrm{NH}_{4}\left[\mathrm{~V}^{\mathrm{IV}} \mathrm{O}_{2}(\mathrm{dbhab})\right]
$$
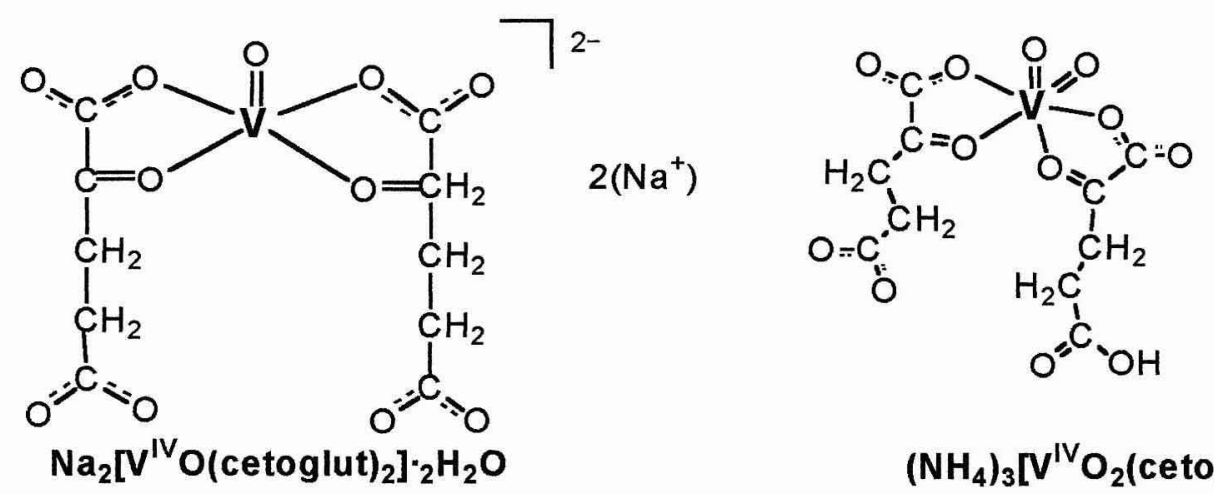

$$
\left.\left(\mathrm{NH}_{4}\right)_{3}\left[\mathrm{~V}^{\mathrm{IV}} \mathrm{O}_{2} \text { (cetoglut }\right)_{2}\right]
$$

Esquema 5. Estruturas dos Compostos de Vanádio(IV) preparados. 


\subsection{Espectroscopia na região do Ultravioleta e Visível}

Quando a radiação eletromagnética correspondente às regiões UV e visível passa através de um composto contendo ligações múltiplas, uma porção da radiação é normalmente absorvida pelo composto. O quanto dessa radiação é absorvido depende do comprimento de onda da radiação e da estrutura eletrônica do composto. Esta absorção de energia é quantizada e conduz os elétrons de orbitais do estado fundamental para orbitais de maior energia, caracterizando um estado excitado [44].

A absorção da radiação na espectroscopia UVNis é causada pela subtração de energia do raio de luz da radiação quando elétrons nos orbitais de energia mais baixa são excitados para orbitais de energia mais elevada.

Os complexos de vanádio(IV) e (V) possuem configuração eletrônica $d^{1}$ e $d^{0}$ respectivamente. Podem adotar os números de coordenação (NC) de 4 a 8 e assim formar complexos tetraédricos $(\mathrm{NC}=4)$, pirâmide tetragonal ou bipirâmide trigonal $(\mathrm{NC}=5)$, octaédrico ou prisma trigonal $(\mathrm{NC}=6)$, bipirâmide pentagonal $(\mathrm{NC}=7)$ e dodecaédrico $(\mathrm{NC}=8)[2,22]$. Íons metálicos de transição com configuração eletrônica $d^{1}$ apresentam efeito Jahn Teller e sua geometria é usualmente D4h achatada (ao contrário de íons $\mathrm{d}^{9}$ ), pois assim ganham mais estabilização, colocando o elétron desemparelhado no plano xy. Complexos de $V(V)\left(d^{0}\right)$ não possuem transições $d-d$ e conseqüentemente não possuem energia de estabilização do campo ligante e apresentam geralmente NC=6.

Os espectros eletrônicos de todos os compostos sintetizados foram registrados utilizando como solvente etanol, metanol, DMSO, DMF ou água, em comprimentos de onda na faixa de 190 a 1100 nm, com posterior determinação dos respectivos valores de absortividade molar $(\varepsilon)$. Esses espectros estão apresentados nas Figuras 5 a 21 
juntamente com suas curvas de regressão linear e os parâmetros espectroscópicos determinados, bem como as respectivas atribuições das bandas de absorção, encontradas na Tabela 2.

As principais bandas de absorção registradas são atribuídas, basicamente, a três tipos de transição. As transições internas do ligante, transições de transferência de carga e transições d-d [28].

As absorções na região do ultravioleta, de alta energia, estão relacionadas com as transições internas do ligante IL, (n $\rightarrow \pi^{*}$ e $\left.\pi \rightarrow \pi^{*}\right)$, onde $n$ é o orbital não ligante, $\pi$ é o orbital ligante e $\pi^{*}$ é o orbital antiligante.

As bandas que aparecem na região do ultravioleta próximo e do visível estão relacionadas às transições de transferência de carga do ligante para o metal, TCLM ( $\pi \rightarrow$ d $\pi$ ) e as de menor intensidade, na região do visível, são atribuídas às transições d-d. 


\subsubsection{Espectros eletrônicos das Iminas sintetizadas}

A seguir são apresentados os espectros UV-Vis de cada um das iminas e dos complexos de vanádio(IV) sintetizados.

\subsubsection{Espectro eletrônico da Imina salen}

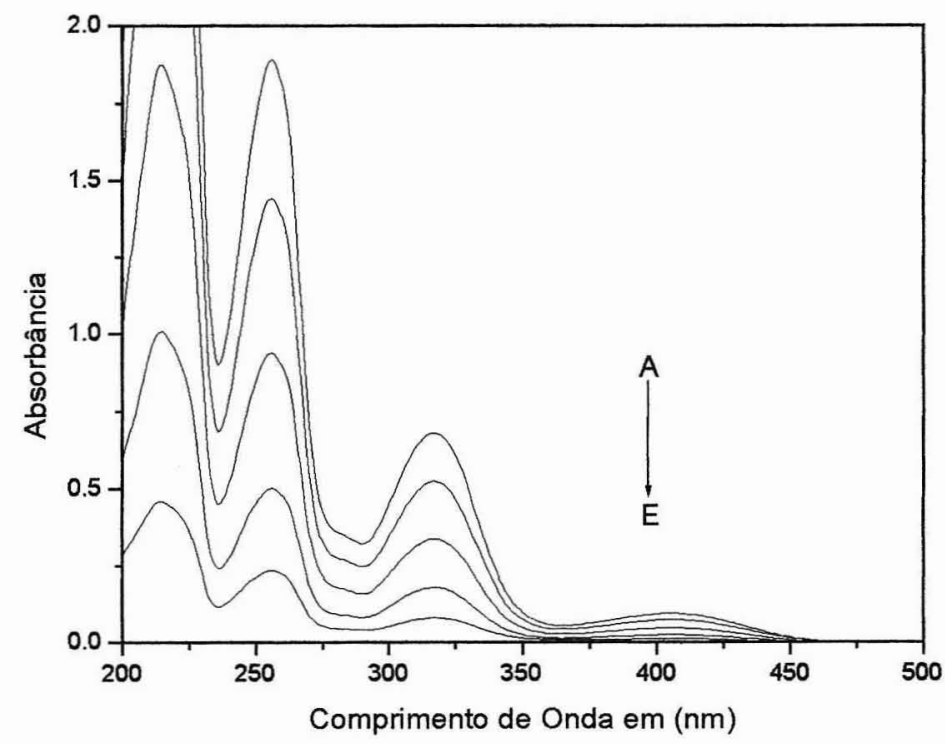

Figura 5. Espectro na região de $200-500 \mathrm{~nm}$ da imina salen em etanol, a concentrações variadas: A) $8,3 X$ $10^{-5} \mathrm{~mol} . \mathrm{L}^{-1}$; B) $6,2 \times 10^{-5} \mathrm{~mol} . \mathrm{L}^{-1}$; C) $4,1 \times 10^{-5} \mathrm{~mol} . \mathrm{L}^{-1}$; D) $2,0 \times 10^{-5} \mathrm{~mol} . \mathrm{L}^{-1}$; E) $1,0 \times 10^{-5} \mathrm{~mol}^{-L^{-1}}$.
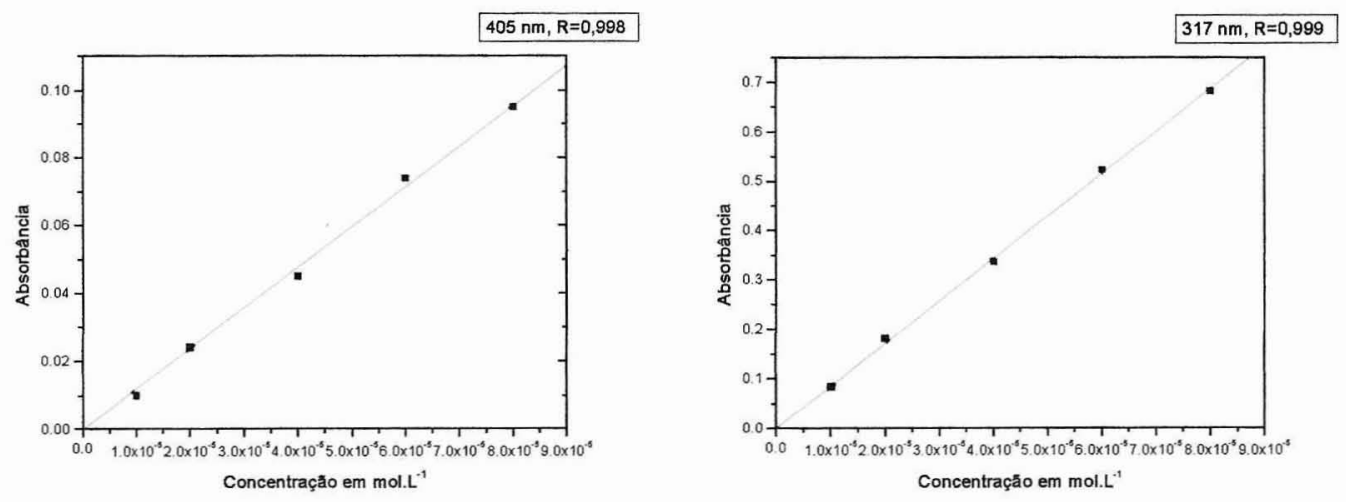

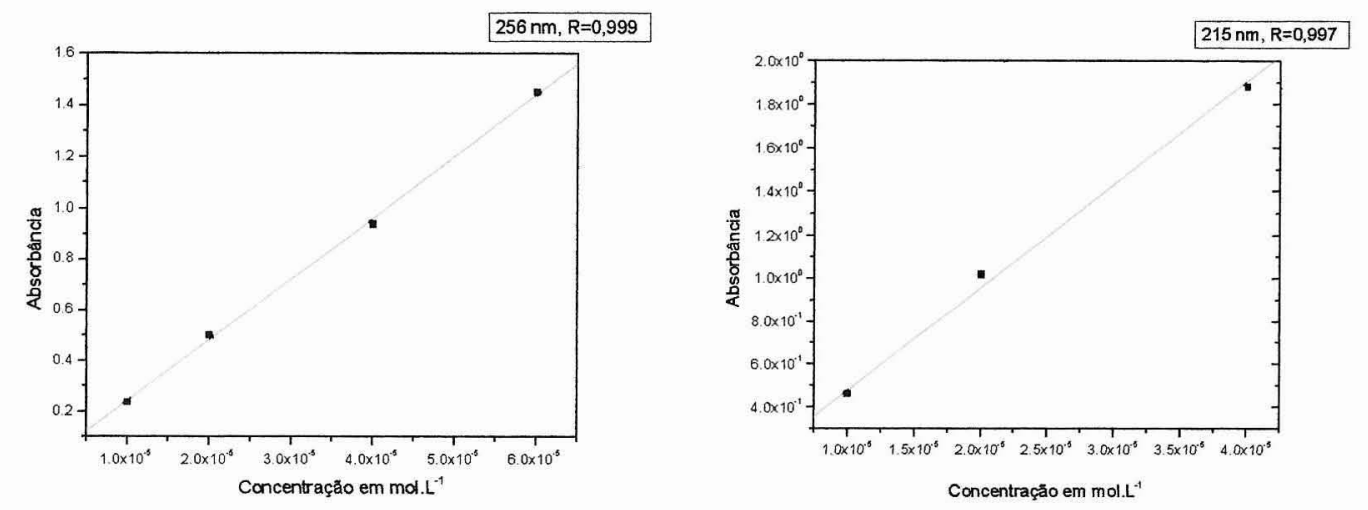

\subsection{Espectro eletrônico da Imina dbhbal}

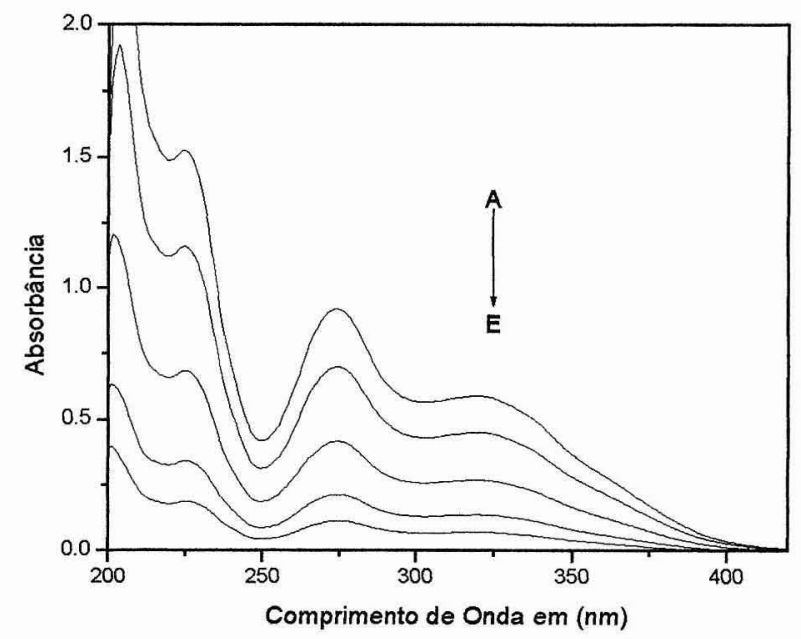

Figura 6. Espectro na região de $200-420 \mathrm{~nm}$ da imina dbhbal em etanol, a concentrações variadas: A) $7,9 \times 10^{-5} \mathrm{~mol}^{-1} \mathrm{~L}^{-1}$;) $5,9 \times 10^{-5} \mathrm{~mol}^{-1} \mathrm{~L}^{-1}$; C) $3,9 \times 10^{-5} \mathrm{~mol}^{-L^{-1}}$; D) $1,9 \times 10^{-5} \mathrm{~mol} . \mathrm{L}^{-1}$; E) $7,9 \times 10^{-6} \mathrm{~mol}^{-L^{-1}}$.
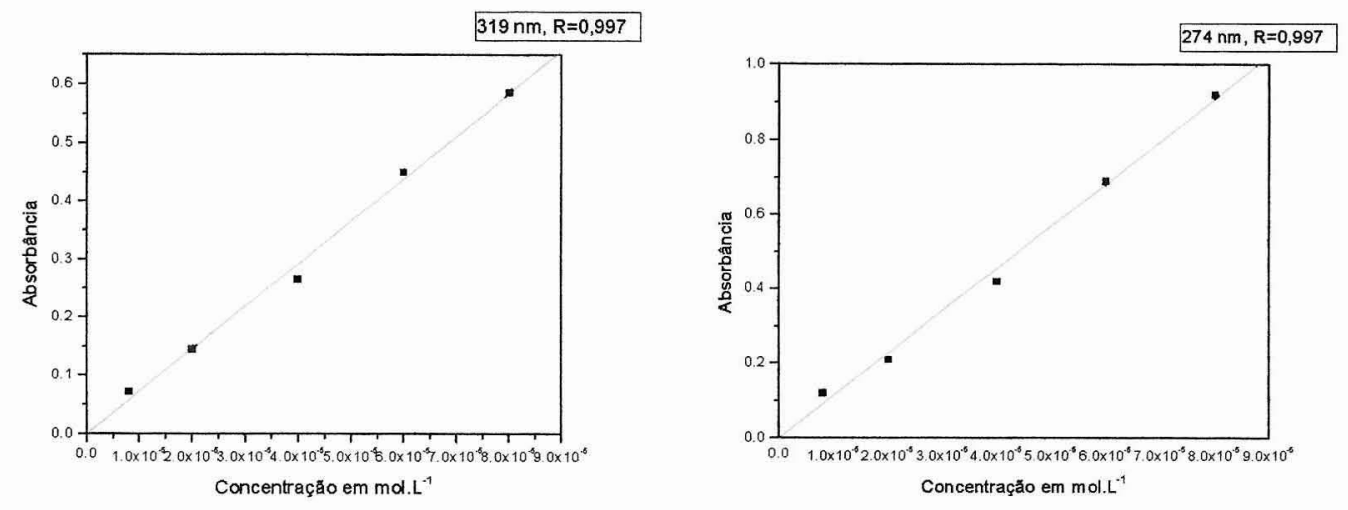


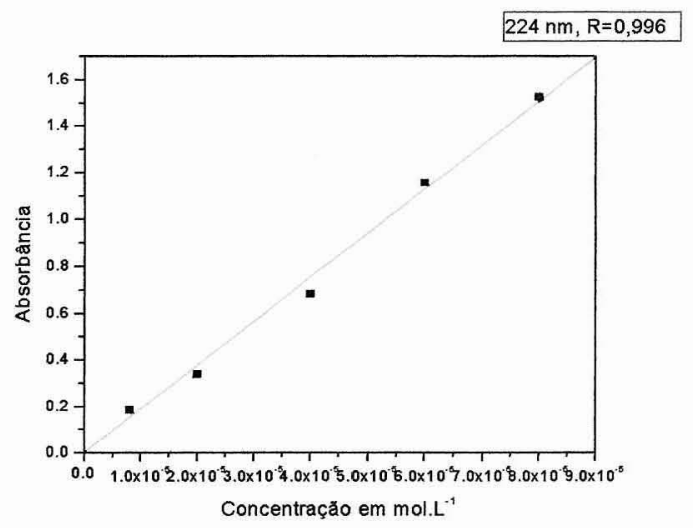

\subsection{Espectro eletrônico da Imina dbhab}

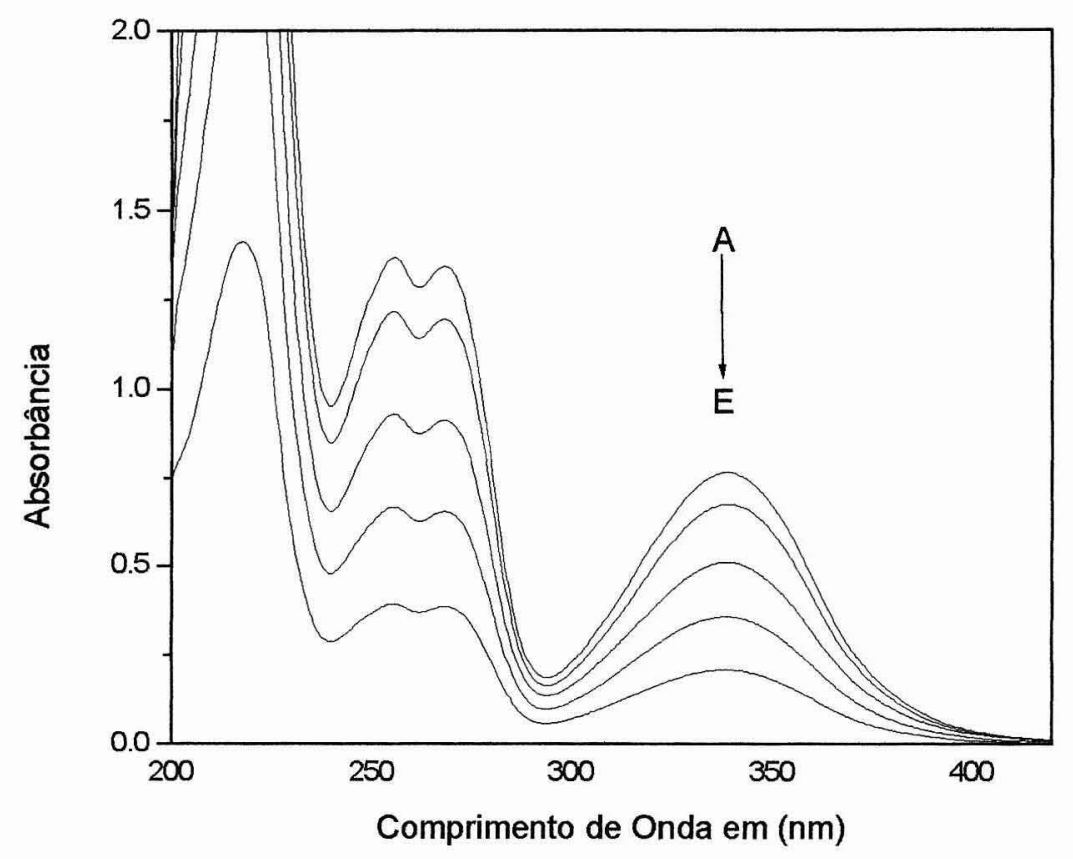

Figura 7. Espectro na região de $200-420 \mathrm{~nm}$ da imina dbhab em etanol, a concentrações variadas: A) $1,0 \times 10^{-4}$ mol.L-1 ; B) $9,2 \times 10^{-5} \mathrm{~mol}^{-1} \mathrm{~L}^{-1}$ C) $7,1 \times 10^{-5} \mathrm{~mol}^{-L^{-1}}$; D) $5,1 \times 10^{-5} \mathrm{~mol} . \mathrm{L}^{-1}$; E) $3,1 \times 10^{-5} \mathrm{~mol}^{-L^{-1}}$. 
$339 \mathrm{~nm}, \mathrm{R}=0,999$

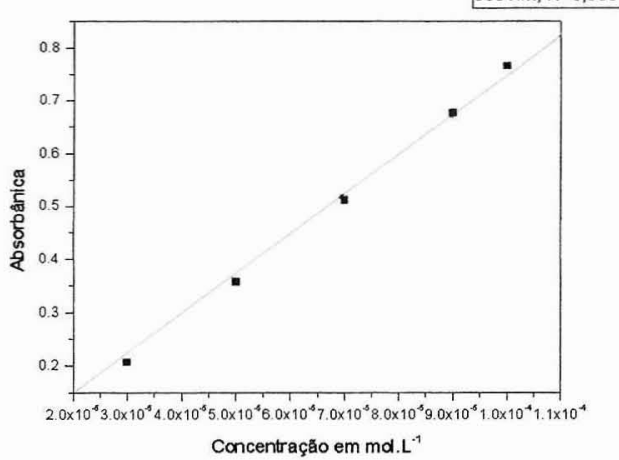

$268 \mathrm{~nm}, \mathrm{R}=0,999$

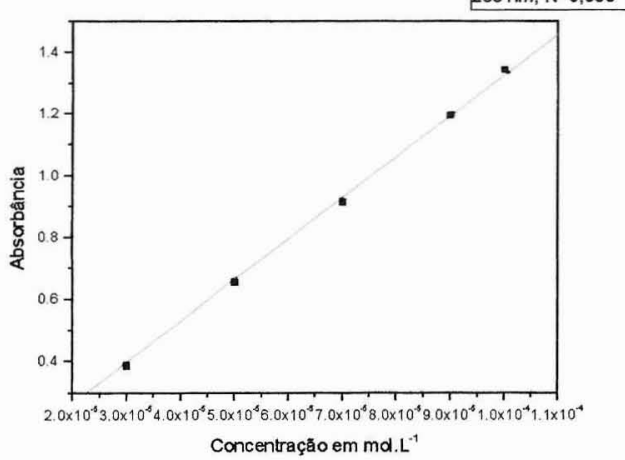

$255 \mathrm{~nm}, \mathrm{R}=0,999$

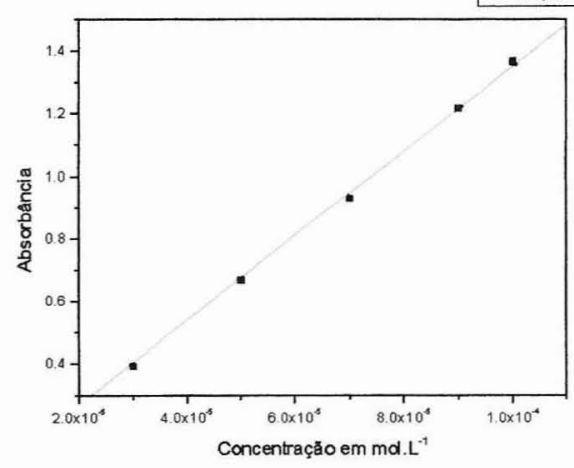




\subsubsection{Espectros eletrônicos dos Complexos de Vanádio(IV)}

\subsection{Espectro eletrônico do [ $\left.\mathrm{V}^{\mathrm{IV}} \mathrm{O}(\mathrm{acac})_{2}\right]$}

A)

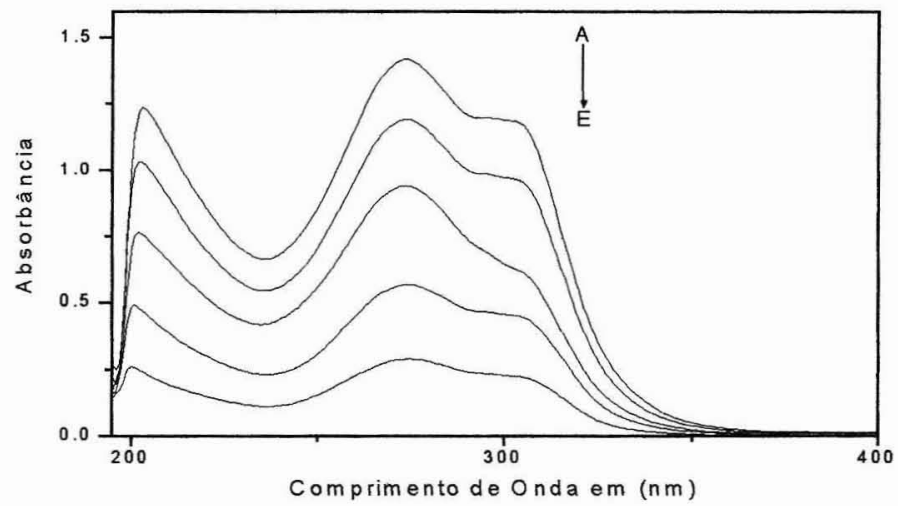

Figura 8. Espectro na região de $190-400 \mathrm{~nm}$ do composto $\left[\mathrm{V}^{\mathrm{I}} \mathrm{O}(\mathrm{acac})_{2}\right]$ em etanol, a concentrações variadas: A) $1,1 \times 10^{-4} \mathrm{~mol} . \mathrm{L}^{-1}$; B) $8,7 \times 10^{-5} \mathrm{~mol}^{-L^{-1}}$; C) $6,5 \times 10^{-5} \mathrm{~mol}^{-L^{-1}}$; D) $4,3 \times 10^{-5} \mathrm{~mol}^{-L^{-1}}$; E) $2,1 \times 10^{-5} \mathrm{~mol}^{-L^{-1}}$.
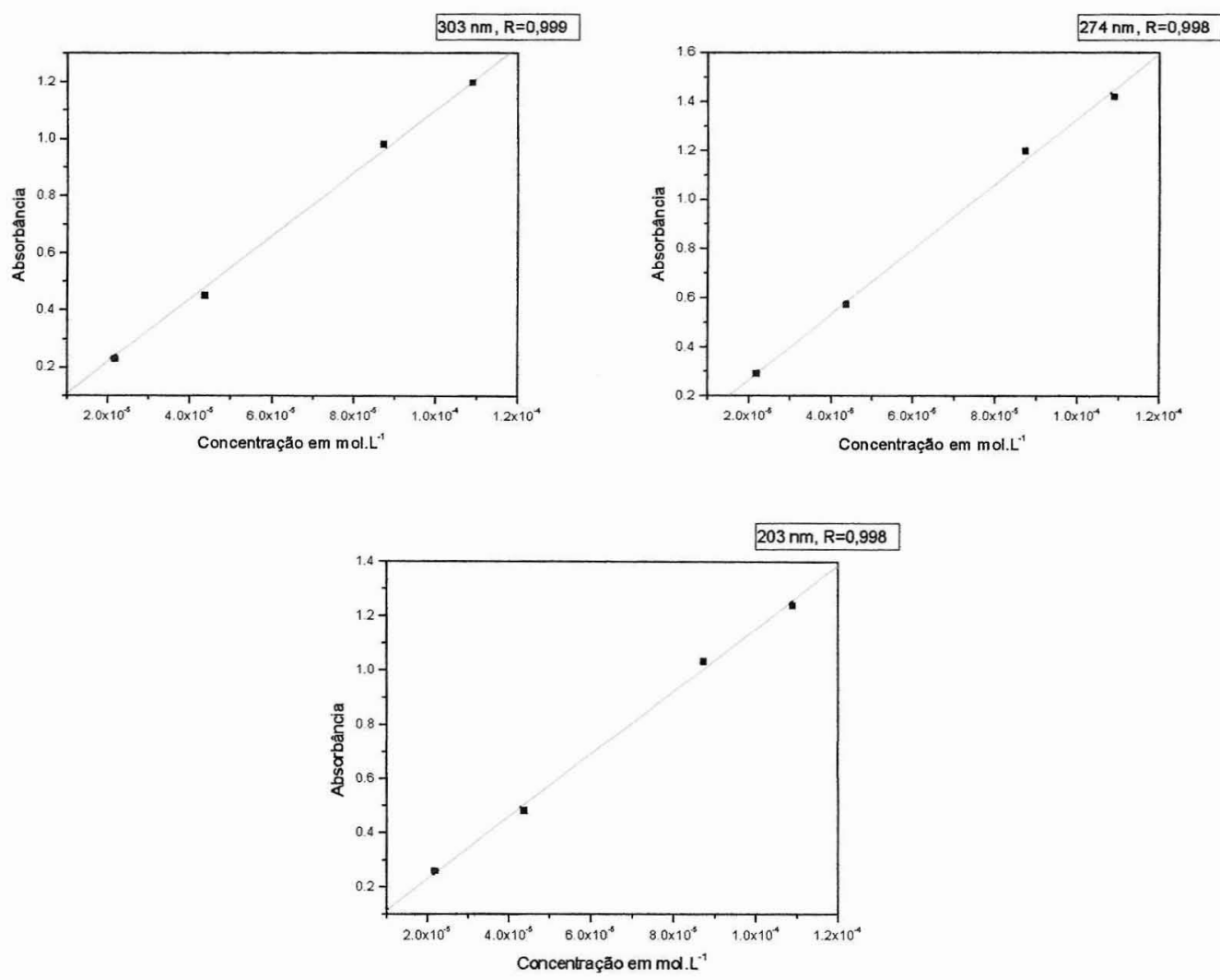
B)

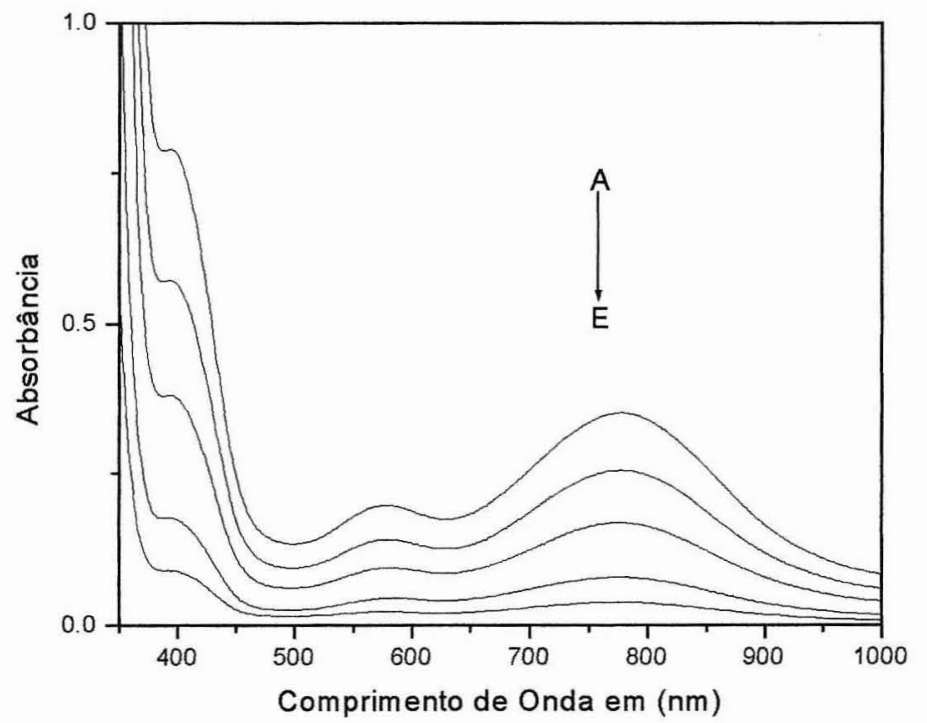

Figura 9. Espectro na região de 350-1000 nm do composto $\left[\mathrm{V}^{\mathrm{I}} \mathrm{O}(\mathrm{acac})_{2}\right]$ em etanol, a concentrações variadas: A) $7,9 \times 10^{-3} \mathrm{~mol}^{-L^{-1}}$; B) $5,9 \times 10^{-3} \mathrm{~mol}^{-1} \mathrm{~L}^{-1}$ C) $3,9 \times 10^{-3} \mathrm{~mol}^{-L^{-1}}$; D) $1,9 \times 10^{-3} \mathrm{~mol}^{-1} \mathrm{~L}^{-1}$; E) $9,0 \times 10^{-4} \mathrm{~mol}^{-L^{-1}}$.
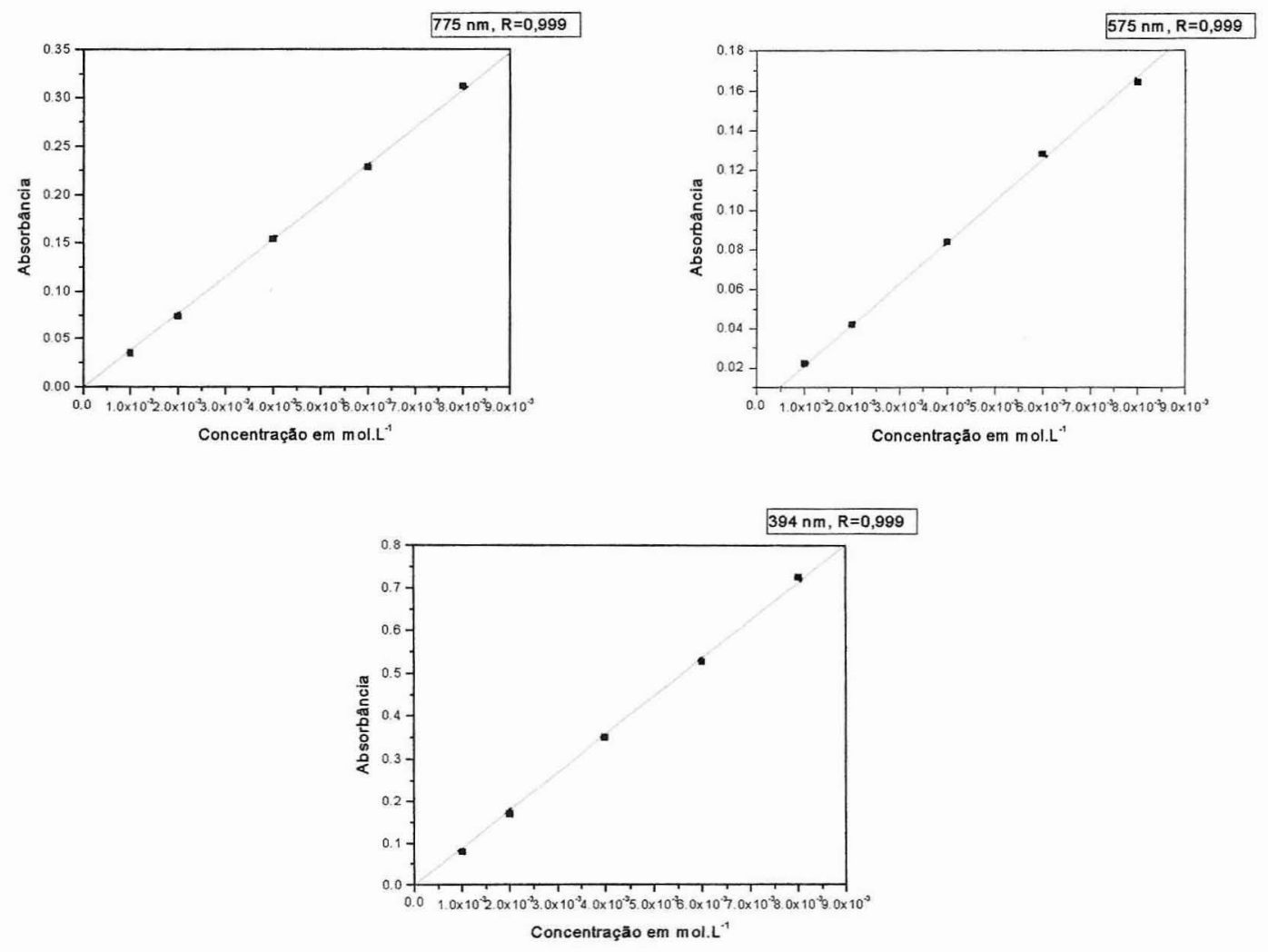


\subsection{Espectro eletrônico do [ $\left.V^{I V} O(s a l e n)\right]$}

A)

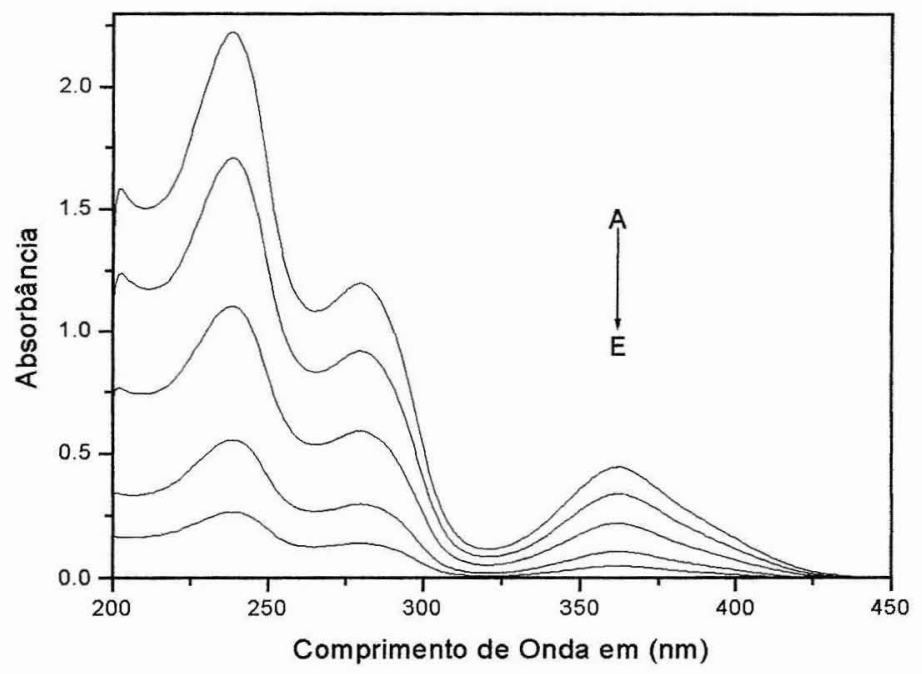

Figura 10. Espectro na região de $200-450 \mathrm{~nm}$ do composto $\left[V^{1} \mathrm{O}(\right.$ salen)] em etanol, a concentrações variadas: A) $1,0 \times 10^{-4} \mathrm{~mol}^{-1} \mathrm{~L}^{-1}$; B) $8,0 \times 10^{-5} \mathrm{~mol}^{-L^{-1}}$; C) $6,0 \times 10^{-5} \mathrm{~mol}^{-L^{-1}}$; D) $4,0 \times 10^{-5} \mathrm{~mol}^{-L^{-1}}$; E) $2,0 \times 10^{-5} \mathrm{~mol}^{-L^{-1}}$.
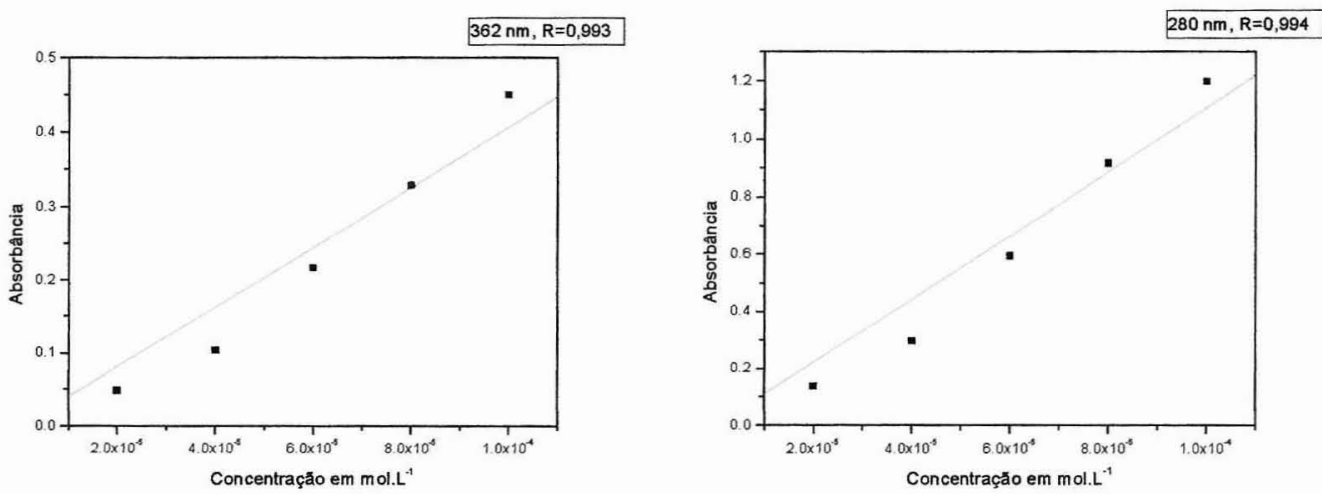


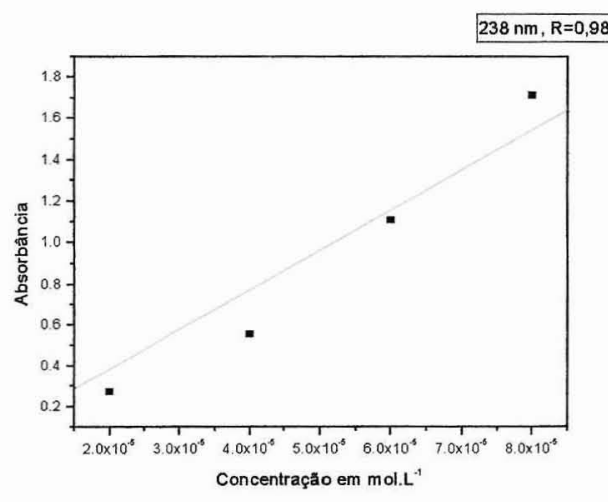

B)

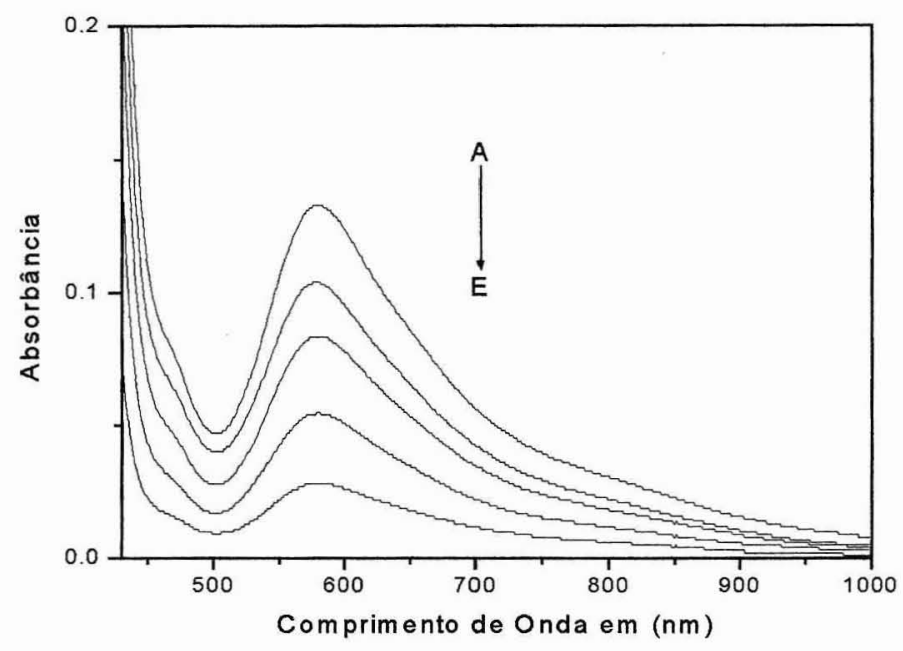

Figura 11. Espectro na região de $430-1000 \mathrm{~nm}$ do composto $\left[\mathrm{V}^{\mathrm{N}} \mathrm{O}\right.$ (salen)] em etanol, a concentrações variadas: A) $1,0 \times 10^{-3} \mathrm{~mol}^{-L^{-1}}$; B) $8,0 \times 10^{-3} \mathrm{~mol}^{-1} \mathrm{~L}^{-1}$ C) $6,0 \times 10^{-4} \mathrm{~mol}^{-L^{-1}}$; D) $4,0 \times 10^{-4} \mathrm{~mol}^{-L^{-1}}$; E) $2,0 \times 10^{-4} \mathrm{~mol} . \mathrm{L}^{-}$ 1.

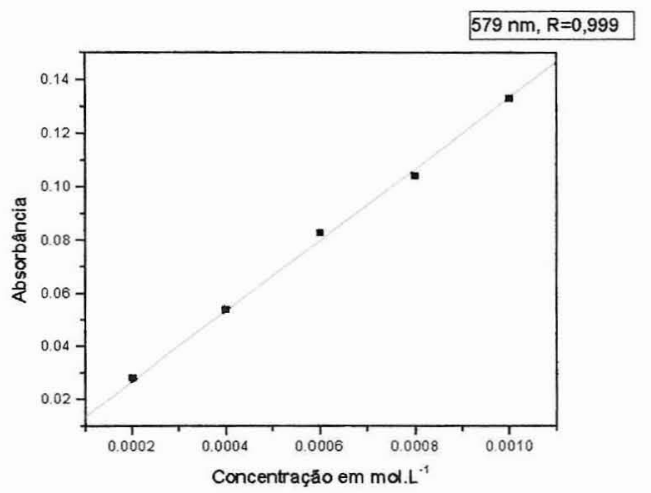




\subsection{Espectro eletrônico do [ $\left.\mathrm{V}^{\mathrm{IV}} \mathrm{O}(\mathrm{dbhbal})_{2}\right]$}

A)

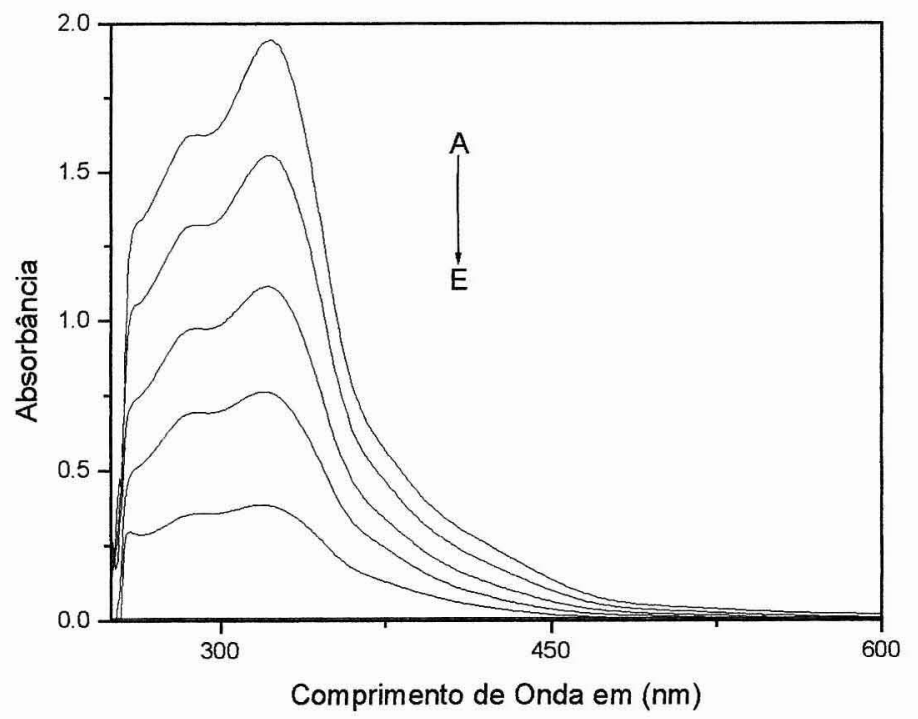

Figura 12. Espectro na região de $250-600 \mathrm{~nm}$ do composto $\left[V^{\mathrm{l}} \mathrm{O}(\mathrm{dbhbal})_{2}\right]$ em $\mathrm{DMSO}$, a concentrações variadas: A) $1,0 \times 10^{-4} \mathrm{~mol}_{\mathrm{L}} \mathrm{L}^{-1}$; B) $8,0 \times 10^{-5} \mathrm{~mol}^{-\mathrm{L}^{-1}}$; C) $6,0 \times 10^{-5} \mathrm{~mol} . \mathrm{L}^{-1}$; D) $4,0 \times 10^{-5} \mathrm{~mol}^{-\mathrm{L}^{-1}}$; E) $2,0 \times 10^{-5} \mathrm{~mol}^{-L^{-1}}$.
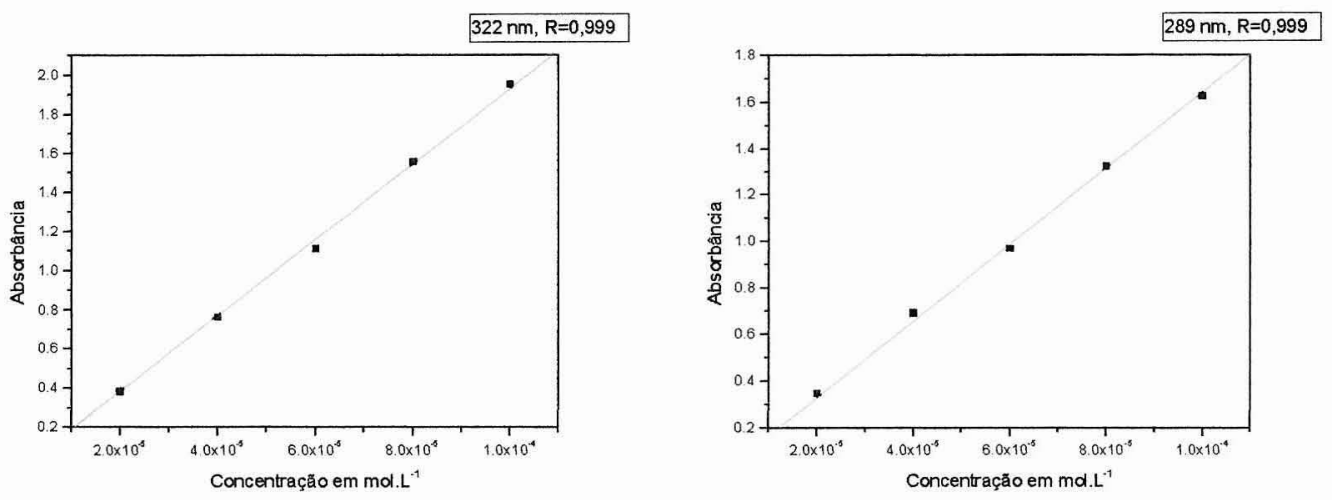
B)

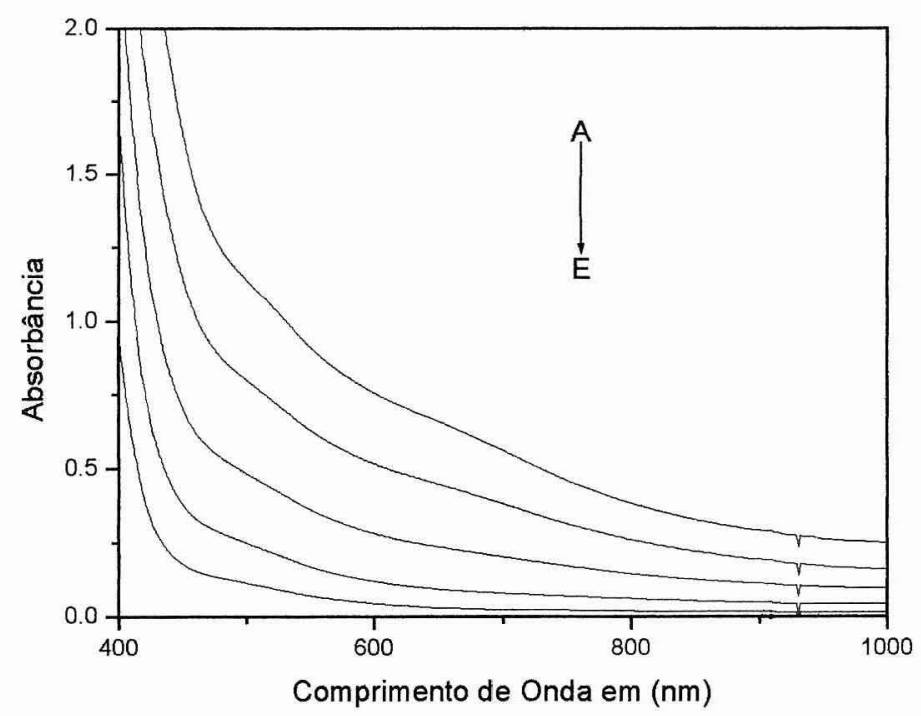

Figura 13. Espectro na região de 400-1000 nm do composto $\left[V^{i V} \mathrm{O}(\mathrm{dbhbal})_{2}\right]$ em $\mathrm{DMF}$, a concentrações variadas: A) $9,9 \times 10^{-4} \mathrm{~mol}^{-1} \mathrm{~L}^{-1}$; $) 7,9 \times 10^{-4} \mathrm{~mol}^{-L^{-1}}$; C) $5,9 \times 10^{-4} \mathrm{~mol} . \mathrm{L}^{-1}$; D) $3,9 \times 10^{-4} \mathrm{~mol}^{-L^{-1}}$; E) $1,9 \times 10^{-4} \mathrm{~mol} . \mathrm{L}^{-}$ 1.
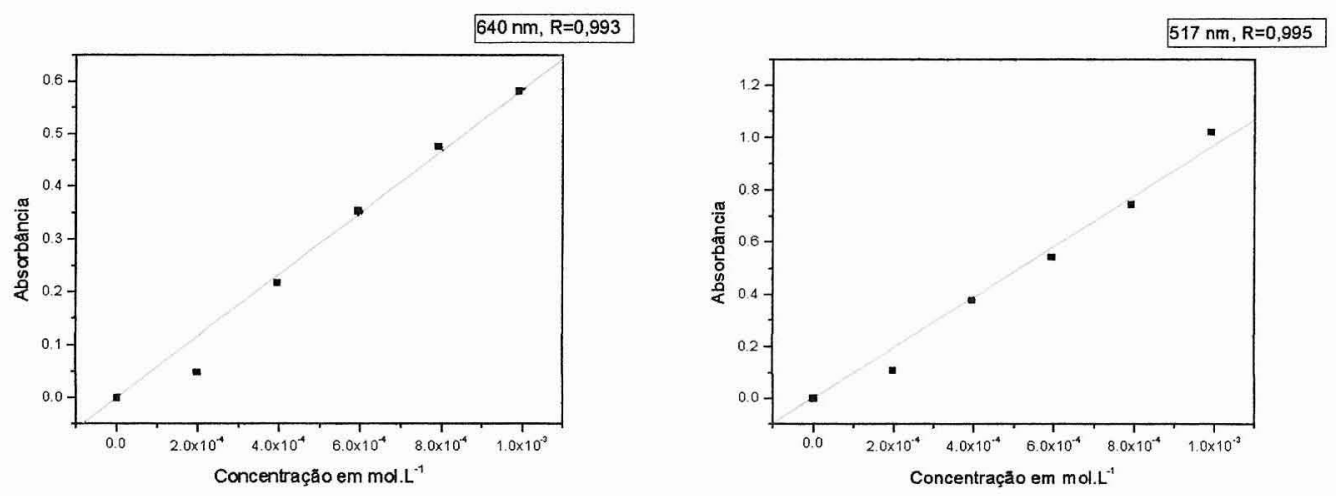


\subsection{Espectro eletrônico do $\left[V^{1 V} O(d b h a b)\right]_{2}$}

A)

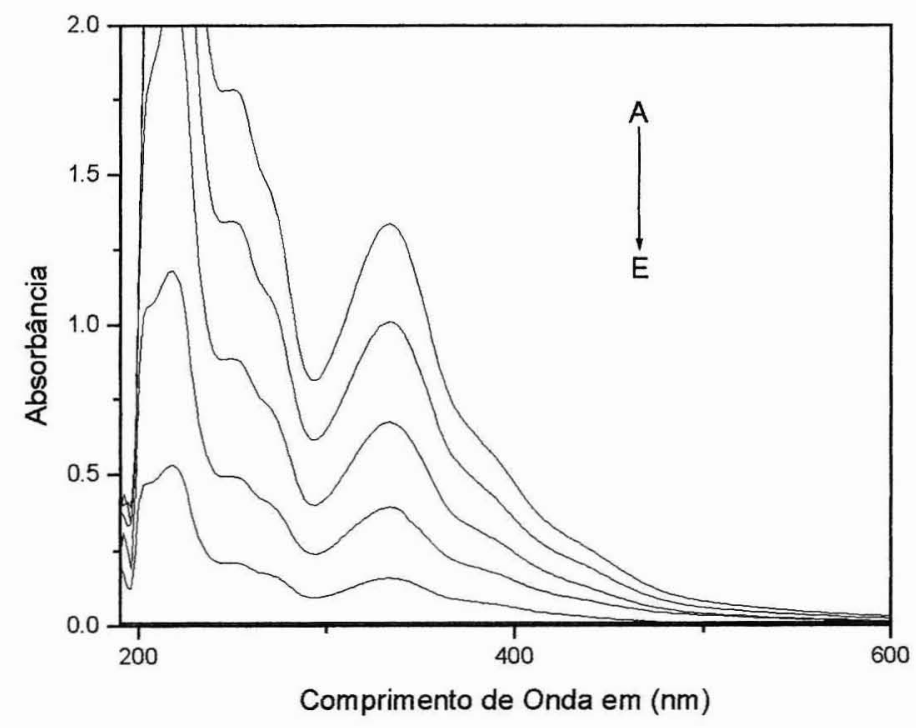

Figura 14. Espectro na região de 190-600 nm do composto $\left[V^{\mathrm{N} O} \mathrm{O}(\mathrm{dbhhab})\right]_{2}$ em DMSO, a concentrações variadas: A) $8,2 \times 10^{-5} \mathrm{~mol}^{-L^{-1}}$; B) $6,1 \times 10^{-5} \mathrm{~mol}^{-L^{-1}}$; C) $4,1 \times 10^{-5} \mathrm{~mol}^{-L^{-1}}$; D) $2,0 \times 10^{-5} \mathrm{~mol}^{-L^{-1}}$; E) $1,0 \times 10^{-5} \mathrm{~mol}^{-L^{-1}}$.
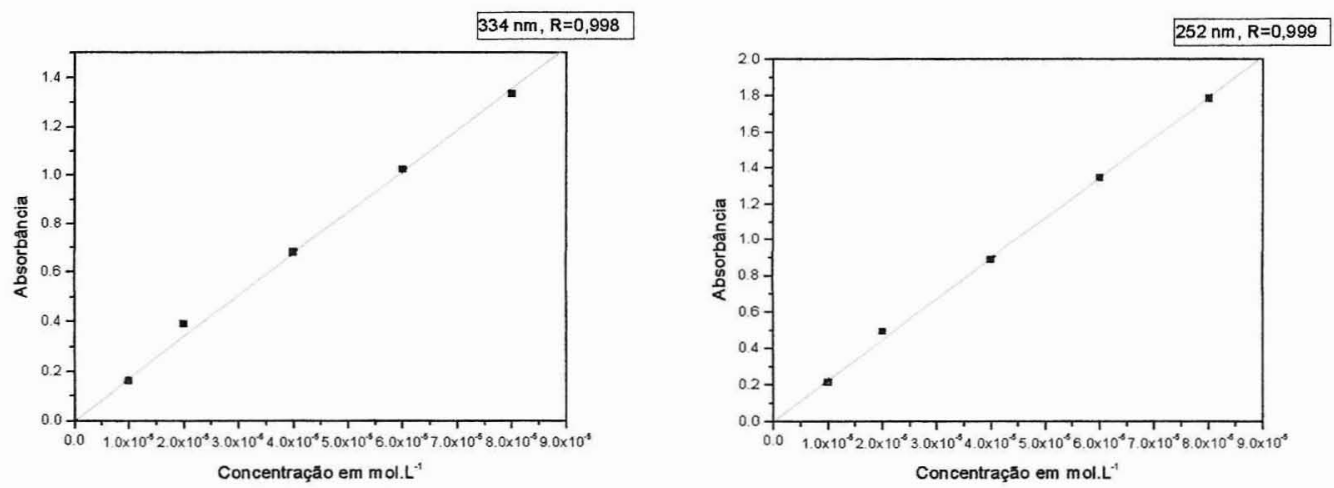


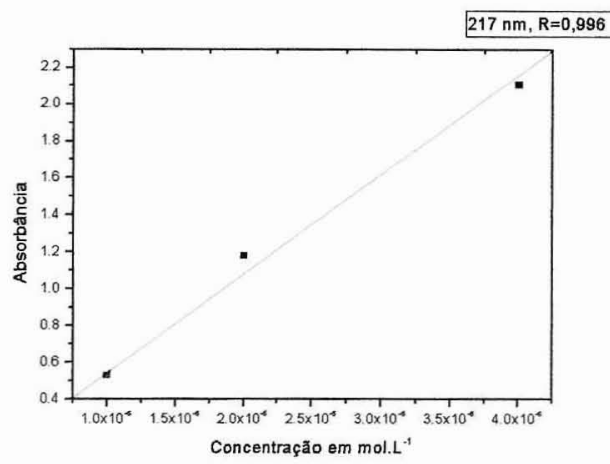

B)

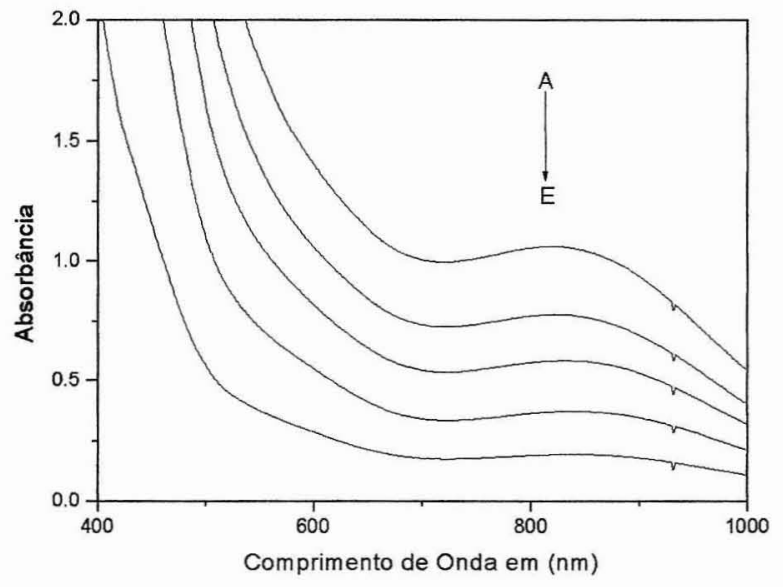

Figura 15. Espectro na região de 400-1000 nm do composto $\left[V^{\prime V O}(d b h a b)\right]_{2}$ em DMSO, a concentrações variadas: A) $9,9 \times 10^{-4} \mathrm{~mol}^{-1}$; B) $7,9 \times 10^{-4} \mathrm{~mol}^{-1}$; C) $5,9 \times 10^{-4} \mathrm{~mol}^{-1} \mathrm{~L}^{-1}$; D) $3,9 \times 10^{-4} \mathrm{~mol}^{-1}$; E) $1,9 \times 10^{-4} \mathrm{~mol}^{-L^{-}}$ 1

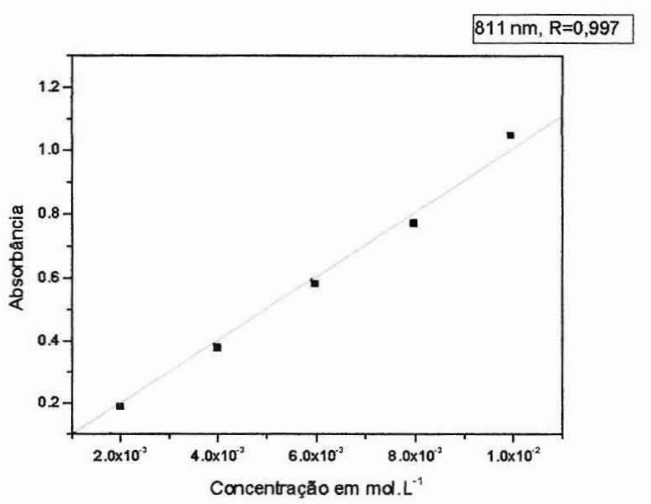




\subsection{Espectro eletrônico do $\mathrm{NH}_{4}\left[\mathrm{~V}^{\mathrm{lV}} \mathrm{O}_{2}(\mathrm{dbhab})\right]$}

A)

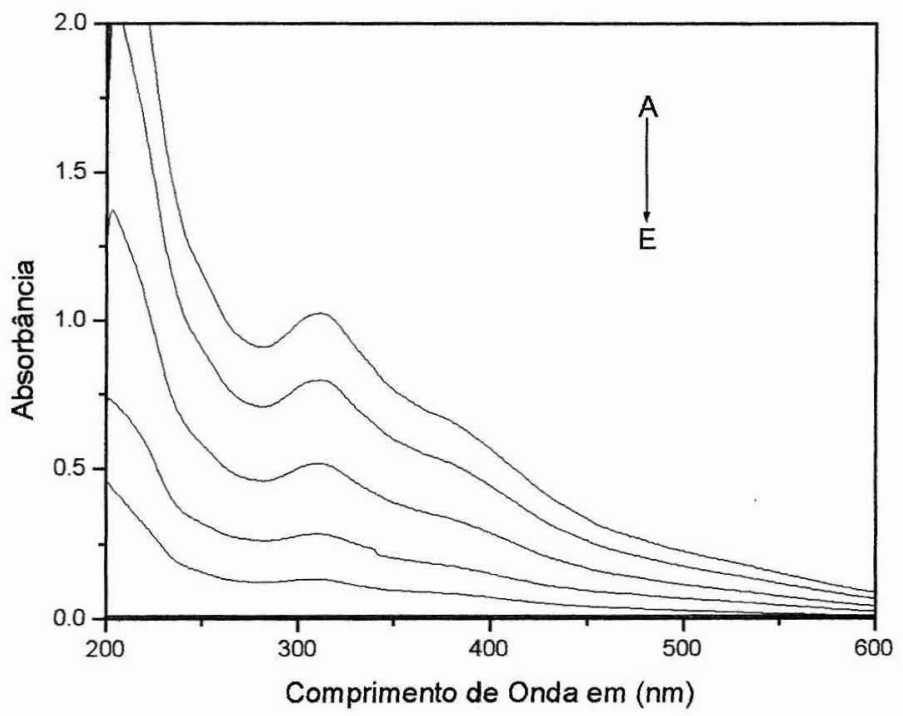

Figura 16. Espectro na região de $200-600 \mathrm{~nm}$ do composto $\mathrm{NH}_{4}\left[\mathrm{~V}^{\mathrm{V}} \mathrm{O}_{2}\right.$ (dbhab)] em etanol, a concentrações variadas: A) $2,0 \times 10^{-3} \mathrm{~mol} . \mathrm{L}^{-1}$ B) $6,0 \times 10^{-4} \mathrm{~mol}^{-L^{-1}}$; C) $4,0 \times 10^{-4} \mathrm{~mol} . \mathrm{L}^{-1}$; D) $2,0 \times 10^{-4} \mathrm{~mol}^{-L^{-1}}$; E) $1,0 \times 10^{-4} \mathrm{~mol}^{-L^{-1}}$.
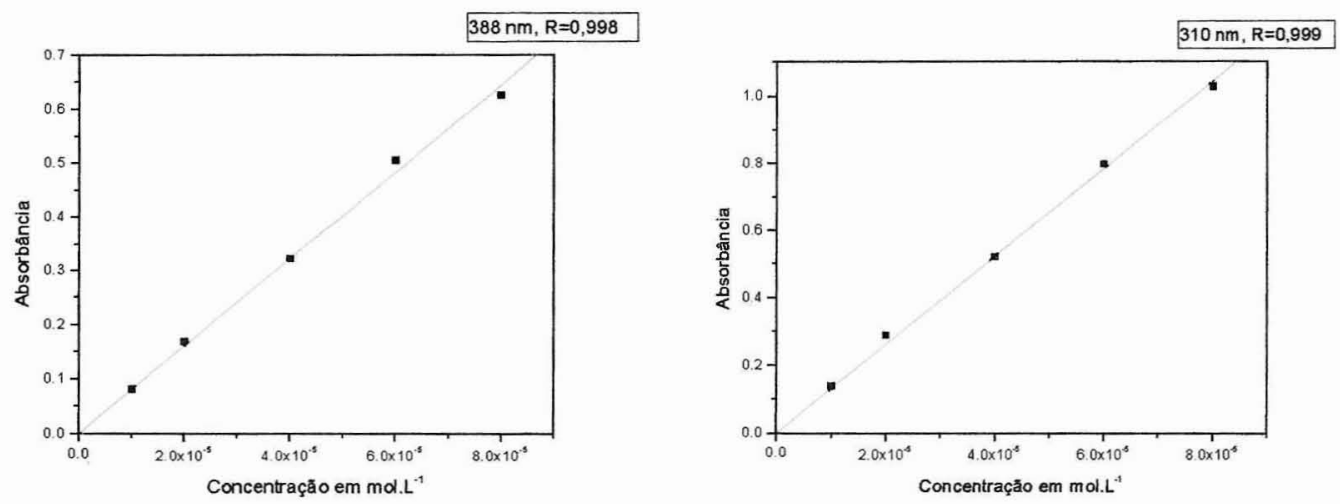
B)

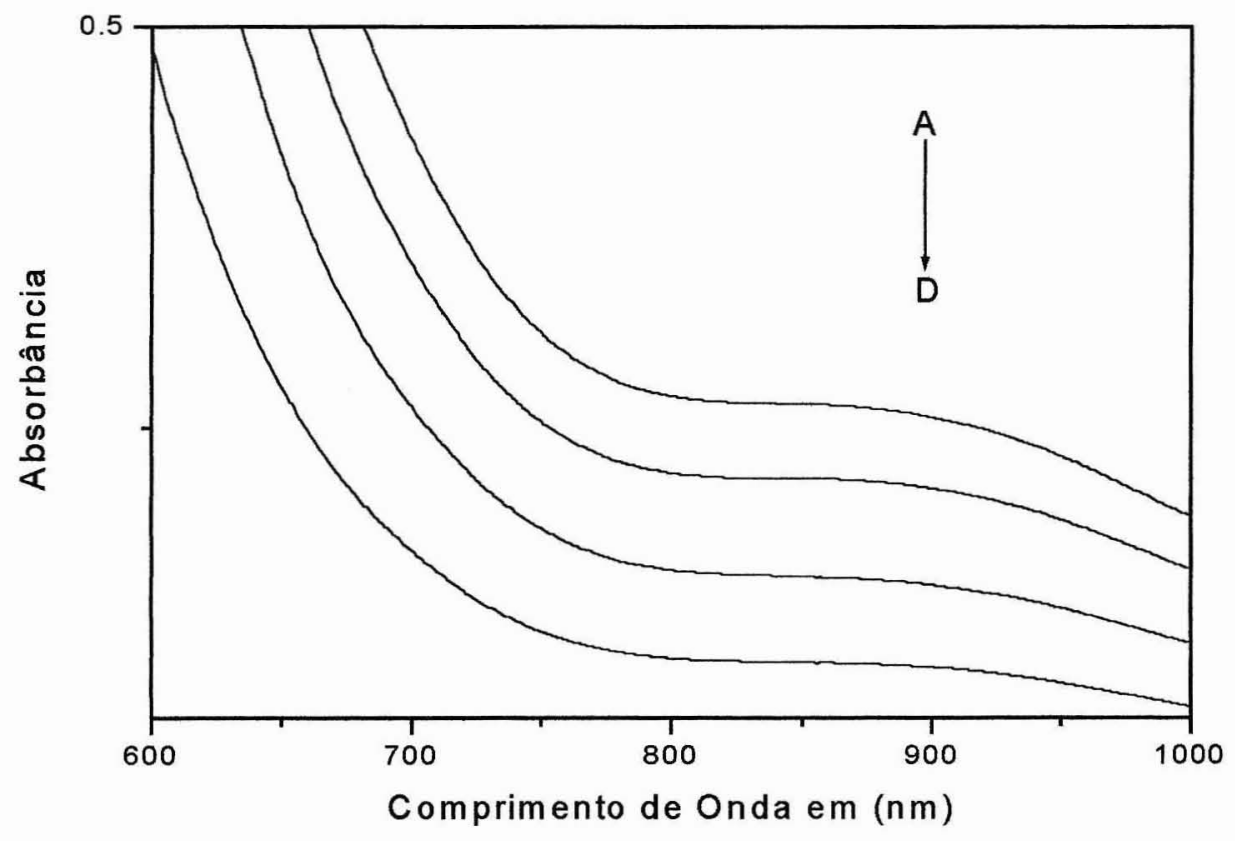

Figura 17. Espectro na região de $600-1000 \mathrm{~nm}$ do composto $\mathrm{NH}_{4} \mathrm{~V}^{\mathrm{N}} \mathrm{O}_{2}$ (dbhab)] em DMSO, a concentrações variadas: A) $9,9 \times 10^{-4} \mathrm{~mol}^{-L^{-1}}$; B) $7,9 \times 10^{-4} \mathrm{~mol}^{-L^{-1}}$; C) $5,9 \times 10^{-4} \mathrm{~mol}^{-L^{-1}}$; D) $3,9 \times 10^{-4} \mathrm{~mol}^{-L^{-1}}$.

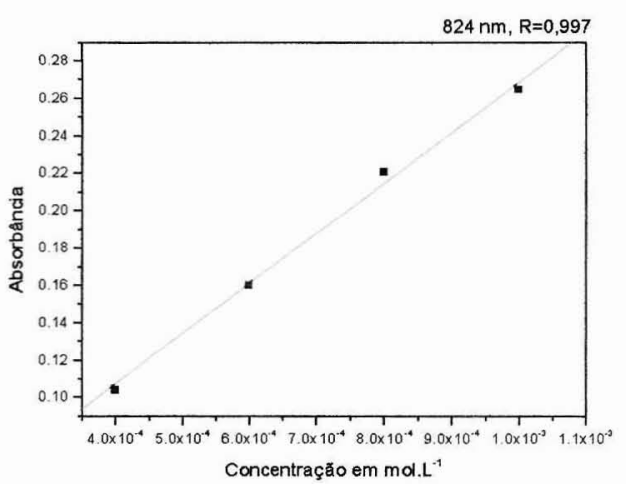




\subsection{Espectro eletrônico do $\mathrm{Na}_{2}\left[\mathrm{~V}^{\mathrm{IV}} \mathrm{O} \text { (cetoglut) }\right)_{2} \cdot 2 \mathrm{H}_{2} \mathrm{O}$}

A)

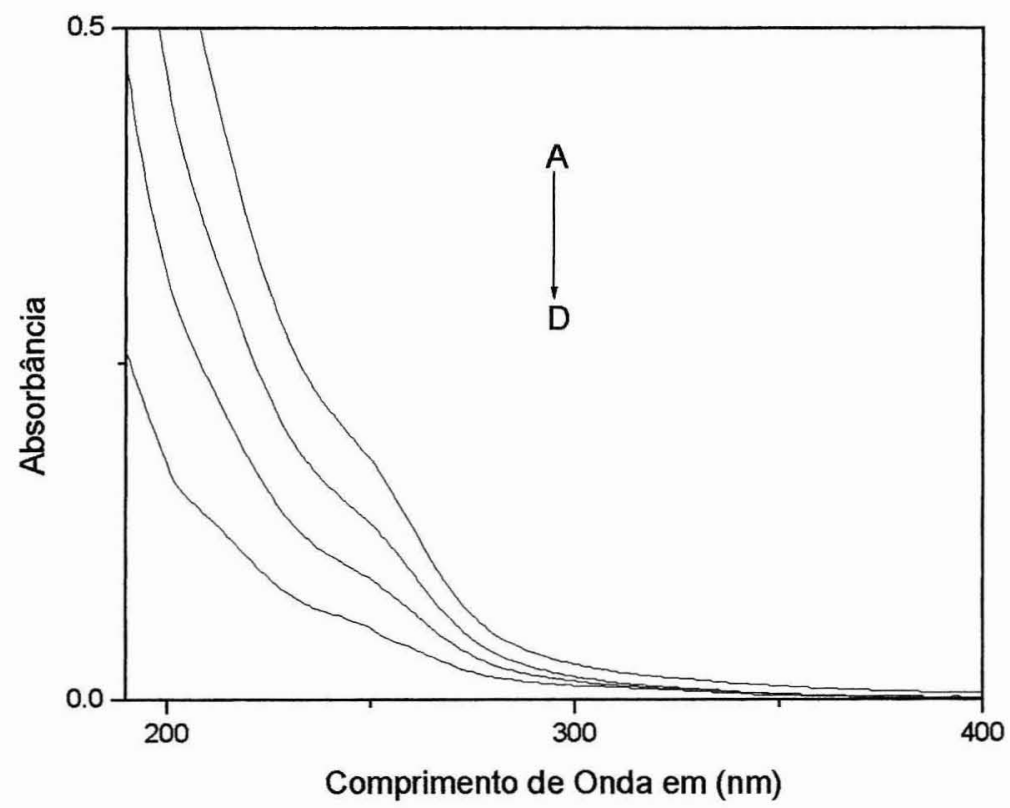

Figura 18. Espectro na região de $190-400 \mathrm{~nm}$ do composto $\mathrm{Na}_{2}\left[\mathrm{~V}^{\mathrm{IV}} \mathrm{O} \text { (cetglut) }\right]_{2} \cdot 2 \mathrm{H}_{2} \mathrm{O}$ em meio aquoso, a concentrações variadas: A) $2,2 \times 10^{-4} \mathrm{~mol} . \mathrm{L}^{-1}$; B) $9,1 \times 10^{-5} \mathrm{~mol}^{-L^{-1}}$; C) $6,8 \times 10^{-5} \mathrm{~mol} . \mathrm{L}^{-1}$; D) $4,5 \times 10^{-5} \mathrm{~mol}^{-L^{-1}}$.

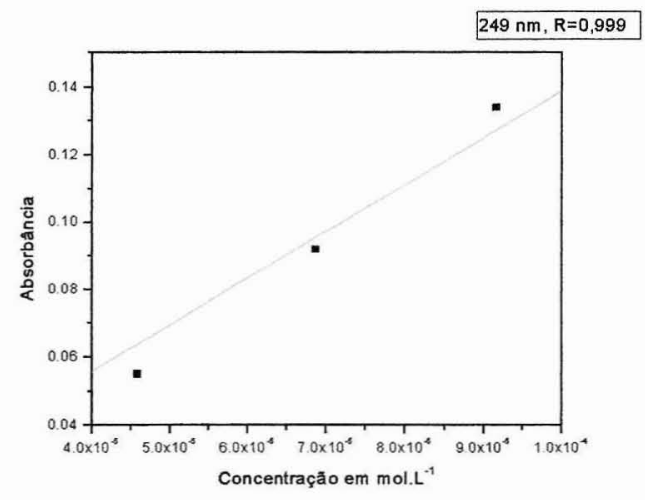


B)

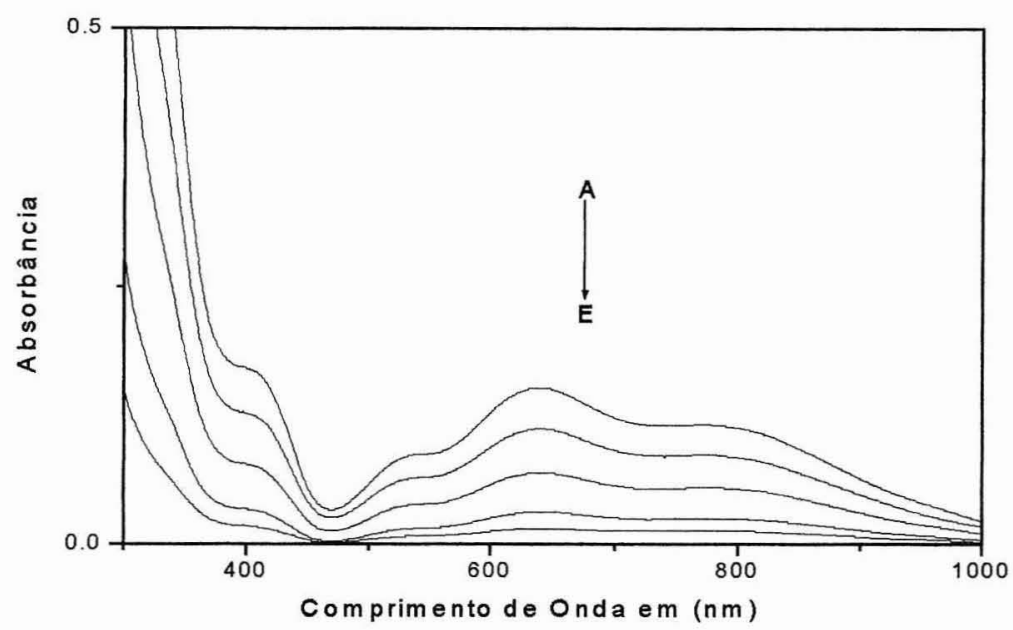

Figura 19. Espectro na região de $300-1000 \mathrm{~nm}$ do composto $\mathrm{Na}_{2}\left[\mathrm{~V}^{\mathrm{IV}} \mathrm{O} \text { (cetoglut) }\right]_{2} \cdot 2 \mathrm{H}_{2} \mathrm{O}$ em $\mathrm{H}_{2} \mathrm{O}$, a concentrações variadas: A) $8,1 \times 10^{-3} \mathrm{~mol}^{-L^{-1}}$; B) $6,1 \times 10^{-3} \mathrm{~mol}^{-L^{-1}}$; C) $4,1 \times 10^{-3} \mathrm{~mol}^{-1}$; D) $2,0 \times 10^{-3} \mathrm{~mol}^{-L^{-1}}$; E) $1,0 \times 10^{-3} \mathrm{~mol} \cdot \mathrm{L}^{-1}$.
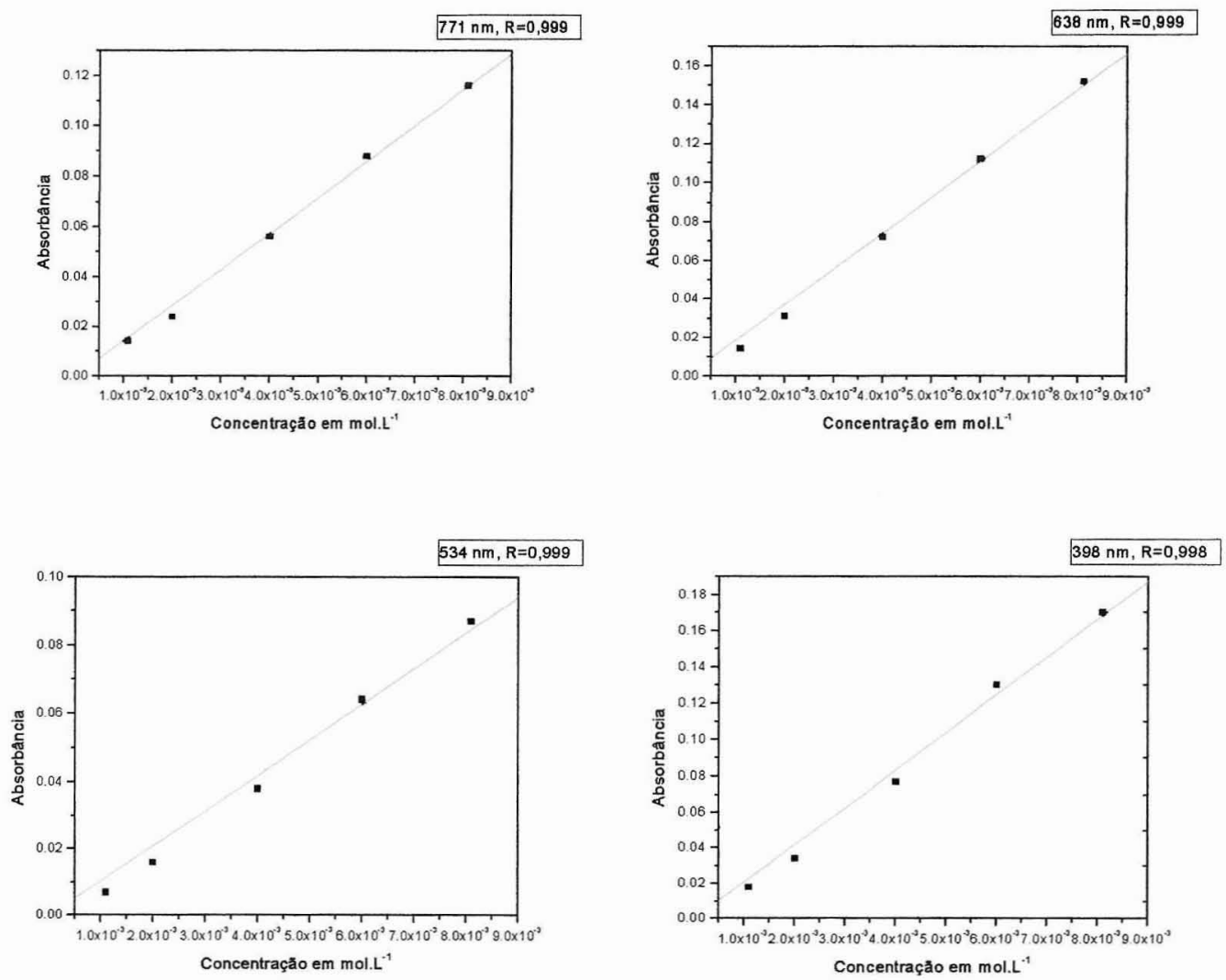


\subsection{Espectro eletrônico do $\left.\left(\mathrm{NH}_{4}\right)_{3}\left[\mathrm{~V}^{\mathrm{lV}} \mathrm{O}_{2} \text { (cetoglut) }\right)_{2}\right]$}

A)

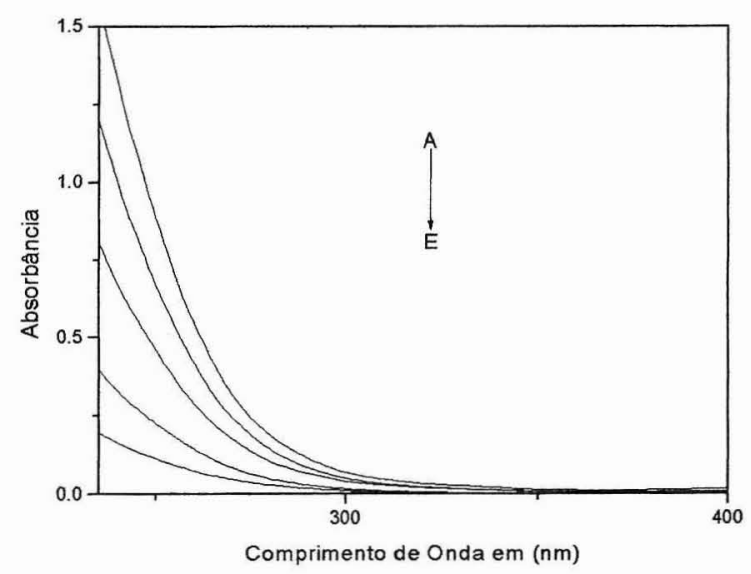

Figura 20. Espectro na região de $190-400 \mathrm{~nm}$ do composto $\left.\left(\mathrm{NH}_{4}\right)_{3}\left[\mathrm{~V}^{\mathrm{N}} \mathrm{O}_{2} \text { (cetoglut) }\right)_{2}\right]$ em meio aquoso, a concentrações variadas: A) $7,9 \times 10^{-4} \mathrm{~mol}^{-L^{-1}}$; B) $5,9 \times 10^{-4} \mathrm{~mol}^{-1} \mathrm{~L}^{-1}$ C) $3,9 \times 10^{-4} \mathrm{~mol} . \mathrm{L}^{-1}$; D) $1,9 \times 10^{-4} \mathrm{~mol}^{-1} \mathrm{~L}^{-1}$; $)$ $9,9 \times 10^{-5} \mathrm{~mol} \cdot \mathrm{L}^{-1}$.

B)

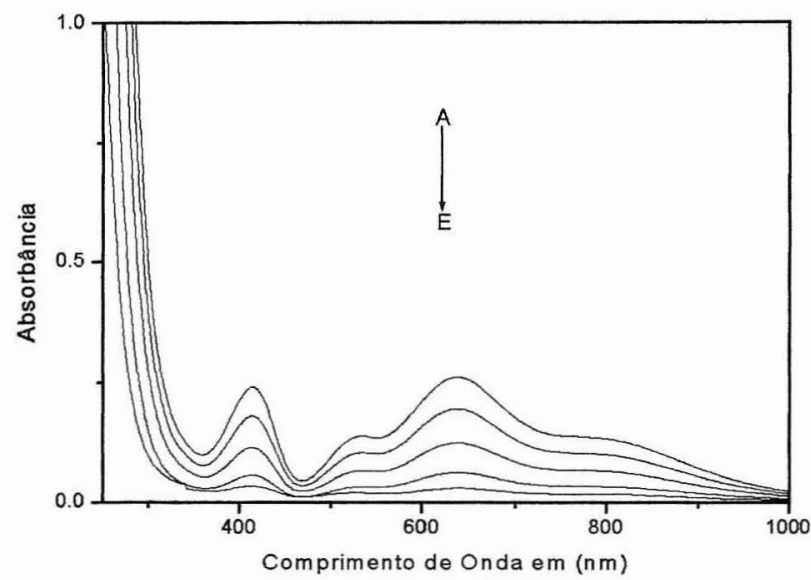

Figura 21. Espectro na região de $250-1100 \mathrm{~nm}$ do composto $\left(\mathrm{NH}_{4}\right)_{3} \mathrm{~V}^{\mathrm{l}} \mathrm{O}_{2}$ (cetoglut) $]$ em meio aquoso, a concentrações variadas: A) $8,0 \times 10^{-3} \mathrm{~mol}^{-L^{-1}}$; B) $6,0 \times 10^{-3} \mathrm{~mol}^{-1} \mathrm{~L}^{-1}$; C) $4,0 \times 10^{-3} \mathrm{~mol}^{-L^{-1}}$; D) $2,0 \times 10^{-3} \mathrm{~mol}^{-1} \mathrm{~L}^{-1}$; E) $1,0 \times 10^{-3} \mathrm{~mol}^{-L^{-1}}$. 
$414 \mathrm{~nm}, \mathrm{R}=0,998$
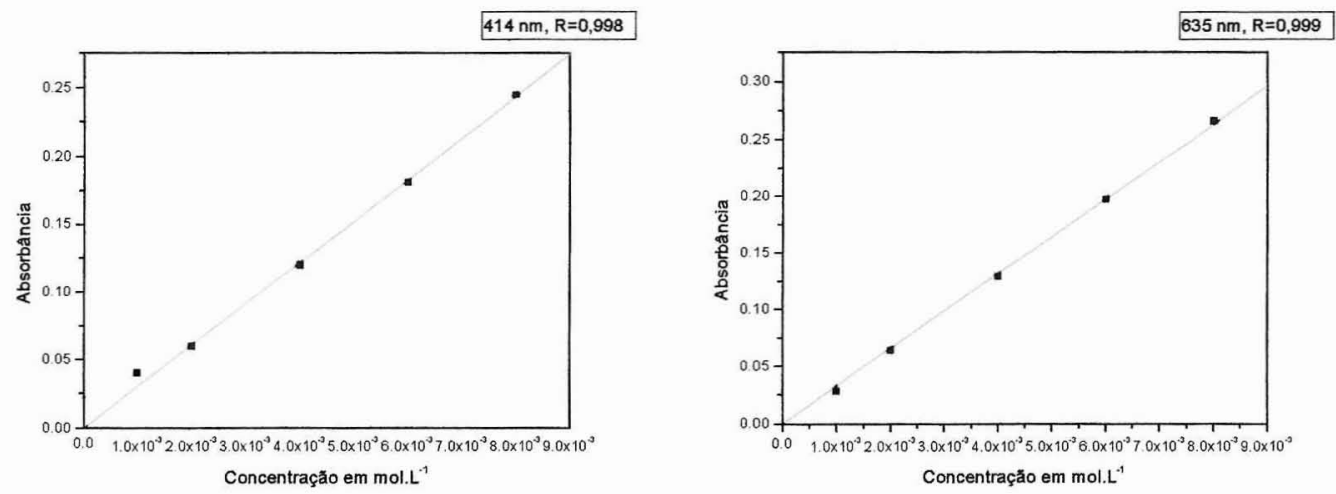

$532 \mathrm{~nm}, \mathrm{R}=0,996$
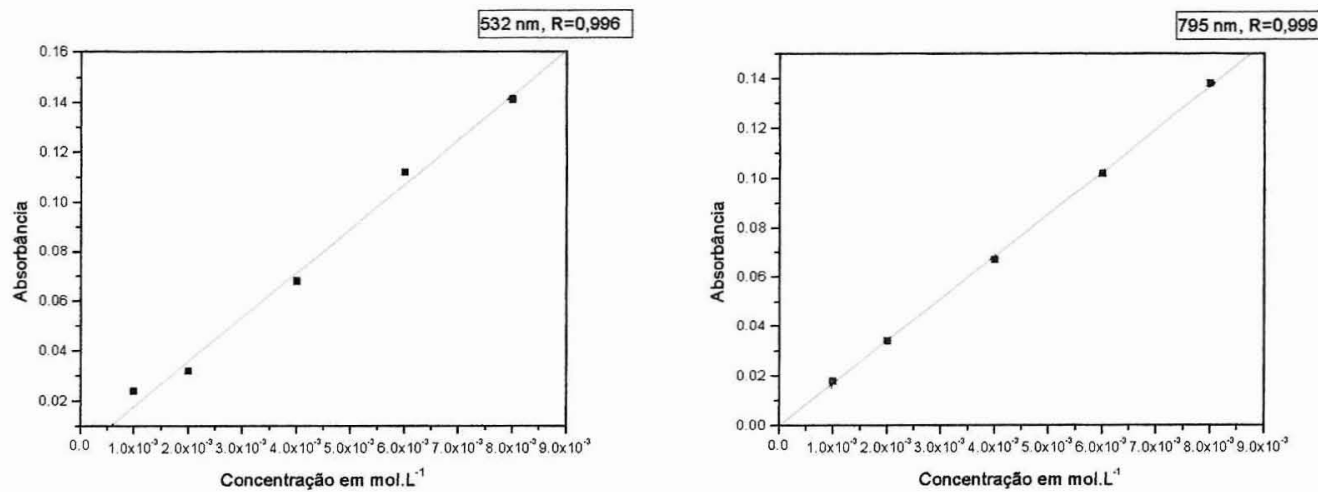
Tabela 2. Parâmetros Espectrais na região do UV-Visível das Iminas e dos Complexos de Vanádio(IV) em etanol, metanol, DMSO, DMF ou água a $25^{\circ} \mathrm{C}$.

\begin{tabular}{|c|c|c|c|c|}
\hline \multirow[b]{2}{*}{ Compostos } & \multicolumn{2}{|c|}{$\lambda_{\text {máx }}(\mathrm{nm})\left(\varepsilon, \mathrm{M}^{-1} \mathrm{~cm}^{-1}\right)$} & \multirow{2}{*}{$\begin{array}{c}\lambda_{\text {Máx }}(\mathrm{nm})\left(\varepsilon, M^{-1} \mathrm{~cm}^{-1}\right) \\
d \rightarrow d\end{array}$} & \multirow[t]{2}{*}{$\begin{array}{l}\text { Provável } \\
\text { Geometria }\end{array}$} \\
\hline & $\begin{array}{l}\text { IL } \mathbf{n} \rightarrow \pi^{*} \\
\text { ou } \pi \rightarrow \pi^{*}\end{array}$ & $\begin{array}{c}\pi \rightarrow \mathrm{d} \pi \\
(\mathrm{TCLM})\end{array}$ & & \\
\hline $\begin{array}{c}\text { salen } \\
\text { *solvente: etanol }\end{array}$ & $\begin{array}{l}317\left(8,6 \times 10^{3}\right) \\
256\left(2,4 \times 10^{4}\right) \\
215\left(4,8 \times 10^{4}\right)\end{array}$ & 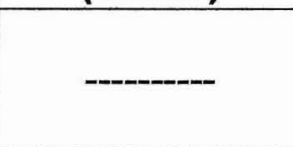 & & \\
\hline $\begin{array}{c}\text { dbhbal } \\
\text { *solvente: etanol }\end{array}$ & $\begin{array}{l}319\left(7,3 \times 10^{3}\right) \\
274\left(1,1 \times 10^{4}\right) \\
224\left(1,9 \times 10^{4}\right)\end{array}$ & - & & \\
\hline $\begin{array}{c}\text { dbhab } \\
\text { *solvente: etanol }\end{array}$ & $\begin{array}{l}339\left(1,5 \times 10^{3}\right) \\
268\left(1,3 \times 10^{4}\right) \\
255\left(1,3 \times 10^{4}\right)\end{array}$ & & & \\
\hline $\begin{array}{c}{\left[\mathrm{V}^{\mathrm{lV}} \mathrm{O}(\mathrm{acac})_{2]}\right]} \\
\text { *solvente: etanol }\end{array}$ & $\begin{array}{l}303\left(1,1 \times 10^{4}\right) \\
274\left(1,3 \times 10^{4}\right) \\
203\left(1,1 \times 10^{4}\right)\end{array}$ & $394\left(8,9 \times 10^{1}\right)$ & $\begin{array}{l}775\left(3,8 \times 10^{1}\right) \\
576\left(2,1 \times 10^{1}\right)\end{array}$ & $\begin{array}{l}\text { Piramidal } \\
\text { quadrado }\end{array}$ \\
\hline $\begin{array}{c}\left.\mathrm{I}^{\mathrm{N}} \mathrm{O}(\text { salen})\right] \\
\text { *solvente: etanol }\end{array}$ & $\begin{array}{l}280\left(1,1 \times 10^{4}\right) \\
238\left(1,9 \times 10^{4}\right)\end{array}$ & $362\left(4,1 \times 10^{3}\right)$ & $579\left(1,3 \times 10^{2}\right)$ & $\begin{array}{l}\text { Piramidal } \\
\text { quadrado }\end{array}$ \\
\hline $\begin{array}{c}{\left[\mathrm{V}^{\mathrm{l} V} \mathrm{O}(\mathrm{dbhbal})_{2}\right]} \\
\text { *Solvente: etanol e DMF }\end{array}$ & $\begin{array}{l}322\left(1,9 \times 10^{4}\right) \\
289\left(1,6 \times 10^{4}\right)\end{array}$ & N.O. & $\begin{array}{l}640\left(5,8 \times 10^{2}\right) \\
517\left(9,7 \times 10^{2}\right)\end{array}$ & $\begin{array}{l}\text { Piramidal } \\
\text { quadrado }\end{array}$ \\
\hline $\begin{array}{c}{\left[\mathrm{V}^{\mathrm{V} O} \mathrm{O}(\mathrm{dbhab})\right]_{2}} \\
{ }^{*} \text { solvente: etanol e DMSO }\end{array}$ & $\begin{array}{l}252\left(2,2 \times 10^{4}\right) \\
217\left(5,4 \times 10^{4}\right)\end{array}$ & $334\left(1,7 \times 10^{4}\right)$ & $811\left(1,0 \times 10^{2}\right)$ & $\begin{array}{l}\text { Quadrado } \\
\text { planar }\end{array}$ \\
\hline $\begin{array}{c}\mathrm{NH}_{4}\left[\mathrm{~V}^{\mathrm{I}} \mathrm{O}_{2}(\mathrm{dbhab})\right] \\
\text { solvente: etanol e DMSO }\end{array}$ & $\begin{array}{l}388\left(8,0 \times 10^{3}\right) \\
310\left(1,3 \times 10^{4}\right)\end{array}$ & $388\left(8,0 \times 10^{3}\right)$ & $824\left(2,7 \times 10^{2}\right)$ & $\begin{array}{l}\text { Bipirâmide } \\
\text { de base } \\
\text { triangular }\end{array}$ \\
\hline $\begin{array}{l}\mathrm{Na}_{2}\left[\mathrm{~V}^{\mathrm{lV}} \mathrm{O}(\text { cetoglut })_{2}\right] \cdot 2 \mathrm{H}_{2} \mathrm{O} \\
\text { *solvente: } \mathrm{H}_{2} \mathrm{O}\end{array}$ & $249\left(1,3 \times 10^{4}\right)$ & $398\left(1,9 \times 10^{1}\right)$ & $\begin{array}{l}771\left(1,4 \times 10^{1}\right) \\
638\left(1,8 \times 10^{1}\right)\end{array}$ & $\begin{array}{l}\text { Quadrado } \\
\text { planar }\end{array}$ \\
\hline $\begin{array}{c}\left.\left(\mathrm{NH}_{4}\right)_{3}\left[\mathrm{~V}^{\mathrm{V}} \mathrm{O}_{2} \text { (cetoglut }\right)_{2}\right] \\
\text { *solvente: } \mathrm{H}_{2} \mathrm{O}\end{array}$ & N.O. & $414\left(3,0 \times 10^{1}\right)$ & $\begin{array}{l}795\left(1,7 \times 10^{1}\right) \\
635\left(3,3 \times 10^{1}\right)\end{array}$ & Octaédrica \\
\hline
\end{tabular}

${ }^{\star}$ Solvente utilizado para o registro dos espectros

Sendo: N.O. Não Observado 
Para os ligantes imínicos livres, as transições internas do ligante são referentes aos grupos cromóforos $\mathrm{C}=\mathrm{C}$ do anel aromático e do grupo imínico $\mathrm{C}=\mathrm{N}$, e são descritos na literatura $[53,54]$ na região entre 340 e $220 \mathrm{~nm}$, com coeficiente de absortividade molar $(\varepsilon)$ característico, da ordem de $10^{3}-10^{4} \mathrm{M}^{-1} \mathrm{~cm}^{-1}$, indicando que as transições são totalmente permitidas pelas regras de seleção. Nos complexos metálicos, estas bandas podem sofrer deslocamentos devido à presença do íon metálico e às interações decorrentes.

No complexo $\mathrm{Na}_{2}\left[\mathrm{~V}^{\mathrm{IV}} \mathrm{O}\right.$ (cetoglut) $\left.{ }_{2}\right] \cdot 2 \mathrm{H}_{2} \mathrm{O}$, onde o ligante se coordena por grupos carboxilato e cetônico, observa-se uma banda-ombro fraca em 249 nm, atribuída à transição $n \rightarrow \pi^{*}$. Para o complexo $\left.\left(\mathrm{NH}_{4}\right)_{3}\left[\mathrm{~V}^{\mathrm{l} V} \mathrm{O}_{2} \text { (cetoglut) }\right)_{2}\right]$ esta banda não foi observada, possivelmente desloca-se para região de maior energia em comprimento de onda menor que $190 \mathrm{~nm}$.

Como já citado anteriormente, as transições do tipo LMCT envolvem uma transição ( $\pi$ $\rightarrow \mathrm{d} \pi$ ) na qual os elétrons de um orbital $\pi$ ocupado, predominantemente localizado no ligante, são excitados para um orbital vazio, de caráter $\mathrm{d} \pi$, localizado no metal. Este tipo de transição ocorre na região de 320 a $450 \mathrm{~nm}$, com $\varepsilon$ característico em torno de $10^{3} \mathrm{M}^{-}$ ${ }^{1} \mathrm{~cm}^{-1}$, e se caracteriza por intensa absorção, sendo permitida pelas regras de seleção [28].

Para o complexo [VO(acac) $)_{2}$, observou-se uma banda em $394 \mathrm{~nm}$ atribuída à transferência de carga do ligante para o metal, de acordo com os dados da literatura [55], onde as características espectroscópicas deste complexo foram estudadas exaustivamente em vários solventes. Nos complexos [ $\left.\mathrm{V}^{\mathrm{IV}} \mathrm{O}(\mathrm{dbhab})\right]_{2}, \mathrm{NH}_{4}\left[\mathrm{~V}^{\mathrm{IV}} \mathrm{O}_{2}(\mathrm{dbhab})\right]$, $\left.\mathrm{Na}_{2}\left[\mathrm{~V}^{\mathrm{IV}} \mathrm{O} \text { (cetoglut) }\right)_{2}\right] \cdot 2 \mathrm{H}_{2} \mathrm{O}$ e $\left.\left(\mathrm{NH}_{4}\right)_{3}\left[\mathrm{~V}^{\mathrm{IV}} \mathrm{O}_{2} \text { (cetoglut) }\right)_{2}\right]$ essas bandas foram observadas entre 334 e $388 \mathrm{~nm}$, com $\varepsilon$ de da ordem de $10^{3} \mathrm{M}^{-1} \mathrm{~cm}^{-1}$. Para o complexo [ $\left.\mathrm{V}^{\mathrm{IV}} \mathrm{O}(\mathrm{dbhbal})_{2}\right]$ 
essa banda possivelmente apresenta-se encoberta pelas bandas de alta intensidade do tipo IL e não foi possível identificá-las.

Os íons vanadila $\left(\mathrm{VO}^{2+}\right)$ absorvem no UV/Vis, na região de 600 a $800 \mathrm{~nm}$ e 500 a 600 $\mathrm{nm}$ com baixas intensidades, ambas com $\varepsilon$ da ordem de $100 \mathrm{M}^{-1} \mathrm{~cm}^{-1}$, correspondente às transições: ${ }^{2} B_{2}\left(d_{x y}\right) \rightarrow{ }^{2} B_{1}\left(d_{x 2}-y_{2}\right)$, e ${ }^{2} B_{2}\left(d_{x y}\right) \rightarrow{ }^{2} E\left(d_{x z}, d_{y z}\right)$. Uma terceira transição $d-d$, $2 B_{2}(d x y) \rightarrow 2 A_{1}\left(d_{z} 2\right)$, vide Figura 22, é encoberta por intensas bandas de transferência de carga, aparecendo ao redor de $400 \mathrm{~nm}[32,56]$. Estas bandas podem sofrer variações de acordo com o tipo de ligante coordenado ao íon metálico e o solvente utilizado para o registro do espectro [55].

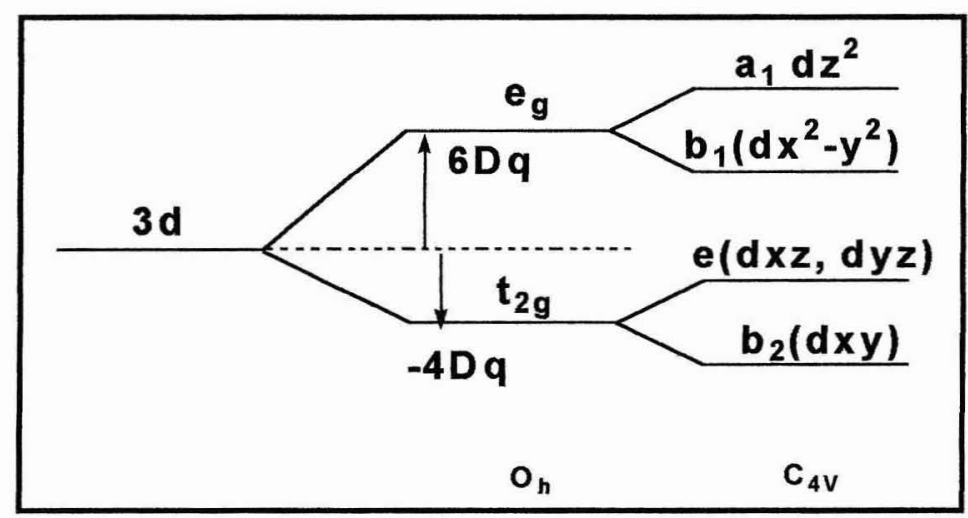

Figura 22. Níveis de energia do campo cristalino de $O_{h}$ e $C_{4 V}$ [56].

Para todos os complexos de vanádio(IV) sintetizados, observaram-se bandas de fraca intensidade na região de $576 \mathrm{~nm}$ e $824 \mathrm{~nm}$ com coeficientes de absortividade molar $(\varepsilon)$ variando entre $10^{1}$ e $10^{2} \mathrm{M}^{-1} \mathrm{~cm}^{-1}$, que são atribuídas a transições do tipo d-d. No complexo [VIV O(salen)] esta banda foi observada em $579 \mathrm{~nm}$, atribuída à transição do tipo d-d, de acordo com a literatura [57] 
No complexo $\left[\mathrm{V}^{\mathrm{IV}} \mathrm{O}(\mathrm{dbhbal})_{2}\right]$ não se observaram bandas de transição do tipo $\mathrm{d}-\mathrm{d}$ tão bem definidas quanto nos outros complexos. Observaram-se apenas dois ombros em $517 \mathrm{~nm}$ e em $640 \mathrm{~nm}$, deslocados para região de maior energia devido ao efeito do solvente, de acordo com a literatura [55].

Os espectros dos complexos $\left.\mathrm{Na}_{2}\left[\mathrm{~V}^{\mathrm{IV}} \mathrm{O} \text { (cetoglut) }\right)_{2}\right]$ e $\left(\mathrm{NH}_{4}\right)_{3}\left[\mathrm{~V}^{\mathrm{IV}} \mathrm{O}_{2}\right.$ (cetoglut) $\left.{ }_{2}\right]$ foram bastante similares, mas a presença de íons amônio acarretou diferenças marcantes nos espectros EPR, como será visto mais tarde. 


\subsection{Espectroscopia na região do Infravermelho}

A espectroscopia no infravermelho corresponde à parte do espectro eletromagnético situada entre as regiões do visível e das microondas. Em geral, utilizase a faixa $4000-400 \mathrm{~cm}^{-1}$ para análises. Como todas as outras formas de espectroscopia, esta também depende da interação de moléculas ou átomos com a radiação eletromagnética, causando aumento da amplitude de vibrações das ligações covalentes entre os átomos e grupos de átomos. A freqüência ou o comprimento de onda de uma absorção depende das massas relativas dos átomos, das constantes de força das ligações e da geometria dos átomos [58]. Esta técnica é simples, rápida e evidencia a presença de vários grupos funcionais nos compostos, através de bandas de absorção características.

Os espectros vibracionais dos compostos sintetizados foram registrados no intervalo de 4000 a $400 \mathrm{~cm}^{-1}$, pelo método de reflectância, a partir da mistura mecânica e moagem de 1-2 mg do composto com $200 \mathrm{mg}$ de $\mathrm{KBr}$ anidro, previamente seco em estufa, à temperatura de $120^{\circ} \mathrm{C}$.

As freqüências das vibrações, características das ligações presentes nos compostos estudados, foram identificadas por comparação com espectros de compostos semelhantes, já descritos na literatura, conforme listado na Tabela 3. Os espectros vibracionais correspondentes estão apresentados nas Figuras 23 a 32. 


\subsubsection{Espectros IV das Iminas sintetizadas}

Nas figuras abaixo são mostrados os espectros na região do infravermelho, tanto das iminas quanto dos complexos de vanádio(IV) obtidos.

\subsubsection{Espectro IV do salen}

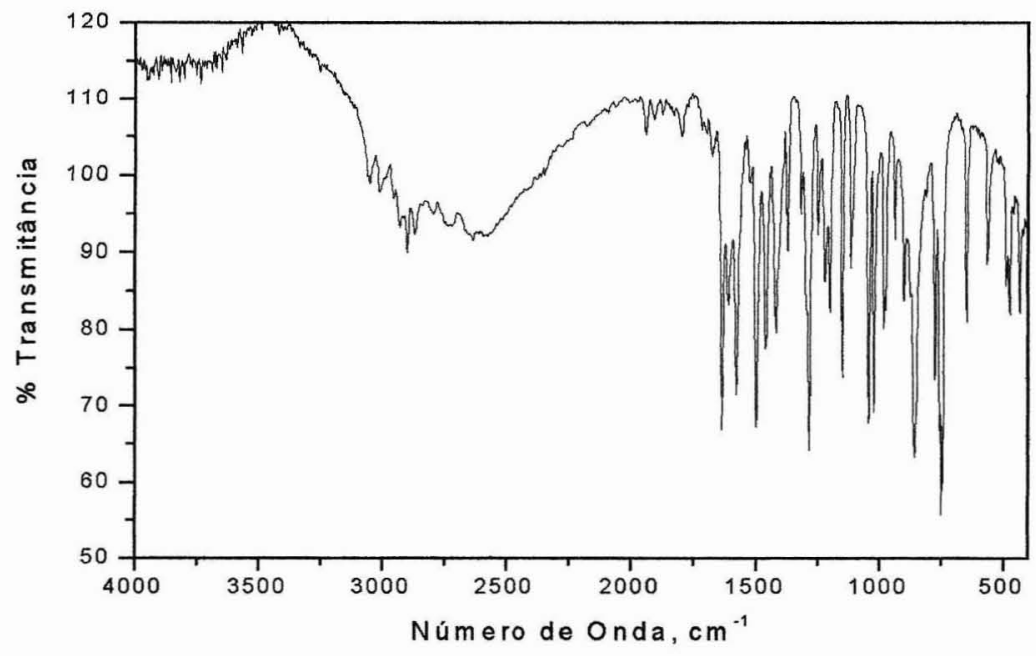

Figura 23. Espectro IV da Imina salen.

\subsubsection{Espectro IV do dbhbal}

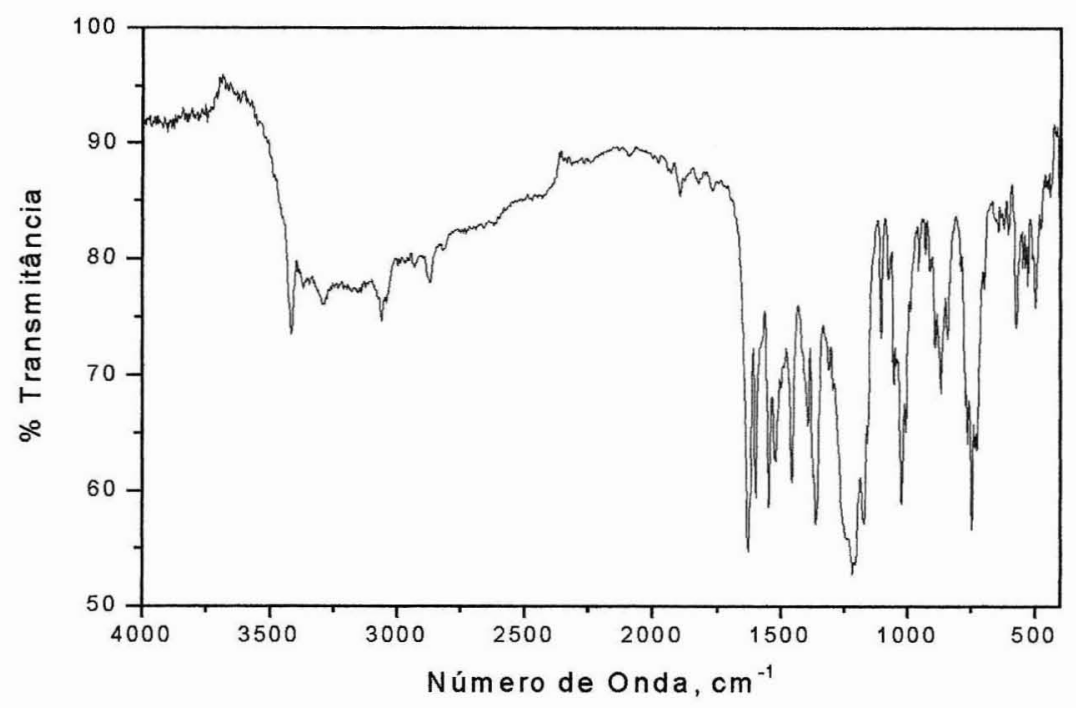

Figura 24. Espectro IV da Imina dbhbal. 


\subsubsection{Espectro IV do dbhab}

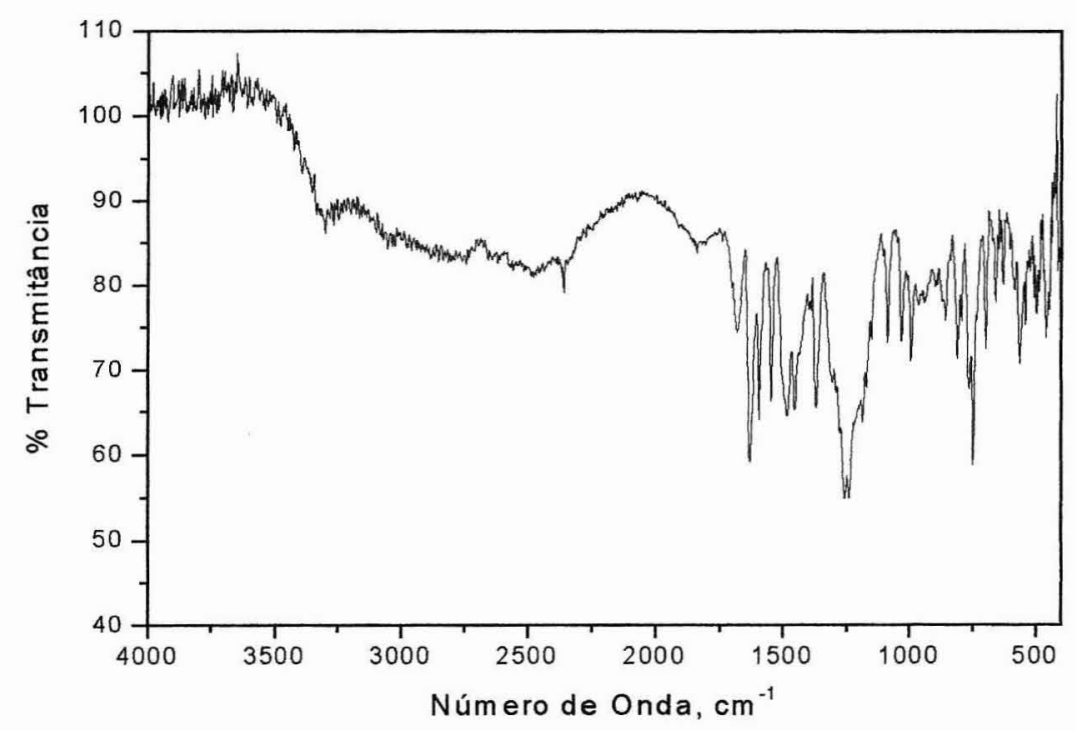

Figura 25. Espectro IV da Imina dbhab.

\subsubsection{Espectros IV dos Complexos de Vanádio}

\subsubsection{Espectro IV do [VO' $\left.(\mathrm{acac})_{2}\right]$}

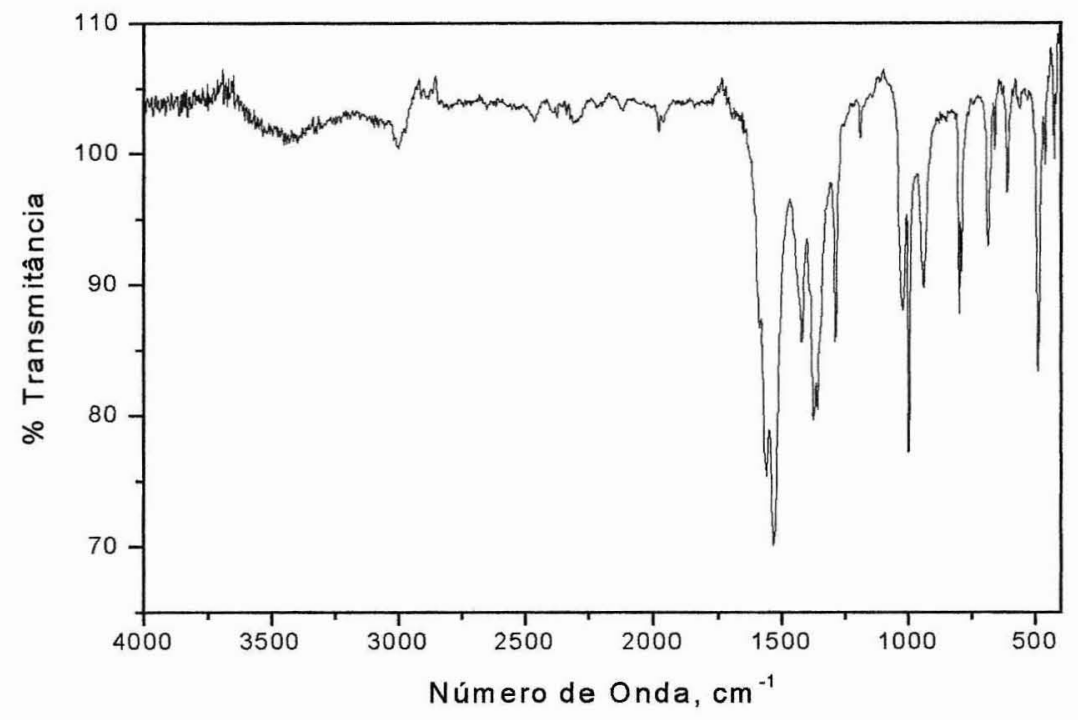

Figura 26. Espectro IV do composto $\left[\mathrm{VO}^{\mathrm{IV}}(\mathrm{acac})_{2}\right]$. 


\subsubsection{Espectro IV do [V $\left.V^{i V} O(s a l e n)\right]$}

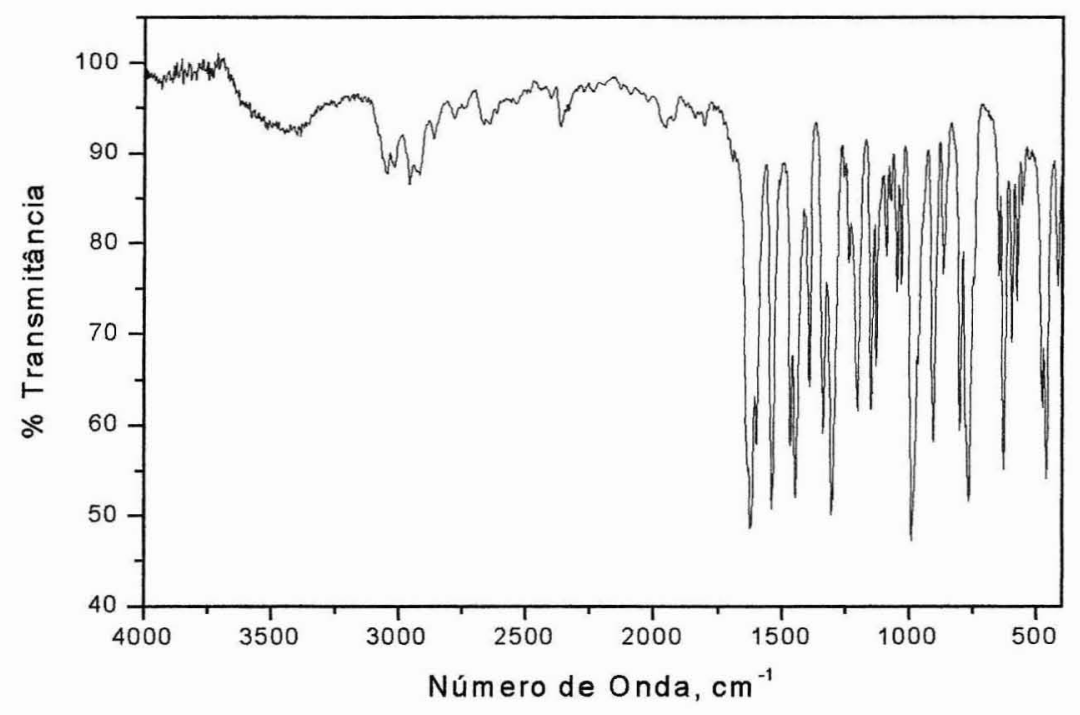

Figura 27. Espectro IV do composto $\left[V^{N} O(\right.$ salen)].

\subsubsection{Espectro IV do Complexo $\left[V^{i V} O(d b h b a l)_{2}\right]$}

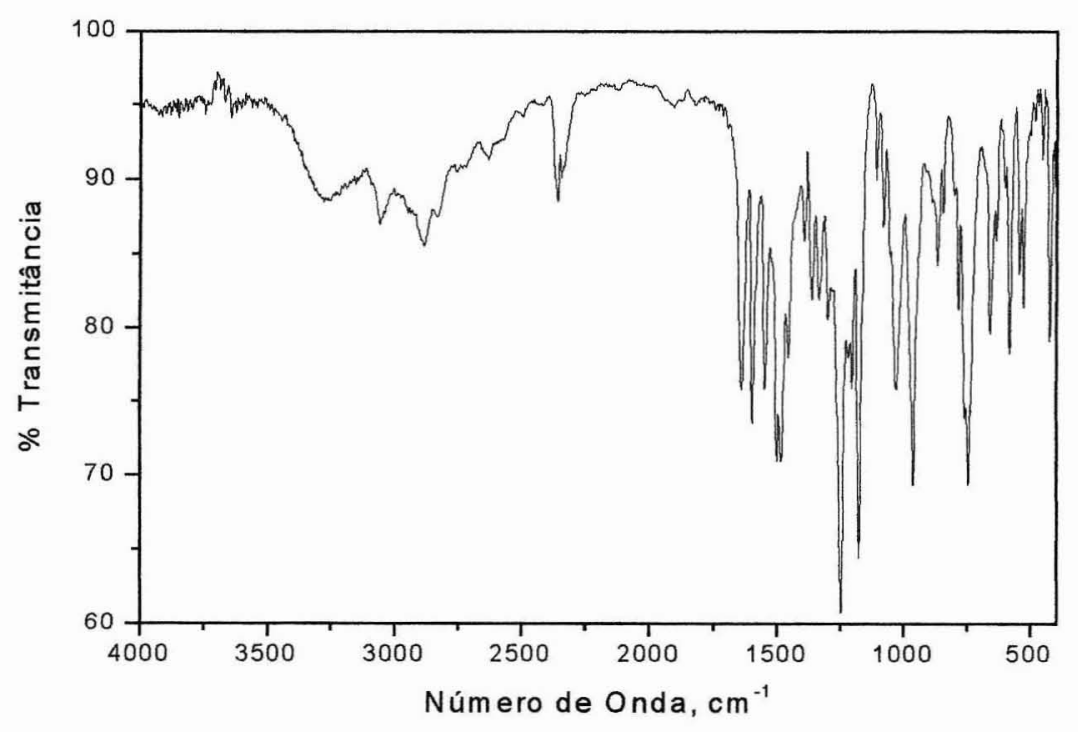

Figura 28. Espectro IV do composto $\left[V^{\mathrm{V} O} \mathrm{O}(\mathrm{dbhbal})_{2}\right]$. 


\subsubsection{Espectro IV do $\left[V^{I V} O(d b h a b)\right]_{2}$}

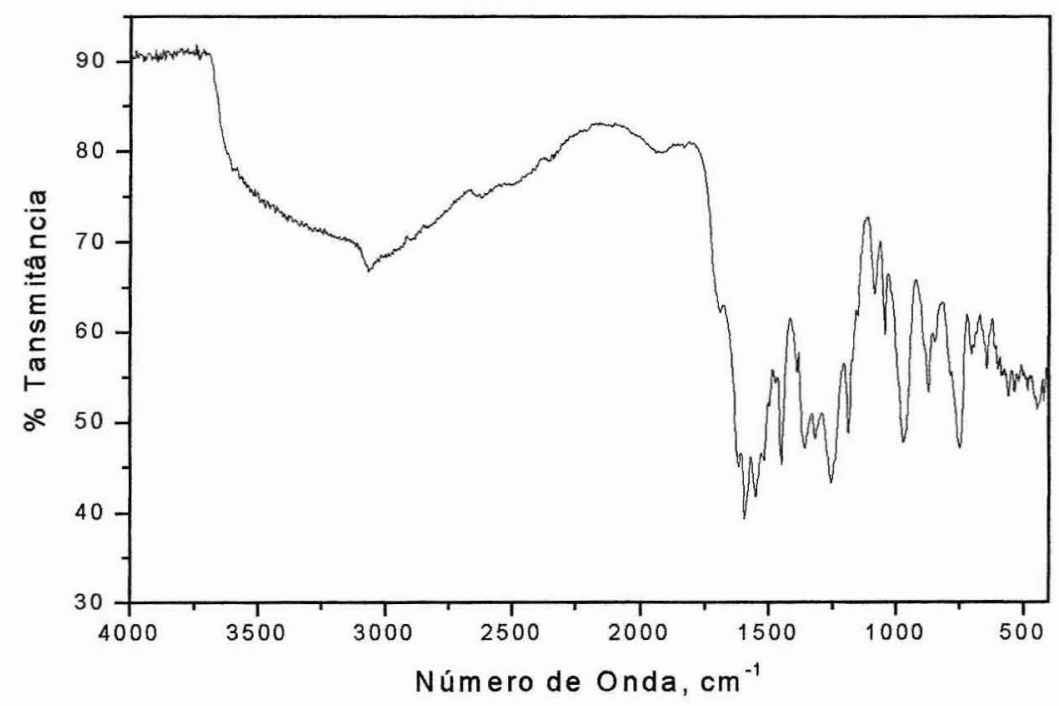

Figura 29. Espectro IV do composto $\left[V^{1 V} O(d b h a b)\right]_{2}$.

\subsubsection{Espectro IV do Complexo $\mathrm{NH}_{4}\left[\mathrm{~V}^{\mathrm{IV}} \mathrm{O}_{2}\right.$ (dbhab)]}

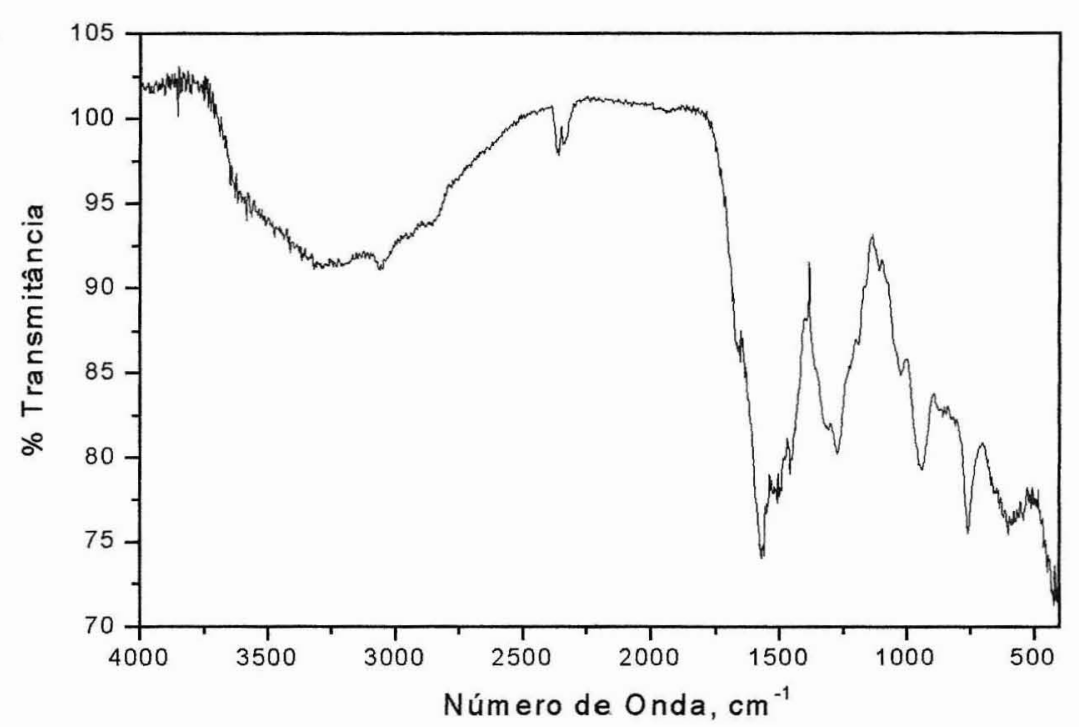

Figura 30. Espectro IV do composto $\mathrm{NH}_{4}\left[\mathrm{~V}^{\mathrm{V}} \mathrm{O}(\mathrm{dbhab})\right]$. 


\subsubsection{Espectro IV do Complexo $\mathrm{Na}_{2}\left[\mathrm{~V}^{\mathrm{IV}} \mathrm{O} \text { (cetoglut) }\right)_{2} \cdot 2 \mathrm{H}_{2} \mathrm{O}$}

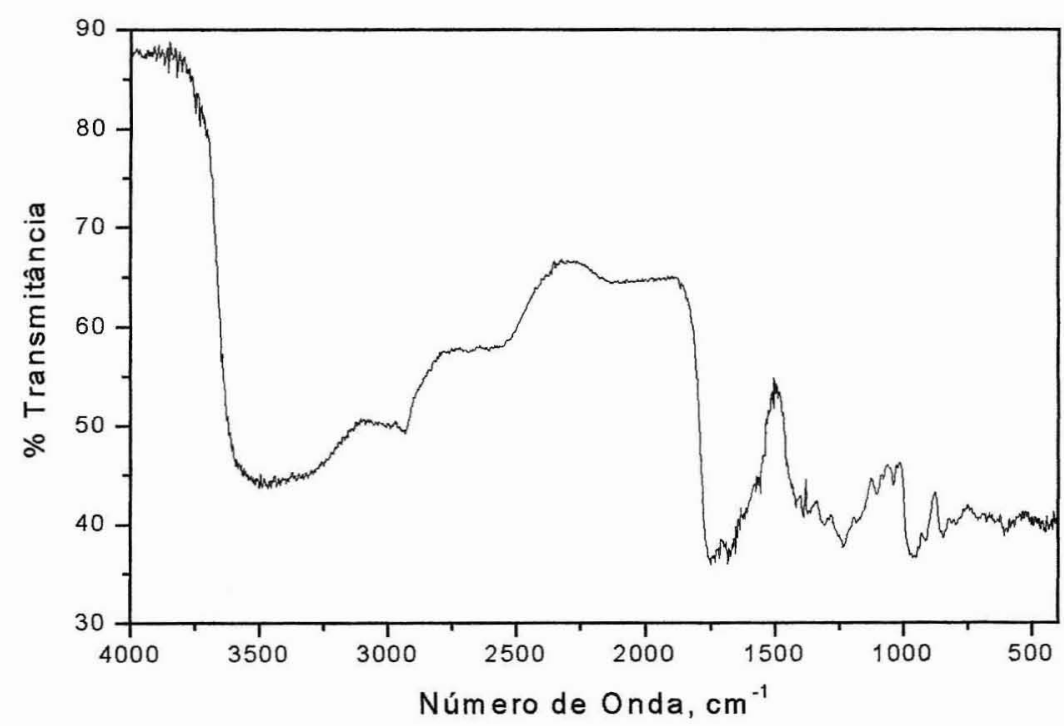

Figura 31. Espectro IV do composto $\mathrm{Na}_{2}\left[\mathrm{~V}^{\mathrm{IV}} \mathrm{O}\right.$ (cetoglut) ${ }_{2} \cdot 2 \mathrm{H}_{2} \mathrm{O}$.

\subsubsection{Espectro IV do Complexo $\left.\left(\mathrm{NH}_{4}\right)_{3}\left[\mathrm{~V}^{\mathrm{IV}} \mathrm{O}_{2} \text { (cetoglut) }\right)_{2}\right]$}

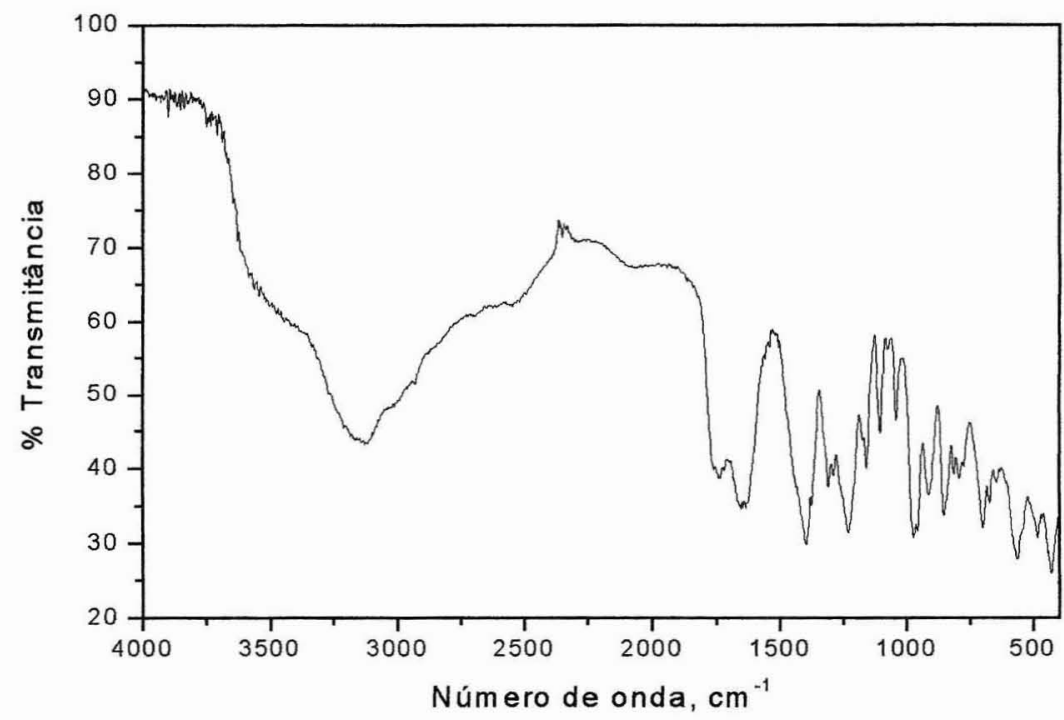

Figura 32. Espectro IV do composto $\left(\mathrm{NH}_{4}\right)_{3}\left(\mathrm{~V}^{\mathrm{IV}} \mathrm{O}_{2} \text { (cetoglut) }\right)_{2}$. 
Tabela 3. Vibrações características das Iminas e dos Complexos de Vanádio(IV) preparados.

\begin{tabular}{|c|c|c|c|c|c|c|c|c|}
\hline Compostos & $v\left(\mathbf{H}_{2} \mathbf{O}\right)$ & $v(\mathrm{~N}-\mathrm{H})$ & $v(\mathrm{C}=\mathrm{N})$ & $v(\mathbf{C}-\mathbf{O})$ & $v(\mathbf{C}=\mathbf{C})$ & $\begin{array}{l}v\left(\mathrm{COO}^{-}\right) \\
\text {simétrica }\end{array}$ & $\begin{array}{c}v\left(\mathrm{COO}^{-}\right) \\
\text {assimétrica }\end{array}$ & $v(V=0)$ \\
\hline salen & -------- & ------- & 1633 & 1578 & 1496 & ------- & ------- & ------ \\
\hline dbhbal & ------ & - & 1621 & 1576 & 1459 & - - & ----- & - \\
\hline dbhab & -------- & ------ & 1629 & 1556 & 1475 & ------ & ----- & ----- \\
\hline$\left[\mathrm{V}^{\mathrm{IV}} \mathrm{O}(\mathrm{acac})_{2}\right]$ & ------- & ------ & ---m- & 1521 & 1413 & --- & ----- & 995 \\
\hline [V ${ }^{\mathrm{IV}} \mathrm{O}($ salen $\left.)\right]$ & --.-- & --- & 1629 & 1537 & 1447 & --..- & ------ & 987 \\
\hline$\left[\mathrm{V}^{\mathrm{IV}} \mathrm{O}(\mathrm{dbhbal})_{2}\right]$ & ----- & ------ & 1597 & 1548 & 1490 & ------ & ------ & 961 \\
\hline$\left[\mathrm{V}^{\mathrm{N}} \mathrm{O}(\mathrm{dbhab})\right]_{2}$ & $\begin{array}{l}3750- \\
3100\end{array}$ & 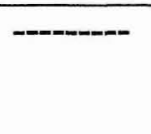 & 1583 & 1463 & 1552 & 1541 & 1448 & 974 \\
\hline $\mathrm{NH}_{4}\left[\mathbf{V}^{\mathrm{IV}} \mathrm{O}_{2}(\mathrm{dbhab})\right]$ & ----- & $\begin{array}{l}3300- \\
3030\end{array}$ & 1567 & 1459 & 1506 & 1567 & ----- & 950 \\
\hline $\mathrm{Na}_{2}\left[\mathrm{~V}^{\mathrm{IV}} \mathrm{O} \text { (cetoglut) }\right)_{2} \cdot 2 \mathrm{H}_{2} \mathrm{O}$ & $\begin{array}{l}3750- \\
3100\end{array}$ & ------ & ---n- & ------- & ----- & 1656 & 1420 & 973 \\
\hline$\left.\left(\mathrm{NH}_{4}\right)_{3}\left[\mathrm{~V}^{\mathrm{IV}} \mathrm{O}_{2} \text { (cetoglut) }\right)_{2}\right]$ & ----- & $\begin{array}{l}3300- \\
3030\end{array}$ & -n-m & ------ & ------- & 1629 & 1400 & 974 \\
\hline
\end{tabular}


A análise dos espectros no IV e a atribuição das respectivas bandas contribuíram para a determinação da presença ou ausência de grupos funcionais existentes nos compostos.

Nos proligantes, ou compostos imínicos livres, observa-se absorções características de ligações de hidrogênio intramolecular, $\mathrm{OH} \longrightarrow \mathrm{N}=\mathrm{C}$, na região de 2554 a $2603 \mathrm{~cm}^{-1}$ [59].

Para todas as iminas observaram-se bandas de intensidade média na faixa de 1500 $1624 \mathrm{~cm}^{-1}$, atribuídas ao estiramento $v(\mathrm{C}=\mathrm{N})$. Essa banda, para os correspondentes complexos de vanádio, apresentaram um pequeno deslocamento para freqüências menores, $\sim 1580 \mathrm{~cm}^{-1}$. Esse deslocamento pode ser atribuído à diminuição na ordem de ligação do grupo carbono-nitrogênio. A diminuição pode também ser atribuída ao fato de o nitrogênio imínico ser muito provavelmente um dos pontos de coordenação ao metal.

Em todos os espectros, tanto das iminas quanto dos complexos de vanádio(IV), as bandas referentes aos estiramentos $\mathrm{C}-\mathrm{H}$, de grupos $\mathrm{CH}, \mathrm{CH}_{2}$, e $\mathrm{CH}_{3}$ alifáticos e $\mathrm{CH}$ aromáticos, foram observadas na região de 2850 a $3070 \mathrm{~cm}^{-1}$. Entre 740 a $1200 \mathrm{~cm}^{-1}$ foram encontradas várias bandas que podem ser atribuídas às deformações angulares ( $\sigma$ ) de ligação $\mathrm{C}-\mathrm{H}$, em cadeias alifáticas, e deformações angulares fora do plano, de $\mathrm{C}-\mathrm{H}$ aromáticas.

Na região em torno de $1520 \mathrm{~cm}^{-1}$ observaram-se bandas características, atribuídas ao estiramento $\mathrm{C}-\mathrm{O}$, presente tanto nas iminas quanto nos complexos.

As vibrações referentes ao cromóforo $\mathrm{C}=\mathrm{C}$ do anel aromático são observadas nas regiões de $1585-1600 \mathrm{~cm}^{-1}$ e $1400-1500 \mathrm{~cm}^{-1}$. Para os compostos obtidos essas vibrações foram observada na região de 1459 a $1475 \mathrm{~cm}^{-1}$, que podem aparecer nos complexos 
deslocadas para freqüências maiores ou menores, com relação ao ligante livre, devido à coordenação do íon metálico.

Em todos os complexos de vanádio observou-se uma absorção de intensidade média na região de 918-996 cm $\mathrm{cm}^{-1}$, característica dos complexos de vanádio [8, 24], correspondente ao estiramento $v(\mathrm{~V}=\mathrm{O})$. $\mathrm{O}$ valor deste estiramento varia em algumas unidades de número de onda, devido ao ambiente químico providenciado pelo grupo funcional coordenado ao íon metálico $[53,60,61]$.

Nos complexos $\left.\left[\mathrm{V}^{\mathrm{IV}} \mathrm{O}(\mathrm{dbhab})\right]_{2}, \quad \mathrm{Na}_{2}\left[\mathrm{~V}^{\mathrm{IV} O} \mathrm{O} \text { (cetoglut) }\right)_{2}\right] \cdot 2 \mathrm{H}_{2} \mathrm{O}$ e $\left(\mathrm{NH}_{4}\right)_{3}\left[\mathrm{~V}^{\mathrm{IV}} \mathrm{O}_{2}\right.$ (cetoglut) $\left.{ }_{2}\right]$ observa-se uma banda do íon carboxilato $\mathrm{COO}^{-}$na região de 1550 a $1650 \mathrm{~cm}^{-1}$ atribuída a estiramento axial assimétrico. Uma outra banda mais fraca é observada em torno de $1400 \mathrm{~cm}^{-1}$, que provém do estiramento axial simétrico [62].

Para os complexos $\left.\mathrm{Na}_{2}\left[\mathrm{~V}^{\mathrm{IV}} \mathrm{O} \text { (cetoglut) }\right)_{2}\right] \cdot 2 \mathrm{H}_{2} \mathrm{O}$ e [VO(dbhab) $]_{2}$ observa-se uma banda larga de estiramento na região de $3100-3600 \mathrm{~cm}^{-1}$ atribuída aos estiramentos da $\mathrm{H}_{2} \mathrm{O}$ presente no complexo para o primeiro caso e, no segundo caso, possivelmente absorvida da umidade do ar.

Nos complexos $\left.\left(\mathrm{NH}_{4}\right)_{3}\left[\mathrm{~V}^{\prime V} \mathrm{O}_{2} \text { (cetoglut) }\right)_{2}\right]$ e $\mathrm{NH}_{4}\left[\mathrm{~V}^{\prime V} \mathrm{O}_{2}(\mathrm{dbab})\right]$, o íon amônio produz uma banda larga e intensa de deformação axial da ligação N-H na região entre 3030 e 3300 $\mathrm{cm}^{-1}$, uma outra banda intensa, também é observada na região de $1429 \mathrm{~cm}^{-1}$ correspondente a deformação angular do íon $\mathrm{NH}_{4}{ }^{+}[58]$.

Entre 738 e $943 \mathrm{~cm}^{-1}$ são encontradas várias bandas que podem ser atribuídas às deformações angulares de $\mathrm{C}-\mathrm{H}$ das ligações alifáticas e deformações angulares fora do plano de grupos funcionais nos hidrocarbonetos. 
As fracas absorções observadas na região de 2200 a $2300 \mathrm{~cm}^{-1}$ são atribuídas ao estiramento do $\mathrm{CO}_{2}$ absorvido no momento de preparação das amostras para análise.

Os espectros IV de todos os compostos isolados corroboraram os resultados obtidos por outras técnicas, reforçando as estruturas a eles atribuídas. 


\subsection{Análise Termogravimétrica (TG)}

A termogravimetria é uma técnica de análise térmica em que a variação de massa da amostra (perda ou ganho) é determinada como função da temperatura e/ou tempo, enquanto a amostra é submetida a uma variação controlada de temperatura. Esta técnica possibilita conhecer, com detalhes, as alterações que o aquecimento pode provocar na massa das substâncias e estabelecer a faixa de temperatura em que essas adquirem composição química definida ou as temperaturas em que os compostos começam a se decompor.

Na TG há um acompanhamento das variações de massas sofridas pela amostra em função da temperatura, quando esta é submetida a um resfriamento ou aquecimento linear. Os experimentos com esta finalidade são executados em uma termobalança, que deve permitir o trabalho sob variadas condições experimentais, faixa ampla de temperaturas e diferentes velocidades de aquecimento.

As curvas geradas possibilitarão obter informações quanto à composição, estabilidade térmica da amostra, compostos intermediários e produtos finais.

A termogravimetria derivada DTG é o registro da curva TG, na qual se deriva a massa em relação ao tempo (dm/dt), em função da temperatura ou do tempo. Desta maneira são obtidas curvas que correspondem à primeira derivada da curva TG e nas quais os degraus observados são substituídos por picos que delimitam áreas proporcionais às alterações de massa sofridas pela amostra.

Como em qualquer técnica instrumental, existe na termogravimetria um grande número de fatores que afetam a natureza, precisão e exatidão dos resultados. 
Dentre estes, pode-se citar o tamanho da amostra, a razão de aquecimento e a natureza do gás que atua sobre a amostra [63].

A análise termogravimétrica foi utilizada neste trabalho, visando obter informações a respeito da estequiometria de alguns dos complexos sintetizados.

As curvas termogravimétricas são apresentadas nas Figuras 33 a 37 e os dados correspondentes são listados na Tabela 4.

\subsubsection{Análises Termogravimétricas das Iminas}

\subsubsection{Análise Termogravimétrica da imina dbhbal}

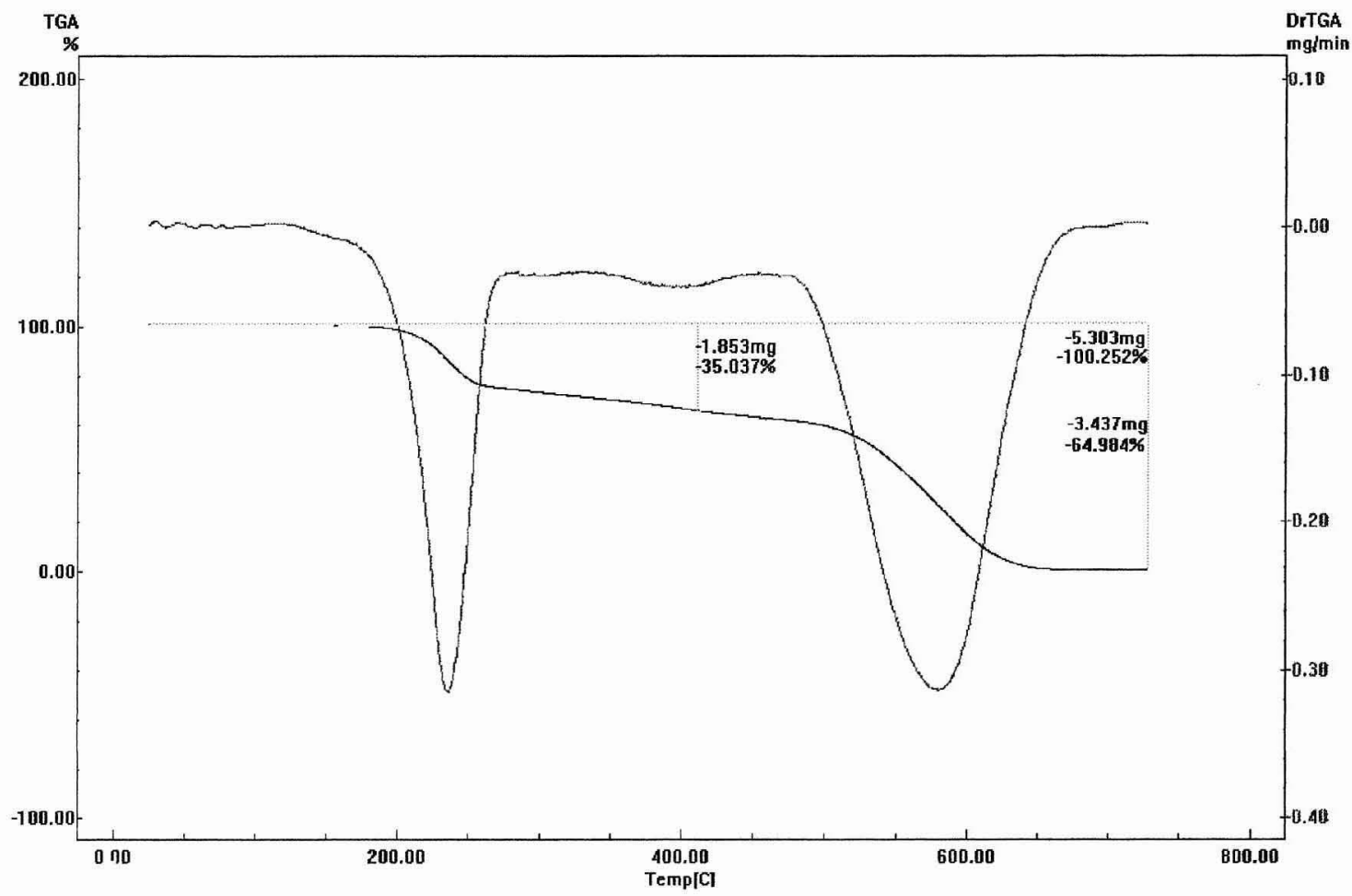

Figura 33. Curva TG e DTG da imina dbhbal, com razão de aquecimento de $10^{\circ} \mathrm{C} \cdot \mathrm{min}^{-1} \mathrm{em}$ atmosfera de ar sintético. 


\subsubsection{Análise Termogravimétrica da imina dbhab}

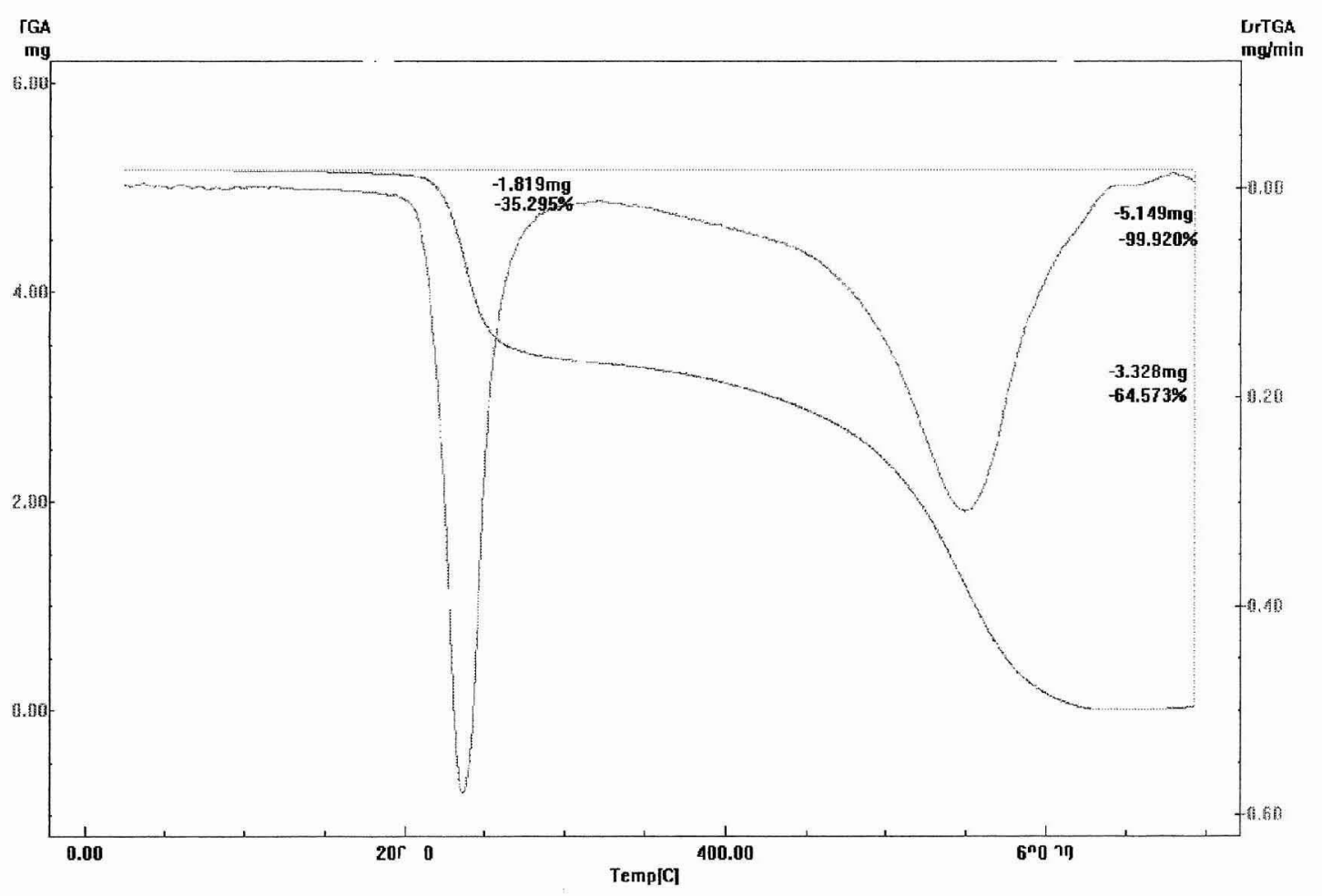

Figura 34. Curva TG e DTG da imina dbhab, com razão de aquecimento de $10^{\circ} \mathrm{C} \cdot \mathrm{min}^{-1} \mathrm{em}$ atmosfera de ar sintético. 


\subsubsection{Análises Termogravimétricas dos Complexos de Vanádio(IV)}

\subsubsection{Análise Termogravimétrica do complexo $\left[\mathrm{V}^{\mathrm{V}} \mathrm{O}(\mathrm{acac})_{2}\right]$}

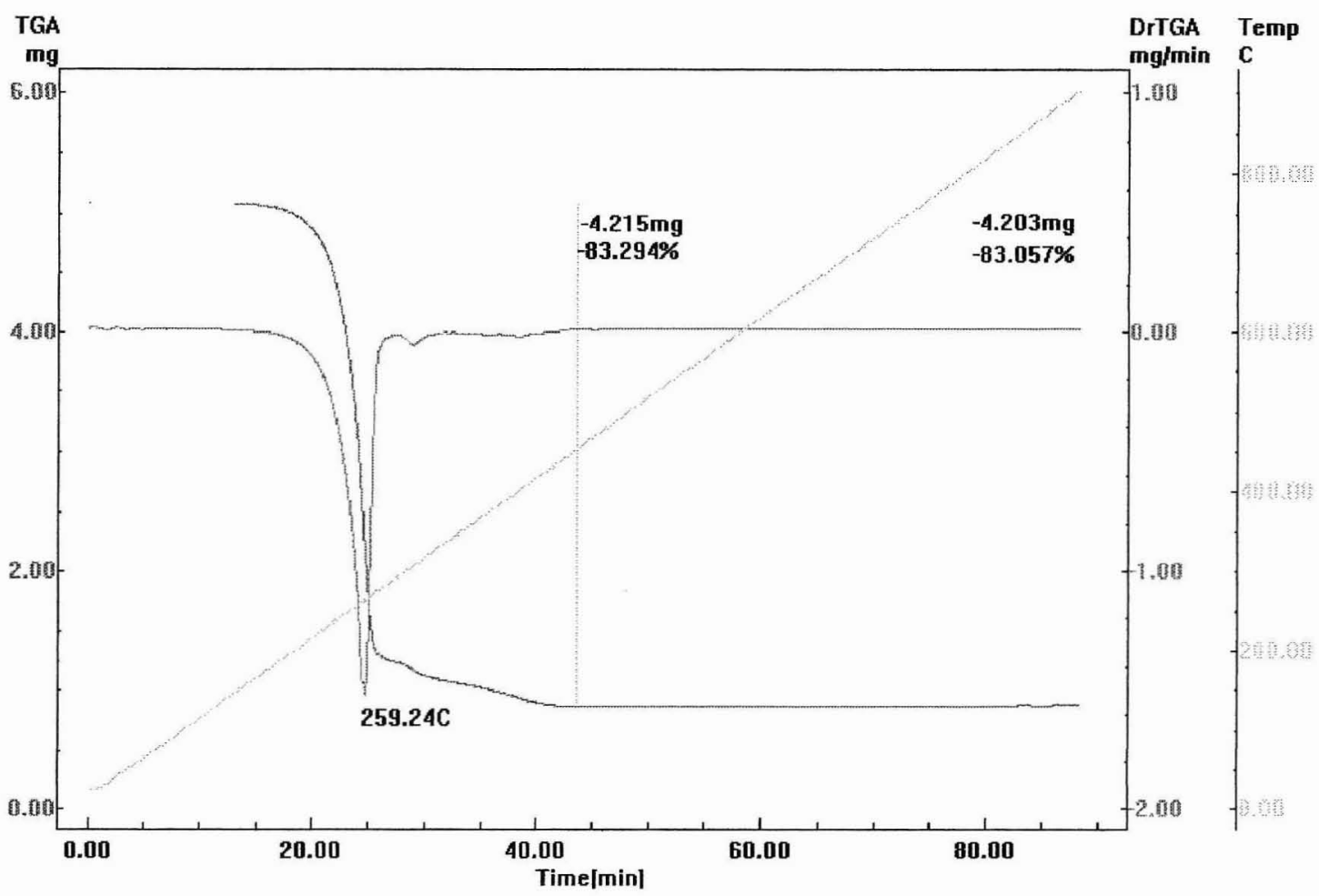

Figura 35. Curva TG e DTG do composto $\left[\mathrm{V}^{\mathrm{V}} \mathrm{O}(\mathrm{acac})_{2}\right]$, com razão de aquecimento de 10 ${ }^{\circ} \mathrm{C} \cdot \mathrm{min}^{-1} \mathrm{em}$ atmosfera de ar sintético. 


\subsubsection{Analise Termogravimétrica do complexo $\left[\mathrm{V}^{\mathrm{IV}} \mathrm{O}(\mathrm{dbhbal})_{2}\right]$}

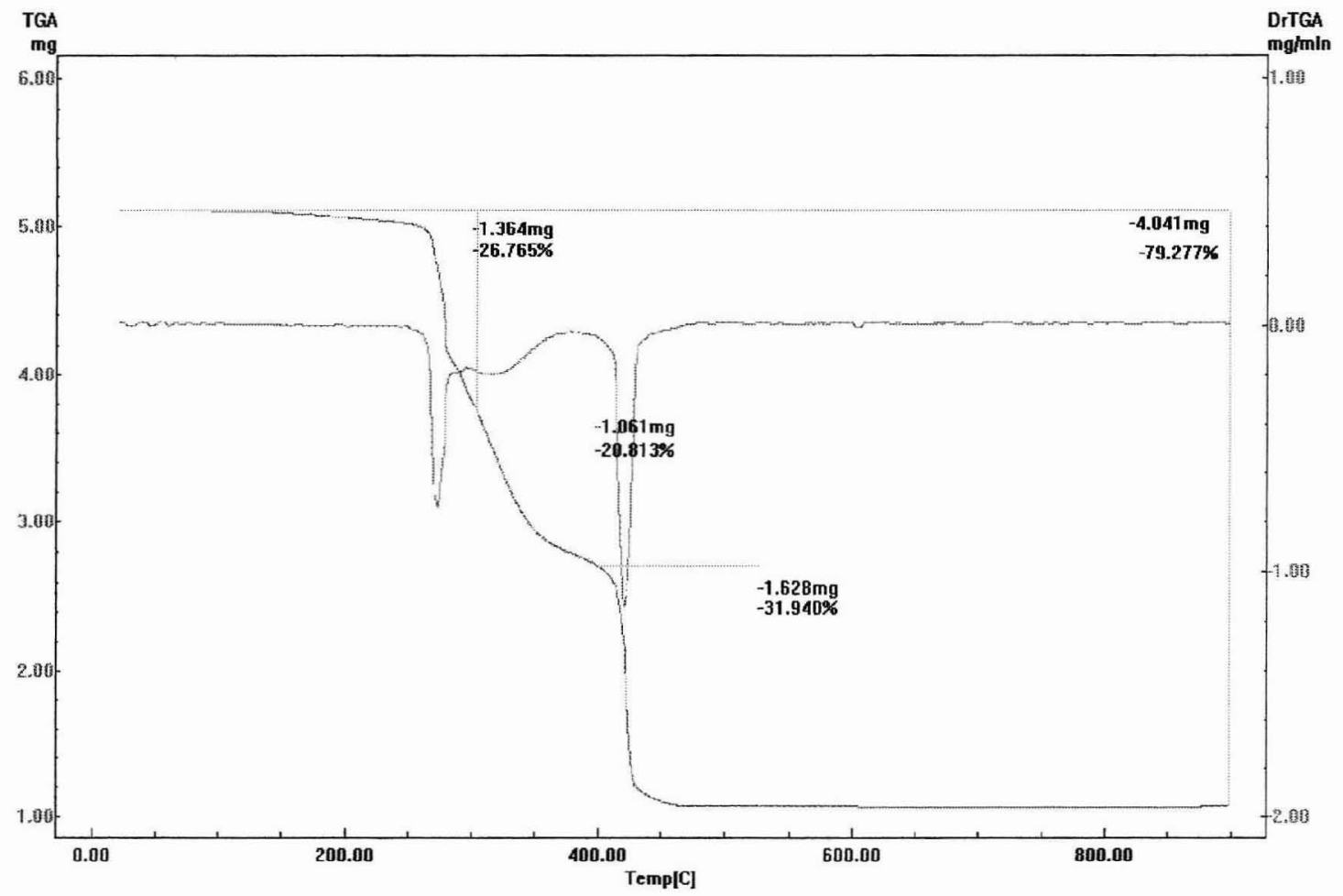

Figura 36. Curva TG e DTG do composto $\left[\mathrm{N}^{\mathrm{N}} \mathrm{O}(\mathrm{dbhbal})_{2}\right.$, com razão de aquecimento de $10^{\circ} \mathrm{C} \cdot \mathrm{min}^{-1} \mathrm{em}$ atmosfera de ar sintético. 


\subsubsection{Análise Termogravimétrica do complexo $\left[\mathrm{V}^{\mathrm{V} O} \mathrm{O}(\mathrm{dbhab})\right]_{2}$}

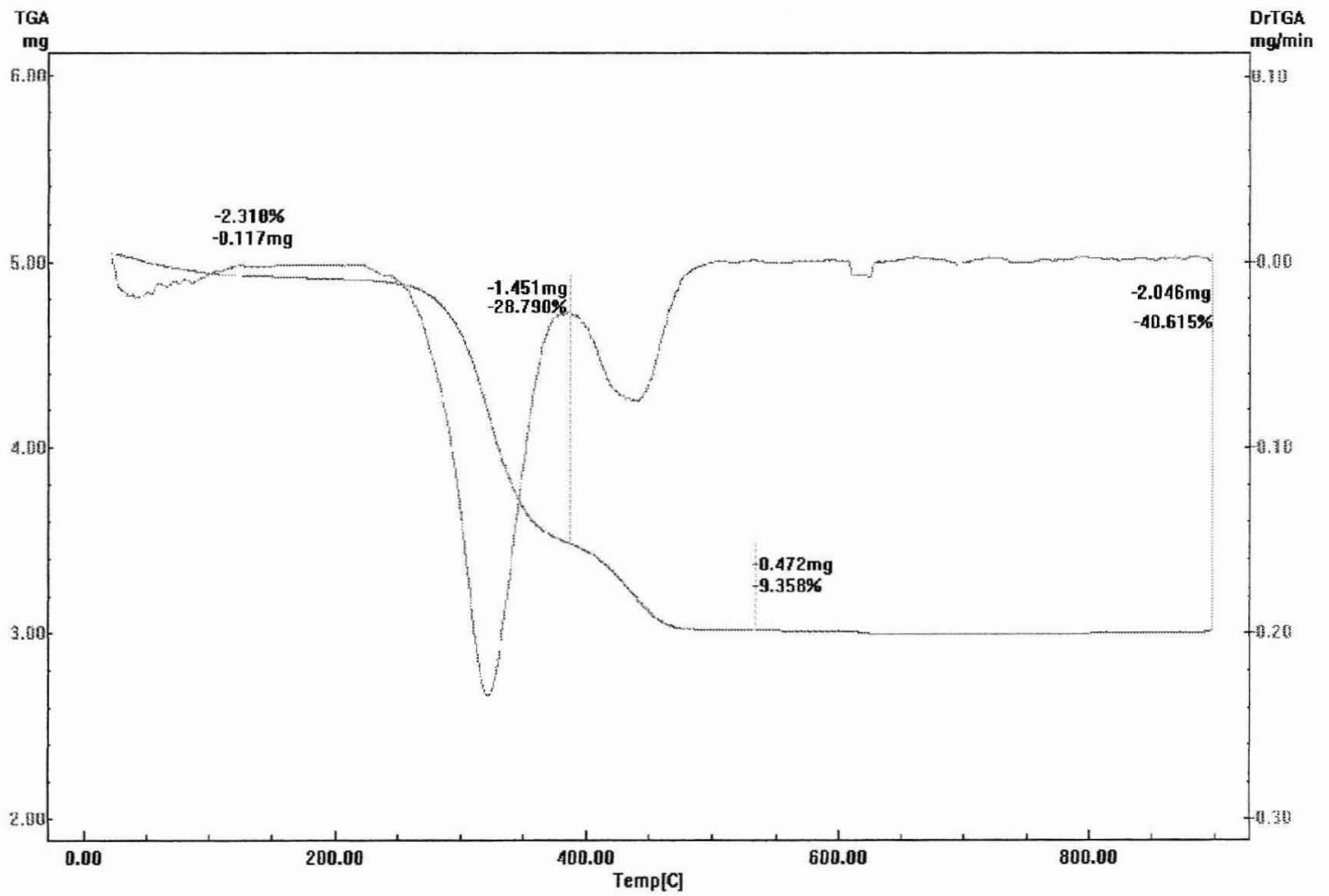

Figura 37. Curva TG e DTG do composto $\left[\mathrm{V}^{\mathrm{N}} \mathrm{O}(\mathrm{dbhab})\right]_{2}$, com razão de aquecimento de 10 ${ }^{\circ} \mathrm{C} \cdot \mathrm{min}^{-1} \mathrm{em}$ atmosfera de ar sintético. 
Tabela 4. Dados das Análises Termogravimétricas das iminas e de alguns dos Complexos de Vanádio(IV).

\begin{tabular}{|c|c|c|c|c|c|}
\hline Compostos & $\begin{array}{c}\text { Faixa de } \\
\text { temperatura em }{ }^{\circ} \mathrm{C} \\
( \pm 0,1)\end{array}$ & $\begin{array}{c}\% \text { Perda de massa } \\
\text { calculada }\end{array}$ & $\begin{array}{l}\text { \%Perda de } \\
\text { massa } \\
\text { experimental }\end{array}$ & $\begin{array}{l}\text { Provável grupo } \\
\text { eliminado }\end{array}$ & Resíduo provável \\
\hline dbhab & 236 a 550 & 100 & $\begin{array}{l}38,82 \\
51,49\end{array}$ & $\begin{array}{c}\mathrm{C}_{14} \mathrm{H}_{11} \mathrm{NO}_{4} \\
\left(\mathrm{CO}_{2}+\mathrm{H}_{2} \mathrm{O}+\mathrm{NO}_{2}\right) \\
\end{array}$ & -------- \\
\hline dbhbal & 238 a 580 & 100 & $\begin{array}{l}29,89 \\
70.32\end{array}$ & $\begin{array}{c}\mathrm{C}_{14} \mathrm{H}_{13} \mathrm{NO}_{3} \\
\left(\mathrm{CO}_{2}+\mathrm{H}_{2} \mathrm{O}+\mathrm{NO}_{2}\right)\end{array}$ & - \\
\hline [VO(acac)2] & 259 & 82,31 & 83,29 & $2\left(\mathrm{C}_{5} \mathrm{H}_{7} \mathrm{O}_{2}\right)+\mathrm{H}_{2} \mathrm{O}$ & $1 / 2 \mathrm{VO}_{2}$ \\
\hline [VO(dbhbal) $)_{2}$ & $\begin{array}{l}271 \text { a } 315 \\
421 \text { a } 900\end{array}$ & $\begin{array}{l}44,11 \\
56,07\end{array}$ & $\begin{array}{l}48,80 \\
54,20\end{array}$ & $\mathrm{C}_{14} \mathrm{H}_{13} \mathrm{NO}_{3}$ & $\begin{array}{c}\text { Mistura de } \\
\text { óxidos } \\
\mathrm{VO}_{2}+1 / 2 \mathrm{VO}\end{array}$ \\
\hline$[\mathrm{VO}(\mathrm{dbhab})]_{2}$ & $\begin{array}{c}42 \\
321 \text { a } 340\end{array}$ & $\begin{array}{c}2,71 \\
39,85\end{array}$ & $\begin{array}{c}2,37 \\
37,96\end{array}$ & $\begin{array}{c}\mathrm{H}_{2} \mathrm{O} \\
\mathrm{C}_{14} \mathrm{H}_{11} \mathrm{NO}_{4}\end{array}$ & $\begin{array}{l}\text { Mistura de } \\
\text { óxidos } \\
3 \mathrm{VO}_{2}+2 \mathrm{VO}\end{array}$ \\
\hline
\end{tabular}


Analisando os dados termogravimétricos das iminas, observa-se que elas sofrem um processo de decomposição em duas etapas e se decompõem completamente formando como possíveis produtos $\mathrm{NO}_{2}, \mathrm{CO}_{2}$ e $\mathrm{H}_{2} \mathrm{O}$. A primeira perda de massa acontece a uma temperatura em tomo de 237 e a segunda de $565^{\circ} \mathrm{C}$.

De acordo com os dados das análises, pode-se observar que os complexos analisados são estáveis até a temperatura de $321^{\circ} \mathrm{C}$, para o $\left[\mathrm{V}^{\mathrm{IV}} \mathrm{O}(\mathrm{dbhab})\right]_{2}, 271^{\circ} \mathrm{C}$ para o $\left[\mathrm{V}^{\mathrm{V} \mathrm{O}} \mathrm{O}(\mathrm{dbhbal})_{2}\right]$ e $259^{\circ} \mathrm{C}$ para o $\left[\mathrm{V}^{\mathrm{IV}} \mathrm{O}(\mathrm{acac})_{2}\right]$.

O complexo [ $\mathrm{VO}(\mathrm{acac})_{2}$ ] apresenta uma única perda de massa de 220,85 g.mol ${ }^{-1}$ correspondente à porcentagem de $83,29 \%$, atribuída à perda dos dois ligantes acetilacetona e uma molécula de $\mathrm{H}_{2} \mathrm{O}$, possivelmente absorvida da umidade do ar. De acordo com os dados calculados, isto corresponderia a uma perda de $218,25 \mathrm{~g} \cdot \mathrm{mol}^{-1}$ ou uma porcentagem do complexo de $82,31 \%$, que estão bem próximos dos valores experimentais verificados. O resíduo apresentou uma massa de 44,31 g.mol ${ }^{-1}$ correspondente à porcentagem de $19,71 \%$ que é atribuída ao resíduo $1 / 2 \mathrm{VO}_{2}$, de coloração azul violáceo. Estes valores estão razoavelmente de acordo com os dados experimentais de $41,47 \mathrm{~g} \cdot \mathrm{mol}^{-1}$, correspondente a $15,64 \%$.

No complexo $\left[\mathrm{V}^{\mathrm{V}} \mathrm{O}(\mathrm{dbhbal})_{2}\right]$, o ligante imínico é perdido em duas etapas, porém com temperaturas um pouco inferiores a do complexo $[\mathrm{VO}(\mathrm{dbhab})]_{2}$ como mostrado à seguir, haja vista que são ligantes semelhantes, porém possuem massa molar e grupos funcionais distintos. As primeiras perdas de massa ocorrem nas temperaturas de $271^{\circ} \mathrm{C}$ e $315^{\circ} \mathrm{C}$, correspondente à massa de 133,64 e 118,94 g.mol ${ }^{-1}$ respectivamente. Somando essas perdas de massa obtém-se uma massa 
total de 252,58 g. mol ${ }^{-1}$ equivalente a $45,80 \%$. A soma dessas duas perdas de massa é atribuída à perda de um ligante imínico, de acordo com os cálculos teóricos, quando se obtém uma massa teórica de $243,26 \mathrm{~g} \cdot \mathrm{mol}^{-1}$ que corresponde a $44,80 \%$ do complexo, bem próximo do valor obtido experimentalmente [64]. Ainda foi observada uma terceira perda de massa de $184,71{\mathrm{~g} \cdot \mathrm{mol}^{-1}}^{\mathrm{na}}$ temperatura de $421^{\circ} \mathrm{C}$, que corresponde a $33,49 \%$ do complexo, ficando um resíduo de $114,16 \mathrm{~g} \cdot \mathrm{mol}^{-1}$ equivalente a uma porcentagem de $20,70 \%$.

O resíduo é atribuído possivelmente a uma mistura de óxidos de vanádio com a composição de $\mathrm{VO}_{2}$ e $1 / 2$ de $\mathrm{VO}$, de acordo com a massa teórica que é de 116,41 g. mol ${ }^{-1}$ (soma da massa de $\mathrm{VO}_{2}$ e $1 / 2$ de VO), correspondente à porcentagem de $21,10 \%$. Comparado estes valores com os valores experimentais que são de $114,15 \mathrm{~g} \cdot \mathrm{mol}^{-1}$ e porcentagem de $20,70 \%$, pode-se observar que estes valores estão bem próximos, ver cálculos abaixo:

Massa molar do complexo $\left[\mathrm{V}^{\mathrm{V}} \mathrm{O}(\mathrm{dbhbal})_{2}\right]=551,45 \mathrm{~g} \cdot \mathrm{mol}^{-1}$

Cálculo teórico Massa molar do resíduo da análise $=114,15 \mathrm{~g} \cdot \mathrm{mol}^{-1}$, que é equivalente a $20,70 \%$ do complexo

Cálculo teórico da massa do resíduo obtido

$$
\begin{gathered}
551,45{\mathrm{~g} . \mathrm{mol}^{-1}}^{-1} 100 \% \\
\times \quad-20,70 \% \\
X=114,15 \mathrm{~g} \cdot \mathrm{mol}^{-1}
\end{gathered}
$$

Cálculo teórico da porcentagem de $\mathrm{VO}_{2}+1 / 2 \mathrm{VO}$, mistura de óxidos de vanádio, como possível resíduo.

Massa molar do $\mathrm{VO}_{2}=82,94 \mathrm{~g} \cdot \mathrm{mol}^{-1}$

Massa molar do $1 / 2 \mathrm{VO}=33,47 \mathrm{~g} \cdot \mathrm{mol}^{-1}$

Massa molar do $\mathrm{VO}_{2}+1 / 2 \mathrm{VO}=116,41 \mathrm{~g} \cdot \mathrm{mol}^{-1}$ 


$$
\begin{gathered}
551,45 \mathrm{~g} \cdot \mathrm{mol}^{-1} \ldots-100 \% \\
116,41 \mathrm{~g} \cdot \mathrm{mol}^{-1} \ldots \\
X=21,10 \%
\end{gathered}
$$

Para o complexo $[\mathrm{VO}(\mathrm{dbhab})]_{2}$ observa-se uma perda de massa à temperatura

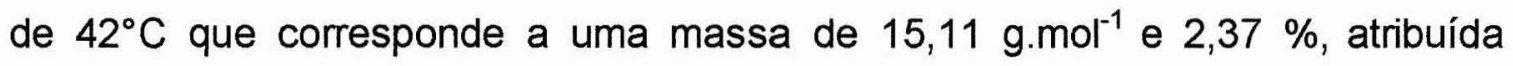
possivelmente à saída de $\mathrm{H}_{2} \mathrm{O}$ proveniente da umidade da amostra, que está de acordo com o valor teórico de $18,01 \mathrm{~g} \cdot \mathrm{mol}^{-1}$ correspondente a $2,71 \%$. O ligante imínico tem também sua perda de massa em duas etapas [64], na temperatura de 321 e $440^{\circ} \mathrm{C}$, correspondente às massas de 182,25 e 60.24 g.mol ${ }^{-1}$ e às porcentagens de 28,64 e $9,31 \%$. Somando estas duas perdas massas obtém-se um valor de 242,49 g.mol ${ }^{-1}$ correspondente a $37,51 \%$. Os valores calculados, supondo a perda de um ligante imínico, estão bem próximos dos experimentais que são de $239,23 \mathrm{~g} \cdot \mathrm{mol}^{-1}$ e porcentagem do complexo de $37,01 \%$. Uma terceira perda de massa é observada à temperatura de $440^{\circ} \mathrm{C}$ com uma massa de 60,24 g. mol $^{-1}$ que corresponde a uma porcentagem de $9,31 \%$, e um resíduo de 385,61 g. $\mathrm{mol}^{-1}$.

Como no composto acima, possivelmente o resíduo formado também é atribuído a uma mistura de óxidos de vanádio, com uma composição de $3 \mathrm{VO}_{2} \mathrm{e}$ $2 \mathrm{VO}$, com massa teórica de 382,70 g. $\mathrm{mol}^{-1}$ e uma porcentagem de $59,20 \%$ (ver cálculo abaixo), que estão razoavelmente de acordo com os valores experimentais obtidos, que são de 385,61 g.mol ${ }^{-1}$ ou $59,66 \%$ (ver cálculos abaixo): 
Massa molar do complexo $\left[\mathrm{V}^{\mathrm{IV}} \mathrm{O}(\mathrm{dbhab})\right]_{2}=646,35 \mathrm{~g} \cdot \mathrm{mol}^{-1}$

Cálculo teórico Massa molar do resíduo da análise $=385,61 \mathrm{~g} \cdot \mathrm{mol}^{-1}$ que é equivalente a $59,66 \%$.

Cálculo teórico da massa do resíduo obtido

$$
\begin{array}{r}
646,35 \mathrm{~g} \cdot \mathrm{mol}^{-1} \\
X \quad 100 \% \\
X=385,61 \mathrm{~g} \cdot \mathrm{mol}^{-1}
\end{array}
$$

Cálculo teórico da porcentagem de $3 \mathrm{VO}_{2}+2 \mathrm{VO}$

$$
\begin{aligned}
& \text { Massa molar do } 3 \mathrm{VO}_{2}=248,82 \mathrm{~g} \cdot \mathrm{mol}^{-1} \\
& \text { Massa molar do } 2 \mathrm{VO}=133,88 \mathrm{~g} \cdot \mathrm{mol}^{-1} \\
& \text { Massa molar do } 3 \mathrm{VO}_{2}+2 \mathrm{VO}=382,70 \mathrm{~g} \cdot \mathrm{mol}^{-1} \\
& \qquad \begin{array}{c}
646,35 \mathrm{~g} \cdot \mathrm{mol}^{-1} \ldots \\
382,70 \mathrm{~g} \cdot \mathrm{mol}^{-1} \ldots
\end{array} \\
& X=59,20 \%
\end{aligned}
$$

Os resíduos não foram caracterizados, porém os aspectos físicos como cor e forma eram iguais, coerentes com os possíveis compostos atribuídos. Apresentavam cor azul violáceo e forma de agulhas, similarmente aos óxidos $\mathrm{VO}_{2}$ e VO.

As curvas das Análises Termogravimétrica dos compostos [VO(dbhbal) $)_{2}$ e [VO(dbhab) $]_{2}$ foram proveitosas para confirmar a estrutura proposta para os complexos. No primeiro, confirmou-se a razão estequiométrica metal: ligante de 1:2 e, no segundo, confirmou-se à estrutura dimérica proposta em conjunto com as outras técnicas. 


\subsection{Condutividade Molar}

As medidas de condutividade molar são geralmente utilizadas na determinação da quantidade e/ou proporção de espécies iônicas, presentes em solução. São medidas importantes para comprovar ou complementar dados obtidos por outras técnicas, na tentativa de melhor caracterizar o composto obtido numa síntese.

Medida de Condutividade: Para medir a condutividade de uma solução, ela é colocada numa célula que dispõe de um par de eletrodos de platina firmemente fixadas numa dada posição. Em geral, é muito difícil medir com precisão a área dos eletrodos e o afastamento entre eles, de modo que quando se desejam valores exatos da condutividade, é necessário determinar a constante da célula mediante a calibração com uma solução cuja condutividade seja conhecida com exatidão; por exemplo, soluções de cloreto de potássio.

As medições se fazem pela ligação da célula a um medidor de condutividade que fornece à célula uma corrente alternada, com a freqüência da ordem de $100 \mathrm{~Hz}$. Com a corrente alternada, fica reduzida a possibilidade de eletrólise, o que provocaria a polarização dos eletrodos. A corrente alternada, porém, introduz a complicação de a célula ter uma capacitância além da resistência. Os condutivímetros modernos têm um circuito eletrônico apropriado que elimina os efeitos da capacitância e podem medir um intervalo amplo de condutividade (p. ex., de $0,001 \Omega \mu \mathrm{cm}^{-1}$ a $1300 \mathrm{~m}^{-1} \mathrm{~cm}^{-1}$ ), com dispositivo de escolha automática do intervalo de medida. Mediante a operação de um dispositivo de calibração, o instrumento é ajustado, de modo que o valor da constante da célula usada aparece no painel digital que registra o valor da condutividade. Ao medidor também fica acoplado um sensor de temperatura; este sensor corrige, automaticamente, as medições de condutividade, efetuadas num certo intervalo de temperatura, ao valor de $25^{\circ} \mathrm{C}$, que é a temperatura de calibração do aparelho. A célula 
de condutividade limpa é lavada com a própria solução e depois cheia com a solução; o resultado da medida é imediatamente registrado no painel [65].

Utilizou-se a solução de cloreto de potássio $10,0 \times 10^{-3} \mathrm{~mol}^{-\mathrm{L}^{-1}}$ como solução padrão de referência; esta apresentou uma condutância específica de $1412,0 \mu \mathrm{S} / \mathrm{cm}$, a $25^{\circ} \mathrm{C}$. Logo, a constante da célula determinada era igual a $1,32 \mathrm{~cm}^{-1}$.

As medidas foram realizadas a $25^{\circ} \mathrm{C}$, com soluções de concentração da ordem de $10^{-3} \mathrm{em}$ etanol ou DMSO. Os resultados obtidos para todos complexos de vanádio(IV) sintetizados estão listados na Tabela 5 abaixo:

Tabela 5. Valores de Condutividade Molar obtidos para os Complexos de Vanádio(IV), a $25^{\circ} \mathrm{C}$.

\begin{tabular}{|c|c|c|}
\hline Compostos & $\begin{array}{c}\Lambda\left(\text { S. } \mathbf{c m}^{2} \cdot \text { mol }^{-1}\right) \\
\text { (Obtido) }\end{array}$ & $\begin{array}{c}\Lambda\left(\text { S. } \mathbf{~ c m}^{2} \cdot \text { mol }^{-1} \text { ) }\right. \\
\text { (referência [66]) }\end{array}$ \\
\hline$\left[\mathrm{V}^{\mathrm{IV}} \mathrm{O}(\mathrm{acac})_{2}\right]$ & & \\
\hline *Solvente: Etanol & 0,80 & \\
\hline [V O(salen)] & & \\
\hline *Solvente: Etanol & 0,94 & -------- \\
\hline [V $\left.\mathrm{V}^{\mathrm{IV}} \mathrm{O}(\mathrm{dbhbal})_{2}\right]$ & & \\
\hline *Solvente: DMSO & 5,51 & --------- \\
\hline$\left[\mathrm{V}^{\mathrm{IV}} \mathrm{O}(\mathrm{dbhab})\right]_{2}$ & & \\
\hline *Solvente: DMSO & 6,41 & -- \\
\hline $\mathrm{NH}_{4}\left[\mathrm{~V}^{\mathrm{N}} \mathrm{O}_{2}\right.$ (dbhab)] & & \\
\hline *Solvente: Etanol & 86,1 & $60-115(1: 1)$ \\
\hline $\left.\mathrm{Na}_{2}\left[\mathrm{~V}^{\mathrm{N}} \mathrm{O} \text { (cetoglut) }\right)_{2}\right] \cdot 2 \mathrm{H}_{2} \mathrm{O}$ & & \\
\hline *Solvente: Etanol/Água & 104,2 & $115-250(2: 1)$ \\
\hline$\left.\left(\mathrm{NH}_{4}\right)_{3}\left[\mathrm{~V}^{\mathrm{IV}} \mathrm{O}_{2} \text { (cetoglut) }\right)_{2}\right]$ & & \\
\hline *Solvente: Etanol/Água & 208,1 & $180-300(3: 1)$ \\
\hline
\end{tabular}

* Solvente utilizado para solubilizar os Complexos de Vanádio(IV) sintetizados.

A partir da análise dos dados da Tabela 5, observa-se que os complexos

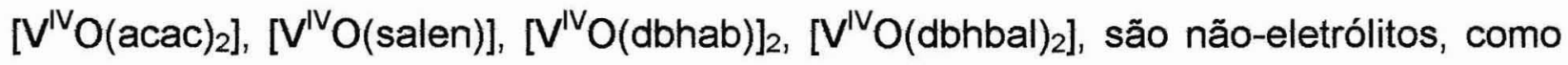
esperado. Os resultados estão de acordo com a estrutura proposta a partir dos dados 
de análise elementar, dados espectroscópicos e com dados da literatura [67] para compostos semelhantes.

Os complexos $\left.\left.\left(\mathrm{NH}_{4}\right)_{3}\left[\mathrm{~V}^{\mathrm{IV}} \mathrm{O} \text { (cetoglut) }\right)_{2}\right], \mathrm{Na}_{2}\left[\mathrm{~V}^{\mathrm{IV}} \mathrm{O} \text { (cetoglut) }\right)_{2}\right]$ e $\mathrm{NH}_{4}\left[\mathrm{~V}^{\mathrm{IV}} \mathrm{O}_{2}(\mathrm{dbhab})\right]$ apresentam medida de condutividade molar de 208,1, 104,2 e 86,1 S. $\mathrm{cm}^{2} . \mathrm{mol}^{-1}$, respectivamente. A partir destes valores e dados da literatura $[23,68]$, pode-se inferir que esses complexos são provavelmente eletrólitos do tipo 3:1, 2:1 e 1:1.

\subsection{Espectroscopia de Ressonância Paramagnética Eletrônica (EPR)}

A ressonância eletrônica do spin (ESR), ou ressonância paramagnética eletrônica (EPR), permite a investigação de moléculas ou íons com elétrons não-emparelhados, feita pela observação dos campos magnéticos que propiciam a ressonância, na presença de radiação eletromagnética monocromática. Os campos magnéticos usados são da ordem de $3 \times 10^{3} \mathrm{G}(0,3 \mathrm{~T})$ e correspondem a ressonâncias com campos eletromagnéticos de freqüência de $10 \mathrm{GHz}\left(10^{10} \mathrm{~Hz}\right)$ e comprimento de onda de $3 \mathrm{~cm}$. Como esta radiação de $3 \mathrm{~cm}$ está na banda $X$ da região de microondas, a espectroscopia EPR é uma técnica de microondas. O espectro de EPR é obtido pelo registro da absorção das microondas em função do campo aplicado. A amostra deve ter elétrons com spins não-emparelhados para ser ativa no EPR. A espectroscopia de EPR é adequada para investigar os radicais livres formados durante reações químicas ou por efeito de radiação, para estudar muitos complexos dos metais de transição d e de moléculas nos estados de tripleto. A técnica é insensível a moléculas normais, com spins emparelhados [69].

No caso dos metais de transição, a interpretação dos valores do parâmetro constante giromagnética $(\mathrm{g})$, das constantes de interação hiperfina $(\mathrm{A})$, das constantes hiperfinas isotrópicas e da anisotropia espectral, permitem obter informações valiosas 
Tabela 6. Principais núcleos ativos no EPR com seus respectivos desdobramentos.

\begin{tabular}{|c|c|c|c|}
\hline Núcleos & Spin & $\mathrm{N}^{\circ}$ de linhas & Desdobramentos (Gauss) \\
\hline${ }^{1} \mathrm{H}$ & $1 / 2$ & 2 & $0-6$ \\
\hline${ }^{14} \mathrm{~N}$ & 1 & 3 & $0-20$ \\
\hline${ }^{19} \mathrm{~F}$ & $1 / 2$ & 2 & $0-30$ \\
\hline${ }^{63} \mathrm{Cu}$ & $3 / 2$ & 4 & $20-200$ \\
\hline${ }^{65} \mathrm{Cu}$ & $3 / 2$ & 4 & $20-200$ \\
\hline${ }^{95} \mathrm{Mo}$ & $5 / 2$ & 6 & 40 \\
\hline${ }^{97} \mathrm{Mo}$ & $5 / 2$ & 6 & 40 \\
\hline${ }^{55} \mathrm{Mo}$ & $5 / 2$ & 6 & 95 \\
\hline${ }^{51} \mathrm{~V}$ & $\mathbf{7 / 2}$ & $\mathbf{8}$ & $\mathbf{2 0 - 2 0 0}$ \\
\hline
\end{tabular}

Em muitos casos, as posições e os desdobramentos das linhas, especificadas pelos valores de $\mathrm{g}$ e das constantes hiperfinas (A), dependem da direção do campo magnético com relação aos eixos moleculares, isto é, da simetria molecular.

Visando obter maiores informações sobre a orientação dos ligantes ao redor do vanádio e confirmação do seu estado de oxidação, prepararam-se amostras sólidas, com massa de $\sim 0,020 \mathrm{~g}$, e soluções dos complexos em DMSO e em DMSO/ $\mathrm{H}_{2} \mathrm{O}$ 3:2, com concentrações de $\sim 3,5 \times 10^{-3} \mathrm{~mol}^{-L^{-1}}$, registrando-se os respectivos espectros, à temperatura de $77 \mathrm{~K}$. Os espectros correspondentes no estado sólido e em solução são apresentados nas Figuras $\mathbf{4 0}$ a $\mathbf{5 3}$ e os valores correspondentes de giso na Tabela 7, enquanto os dados de g// e A// são mostrados na Tabela 8. 
A partir dos espectros EPR dos complexos de vanádio(IV), no estado sólido, obtiveram-se informações razoáveis quanto à confirmação do estado de oxidação do metal. Porém, estes espectros ainda não forneceram informações sobre a vizinhança ao redor dos íons vanadila, pois não apresentaram linhas hiperfinas definidas, como será observado nos espectros em solução.

Para todos os espectros dos vários compostos, observou-se um valor isotrópico de giso correspondente, que é obtido no cruzamento do centro da linha com a linha base, como mostrado nos espectros acima. Estes valores, mostrados na Tabela 7, foram consistentes com o valor usual, da ordem de 2,0, característico dos complexos de vanádio(IV) para um estrutura geométrica piramidal de base quadrada, de acordo com a literatura [72].

Para os complexos $\quad\left[\mathrm{V}^{\mathrm{IV}} \mathrm{O}(\mathrm{acac})_{2}\right], \quad\left[\mathrm{V}^{\mathrm{IV}} \mathrm{O}(\right.$ salen $\left.)\right], \quad\left[\mathrm{V}^{\mathrm{IV}} \mathrm{O}(\mathrm{dbhbal})_{2}\right]$, $\left.\mathrm{Na}_{2}\left[\mathrm{~V}^{\mathrm{IV}} \mathrm{O} \text { (cetoglut) }\right)_{2}\right]$ e $\left.\left(\mathrm{NH}_{4}\right)_{3}\left[\mathrm{~V}^{\mathrm{IV}} \mathrm{O}_{2} \text { (cetoglut) }\right)_{2}\right]$, não se observaram linhas hiperfinas. Entretanto, nos espectros dos complexos $\left[\mathrm{V}^{\mathrm{IV}} \mathrm{O}(\mathrm{dbhab})\right]_{2}$ e $\mathrm{NH}_{4}\left[\mathrm{~V}^{\mathrm{IV}} \mathrm{O}_{2}(\mathrm{dbhab})\right]$ elas foram observadas, embora não tão bem definidas quanto em solução. Estes complexos possuem uma estrutura geométrica com maior simetria em relação ao outros complexos, como pode ser visto também em solução e será discutido abaixo.

Para o complexo $\left[\mathrm{V}^{\mathrm{IV}} \mathrm{O}(\mathrm{dbhab})\right]_{2}$ as poucas linhas hiperfinas observadas podem ser atribuídas a uma possível interação de dois núcleos de vanádio próximos, confirmando assim uma estrutura dimérica, como foi proposto ao longo deste trabalho para este complexo. 


\subsubsection{Espectros EIPR dos Complexos de Vanádio(IV) em solução}

A seguir são mostrados os espectros EPR resgistrados em solução, para cada um dos compostos de vanádio estudados.

\subsubsection{Espectros EPR do composto $\left[\mathrm{V}^{\mathrm{IV}} \mathrm{O}(\mathrm{acac})_{2}\right]$}

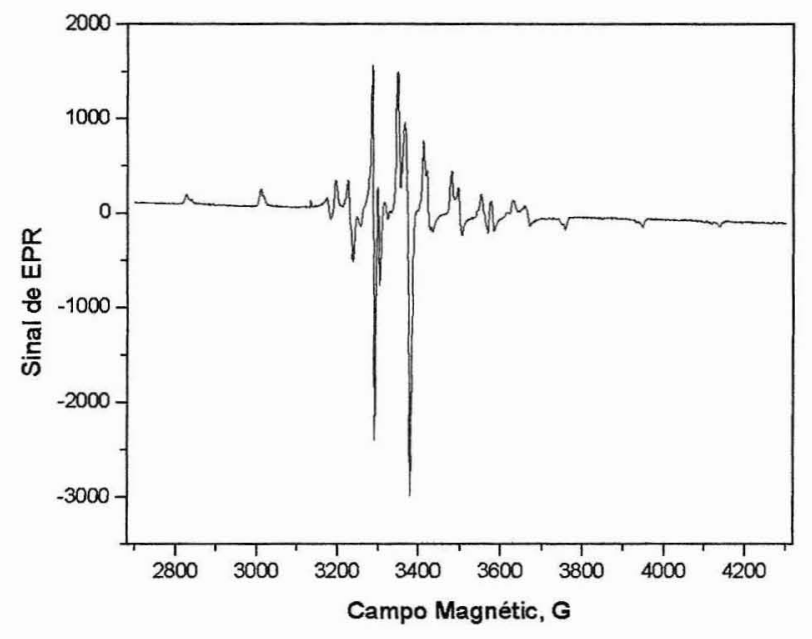

Figura 47. Espectro EPR do composto $\left[\mathrm{V}^{\mathrm{IV}} \mathrm{O}(\mathrm{acac})_{2}\right]$ em solução de etanol com concentração de $3,3 \times 10^{-3} \mathrm{~mol}^{-L^{-1}}$ em etanol à temperatura de $77 \mathrm{~K}$.

\subsubsection{Espectros EPR do composto [ $\mathrm{V}^{\mathrm{IV}} \mathrm{O}($ salen)]}

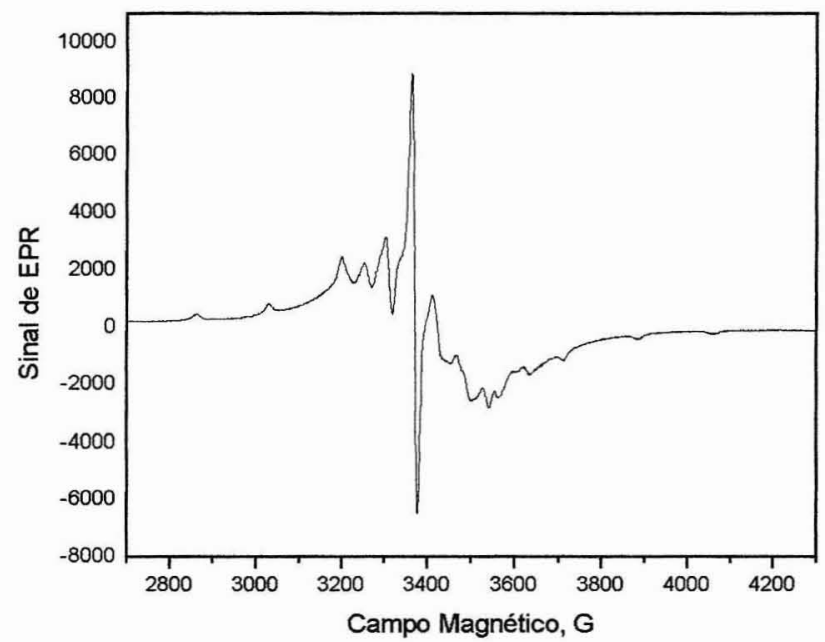

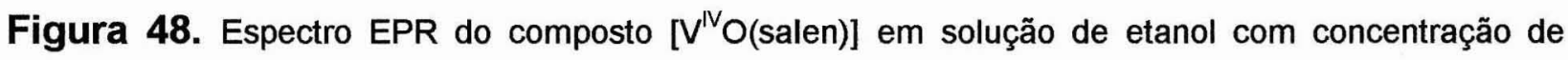
$3,1 \times 10^{-3} \mathrm{~mol} . \mathrm{L}^{-1} \mathrm{em}$ etanol à temperatura de $77 \mathrm{~K}$. 


\subsubsection{Espectros EPR do composto $\left[\mathrm{V}^{\mathrm{IV}} \mathrm{O}(\mathrm{dbhbal})_{2}\right]$}

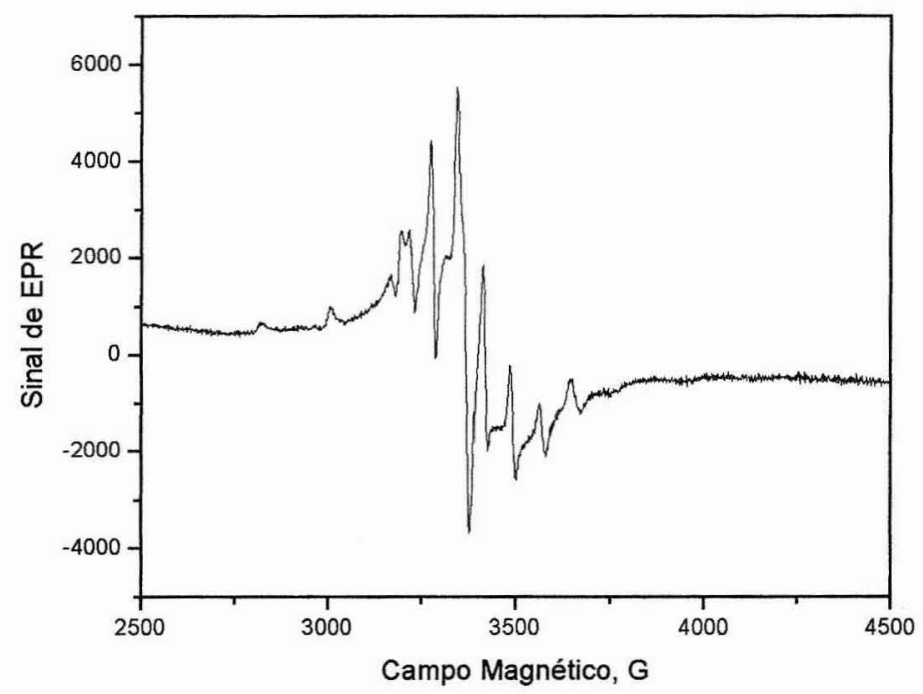

Figura 49. Espectro EPR do composto $\left[\mathrm{V}^{\mathrm{IV}} \mathrm{O}(\mathrm{dbhbal})_{2}\right]$ em solução de DMSO com concentração de $2,7 \times 10^{-3}$ mol. $\mathrm{L}^{-1} \mathrm{em}$ etanol à temperatura de $77 \mathrm{~K}$.

\subsubsection{Espectros EPR do composto $\left[V^{1 \mathrm{~V}} \mathrm{O}(\mathrm{dbhab})\right]_{2}$}

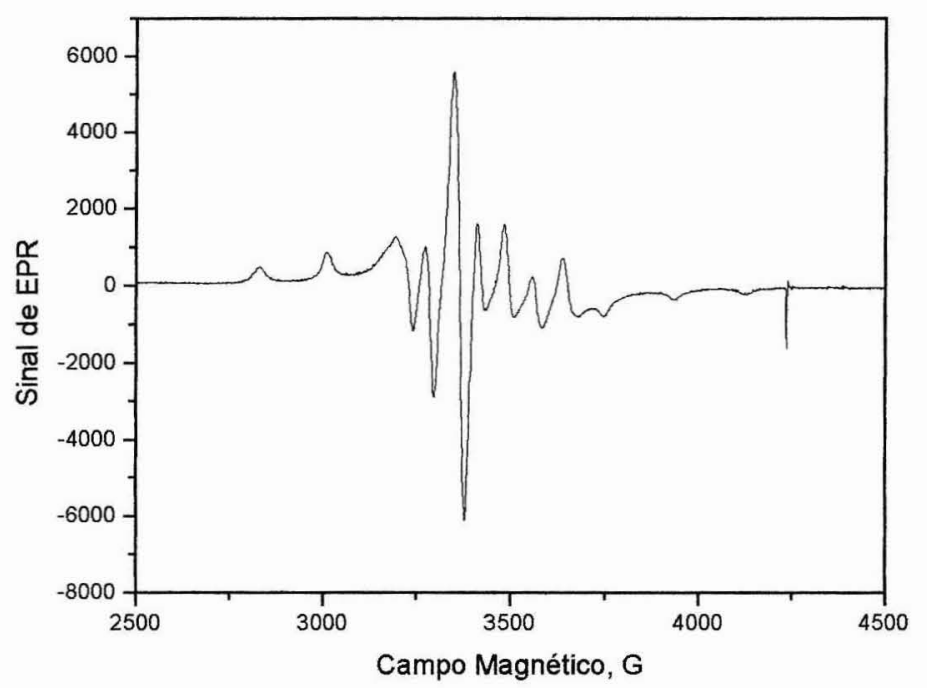

Figura 50. Espectro EPR do composto $\left[\mathrm{V}^{\mathrm{lV}} \mathrm{O}(\mathrm{dbhab})\right]_{2}$ em solução de DMSO com concentração de $3,9 \times 10^{-3} \mathrm{~mol} . \mathrm{L}^{-1}$ em DMSO à temperatura de $77 \mathrm{~K}$. 


\subsubsection{Espectros EPR do composto $\mathrm{NH}_{4}\left[\mathrm{~V}^{\mathrm{IV}} \mathrm{O}_{2}\right.$ (dbhab)]}

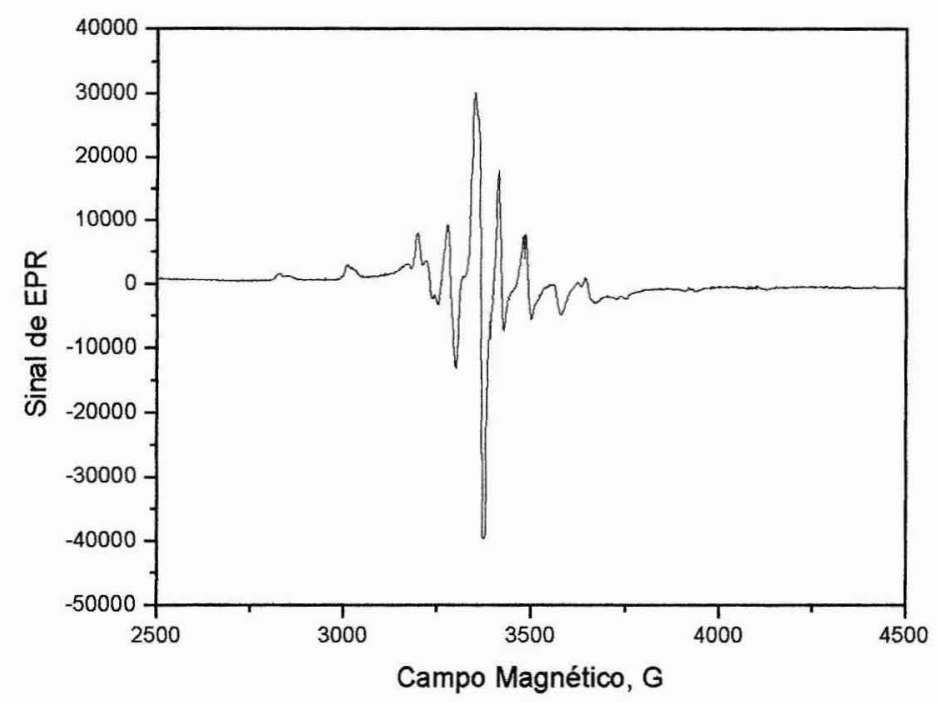

Figura 51. Espectro EPR do composto $\mathrm{NH}_{4}\left[\mathrm{~V}^{\mathrm{V}} \mathrm{O}_{2}\right.$ (dbhab)] em solução de DMSO com concentração de $4,1 \times 10^{-3} \mathrm{~mol}^{-L^{-1}}$ em DMSO à temperatura de $77 \mathrm{~K}$.

\subsubsection{Espectros EPR do composto $\left.\mathrm{Na}_{2}\left[\mathrm{~V}^{\mathrm{lV}} \mathrm{O} \text { (cetoglut) }\right)_{2}\right]$}

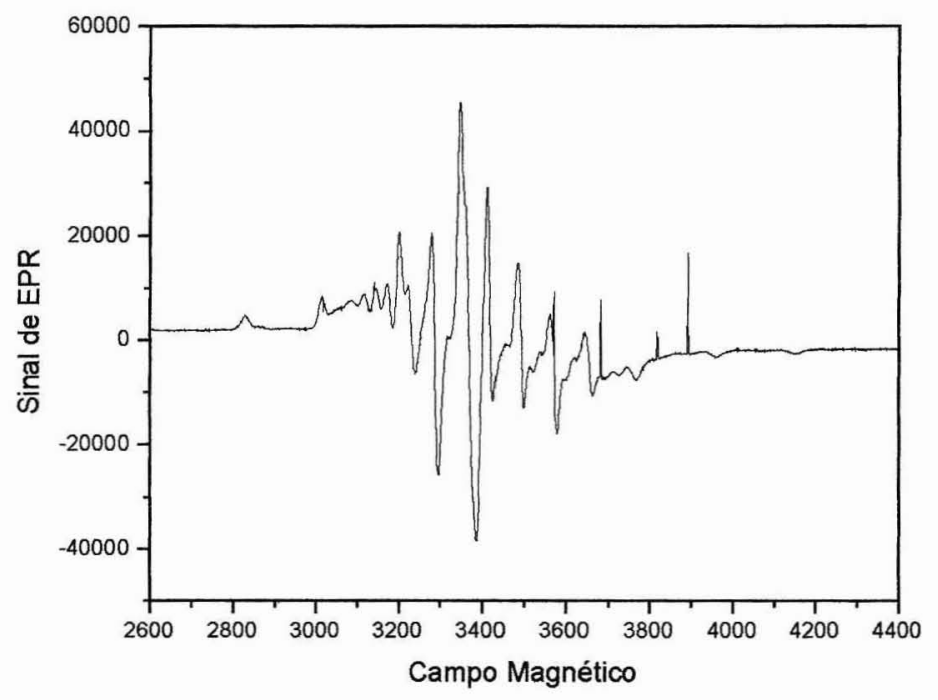

Figura 52. Espectro EPR do composto $\mathrm{Na}_{2}\left[\mathrm{~V}^{\mathrm{V}} \mathrm{O}(\text { cetoglut })_{2}\right]$ em solução de $\mathrm{DMSO} / \mathrm{H}_{2} \mathrm{O}$ com concentração de $3,1 \times 10^{-4} \mathrm{~mol}^{-L^{-1}}$ em DMSO à temperatura de $77 \mathrm{~K}$. 


\subsubsection{Espectros EPR do composto $\left.\left(\mathrm{NH}_{4}\right)_{3}\left[\mathrm{~V}^{\mathrm{IV}} \mathrm{O}_{2} \text { (cetoglut }\right)_{2}\right]$}

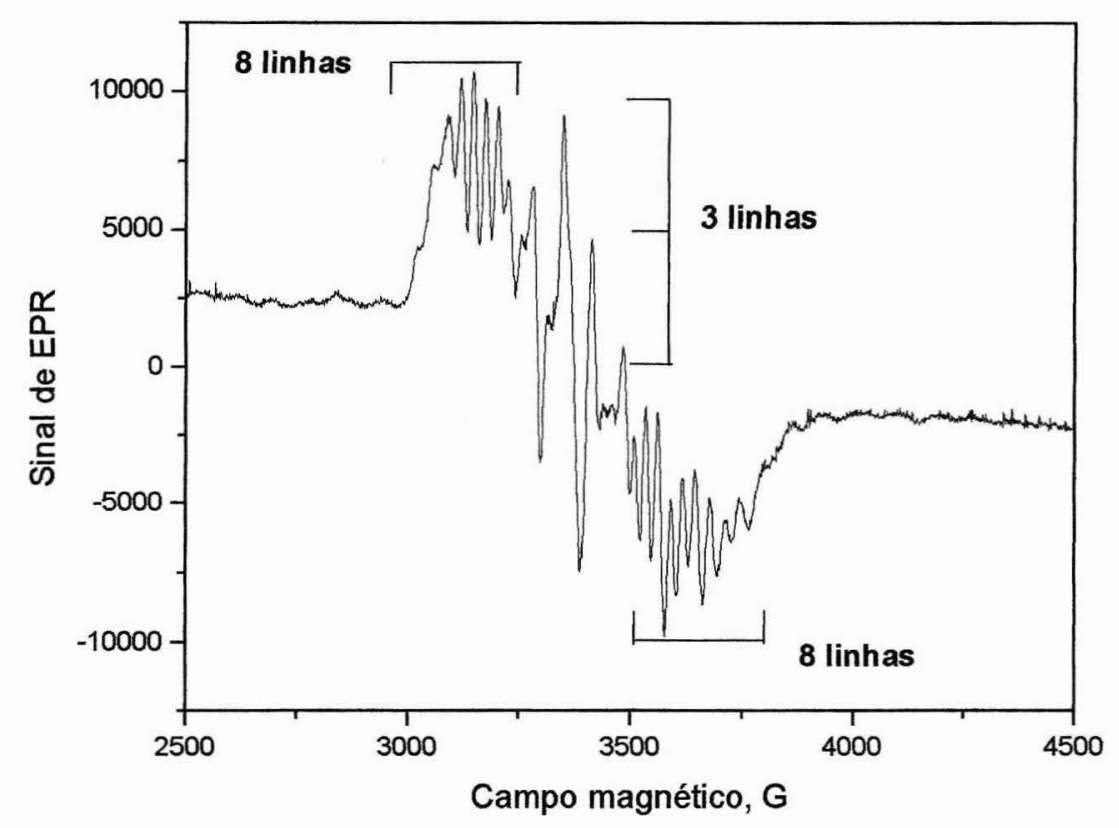

Figura 53. Espectro EPR do composto $\left.\left[V^{1 /} \mathrm{O}_{2} \text { (cetoglut) }\right)_{2}\right]$ em solução de $D M S O / \mathrm{H}_{2} \mathrm{O}$ com concentração de $3,1 \times 10^{-4}$ mol. $L^{-1}$ em DMSO à temperatura de $77 \mathrm{~K}$. 
Tabela 8. Valores dos parâmetros $g$ e das constantes hiperfinas (A) dos compostos, em solução de etanol, DMSO ou DMSO/ $\mathrm{H}_{2} \mathrm{O}$ 1,5:1, a temperatura de $77 \mathrm{~K}$ (Dewar com $\mathrm{N}_{2}$ líquido). DPPH (difenil picril hidrazil) foi utilizado como padrão de referência.

\begin{tabular}{|c|c|c|}
\hline Composto & $\mathrm{g} / /$ & $\mathrm{A}_{/ /}$ \\
\hline$\left[\mathrm{V}^{\mathrm{IV}} \mathrm{O}(\text { acac })_{2}\right]$ & $\begin{array}{l}1,94 \\
1,95 \text { [literatura, } 73]\end{array}$ & 186,8 \\
\hline$\left[\mathrm{V}^{\mathbb{V} \mathrm{O}(\text { salen })]}\right.$ & 1,98 & 171,4 \\
\hline$\left[\mathrm{V}^{\mathrm{N}} \mathrm{O}(\mathrm{dbhbal})_{2}\right]$ & 2,03 & 185,8 \\
\hline$\left[\mathrm{V}^{\mathrm{V}} \mathrm{O}(\mathrm{dbhab})\right]_{2}$ & 1,95 & 181,6 \\
\hline $\mathrm{NH}_{4}\left[\mathrm{~V}^{\mathrm{IV}} \mathrm{O}_{2}(\mathrm{dbhab})\right]$ & 1,98 & 183,7 \\
\hline $\left.\mathrm{Na}_{2}\left[\mathrm{~V}^{\mathrm{IV}} \mathrm{O} \text { (cetoglut) }\right)_{2}\right] \cdot 2 \mathrm{H}_{2} \mathrm{O}$ & 2,04 & 185,8 \\
\hline$\left.\left(\mathrm{NH}_{4}\right)_{3}\left[\mathrm{~V}^{\mathrm{V}} \mathrm{O}_{2} \text { (cetoglut }\right)_{2}\right]$ & 2,12 & ----- \\
\hline $\begin{array}{c}\text { cis- }\left[\mathrm{NO}\left({ }_{3} \mathrm{COOHpzc}\right)_{2}\left(\mathrm{H}_{2} \mathrm{O}\right)\right] \\
\text { Referência [74] }\end{array}$ & 1,94 & 168 \\
\hline
\end{tabular}


Os complexos de vanádio no estado de oxidação (IV), com configuração $d^{1}$, têm apenas um elétron desemparelhado no orbital $\underline{\mathrm{d}}$. como mostra o diagrama da Figura 54, onde o íon vanadila apresenta geometria bipiramidal triangular. Os íons vanádio(IV) são paramagnéticos e possuem spin nuclear de 7/2. Portanto, os estados são divididos em $2 l+1=8$, se a configuração eletrônica ao redor do vanádio tiver um único eixo de simetria. Ao se obter o espectro em $1^{\text {a }}$ derivada, observa-se a sobreposição de 2 espectros de 8 linhas cada, com diferentes separações das hiperfinas, devido ao núcleo de vanádio ${ }^{51} \mathrm{~V}$. O Vanádio no estado de oxidação(V) apresenta espectro silencioso, já que não possui elétrons isolados para interagir com o campo magnético [72].

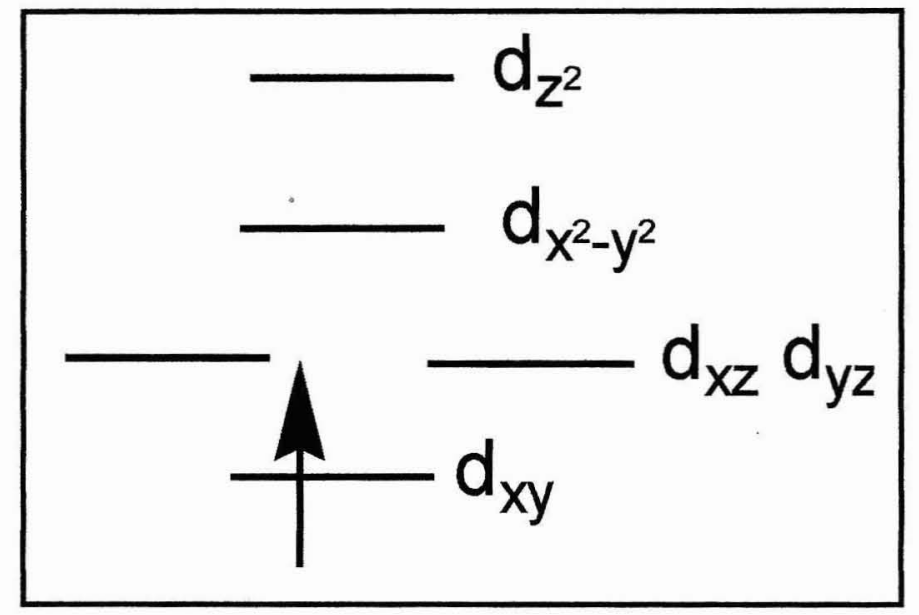

Figura 54. Níveis de energia para o elétron $\underline{\mathrm{d}}$ do íon vanadila, $\mathrm{VO}^{2+}$, com simetria axial

Como a espectroscopia de EPR examina a transição entre os estados de spin em presença de um campo magnético externo, estes estados são separados por uma energia dependente do valor de g observado nas espécies (o valor teórico para o elétron livre é, $g=2,0023$ ) e o campo magnético, como mostrado na Figura 55 . Os valores de g no espectro EPR dos complexos de vanádio(IV) obtidos, são tipicamente menores que os valores teóricos do elétron livre, sendo usualmente iguais a 1,95, vide Tabela 8. 


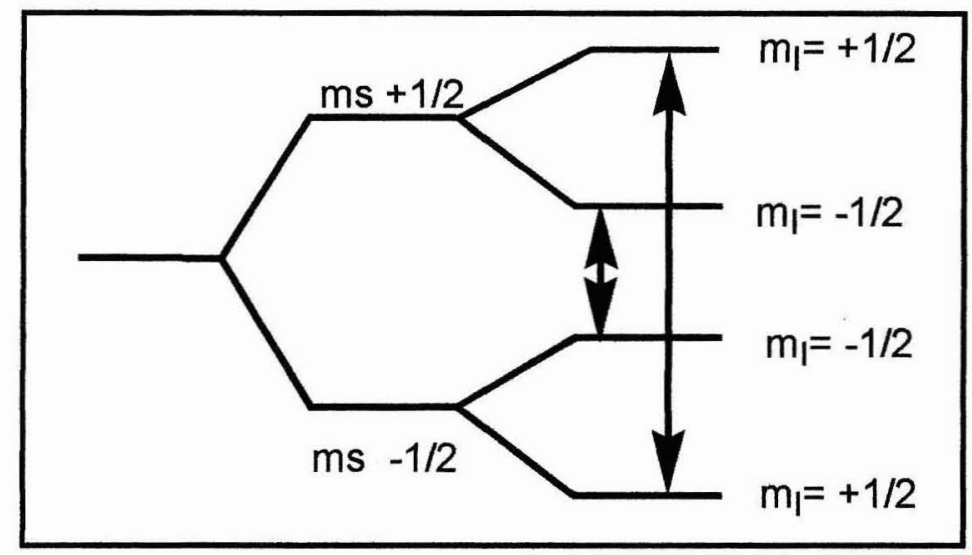

Figura 55. Transições de spin esperadas para um sistema com spin nuclear $I=1 / 2$ e spin eletrônico $S=1 / 2$.

O valor de $\mathrm{A} / \mathrm{f}$ foi obtido a partir da distância entre as duas linhas mais extremas observadas nos espectros e dividindo-a por 7 (correspondente a 8 linhas). Os valores obtidos são consistentes com valores da literatura para complexos similares, ver Tabela 8 [72].

Os complexos de vanádio no estado de oxidação(IV) possuem tipicamente geometria quadrado planar que a depender do tipo de ligante coordenado ao metal pode estar com a geometria mais ou menos distorcida, nos eixos xy e z. Observa-se que os complexos $\quad\left[\mathrm{V}^{\mathrm{IV} O} \mathrm{O}(\mathrm{acac})_{2}\right], \quad\left[\mathrm{V}^{\mathrm{IV} O} \mathrm{O}(\mathrm{dbhab})\right]_{2}, \quad \mathrm{NH}_{4}\left[\mathrm{~V}^{\mathrm{IV}} \mathrm{O}_{2}\right.$ (dbhab) $] \quad$ e $\left.\mathrm{Na}_{2}\left[\mathrm{~V}^{\mathrm{IV}} \mathrm{O} \text { (cetoglut) }\right)_{2}\right]$ possuem estrutura mais simétrica, mais próxima de uma pirâmide de base quadrada, com pequenas distorções nos eixos $x y$, enquanto que para os complexos $\left[\mathrm{V}^{\mathrm{IV} O} \mathrm{O}\right.$ (salen)], [ $\left.\mathrm{V}^{\mathrm{IV} O} \mathrm{O}(\mathrm{dbhbal})_{2}\right]$ e $\left.\left(\mathrm{NH}_{4}\right)_{3}\left[\mathrm{~V}^{\mathrm{IV}} \mathrm{O}_{2} \text { (cetoglut) }\right)_{2}\right]$ os espectros indicam uma distorção maior.

Através da espectroscopia de EPR, foi possível confirmar nos complexos estudados o estado de oxidação do metal. Para os complexos $\left[\mathrm{V}^{\mathrm{IV}} \mathrm{O}(\mathrm{acac})_{2}\right]$,

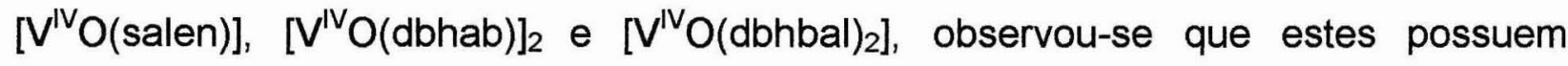


espectro de até 16 linhas hiperfinas como esperado, confirmando assim seu estados de oxidação (IV).

Os complexos $\mathrm{NH}_{4}\left[\mathrm{~V}^{\prime V} \mathrm{O}_{2}(\mathrm{dbhab})\right]$ e $\left.\left(\mathrm{NH}_{4}\right)_{3}\left[\mathrm{~V}^{\mathrm{IV}} \mathrm{O}_{2} \text { (cetoglut) }\right)_{2}\right]$ foram inicialmente caracterizados com estado de oxidação(V), a partir da análise elementar, pois em sua síntese utilizou-se como precursor o metavanadato de amônio. Porém, através das análises dos espectros de UVNis em conjunto com o de EPR pode-se constatar que nestes complexos o vanádio na realidade está no estado de oxidação (IV), pois estes apresentaram sinais característicos deste estado de oxidação e não foram silenciosos no EPR, como seria esperado. No espectro de UVNis observaram-se bandas de transição d-d característica de complexos de vanádio(IV) na região de 600 a 800 nm. Possivelmente o ligante, bem como as condições utilizadas nas sínteses, provocaram a redução do vanádio do estado de oxidação(V) para (IV), como foi mostrado nas reações da página 23 [3].

No espectro do complexo $\left.\left(\mathrm{NH}_{4}\right)_{3}\left[\mathrm{~V}^{\mathrm{V} V} \mathrm{O}_{2} \text { (cetoglut }\right)_{2}\right]$ observam-se várias linhas hiperfinas, deixando-o bem complicado, o que foi atribuído a uma possível interação entre os centros de vanádio através de pontes entre os íons amônio e os ligantes carboxilatos [74]. Observam-se neste espectro pelo menos 19 linhas hiperfinas, sendo que 16 delas são devidas ao núcleo de ${ }^{51} \mathrm{~V}$ e outras 3 à interação do elétron com os núcleos de ${ }^{14} \mathrm{~N}$. 


\section{CONCLUSÕES}

Diferentes complexos de vanádio(IV) com ligantes do tipo imínico e carboxilato, mono- e dinucleares, foram isolados e caracterizados por diferentes técnicas espectroscópicas (UV/Vis, FT/IR e EPR), além de Análise Elementar, medidas de Condutividade Molar e Análises Termogravimétricas. As rotas sintéticas utilizadas foram bastante eficientes e as sínteses foram bem sucedidas, de acordo com os rendimentos obtidos e as caracterizações realizadas.

Através dos dados obtidos e de comparações com dados obtidos da literatura para compostos semelhantes, pode-se confirmar e elucidar a estrutura proposta, bem como o estado de oxidação do vanádio nos vários complexos sintetizados. Por exemplo, para os compostos $\mathrm{NH}_{4}\left[\mathrm{~V}^{\mathrm{IV}} \mathrm{O}_{2}\right.$ (dbhab)] e $\left.\left(\mathrm{NH}_{4}\right)_{3}\left[\mathrm{~V}^{\mathrm{IV}} \mathrm{O}_{2} \text { (cetoglut) }\right)_{2}\right]$ que inicialmente se pensava ser compostos no estado de oxidação (V), dados de espectroscopia UVNis e EPR indicaram estado de oxidação (IV). Através da espectroscopia de EPR pode-se confirmar ainda a natureza dimérica do complexo $\left[\mathrm{V}^{\mathrm{IV}} \mathrm{O}(\mathrm{dbhab})\right]_{2}$, bem como elucidar sua estrutura que possui maior simetria quando comparada à do complexo $\mathrm{NH}_{4}\left[\mathrm{~V}^{\mathrm{IV}} \mathrm{O}_{2}\right.$ (dbhab)], que possui o mesmo ligante, porém com arranjo geométrico diferente.

Comparando-se os espectros EPR dos compostos $\mathrm{Na}_{2}\left[\mathrm{~V}^{\mathrm{IV}} \mathrm{O}_{2}\right.$ (cetoglut) $\left.{ }_{2}\right]$ e $\left.\left(\mathrm{NH}_{4}\right)_{3}\left[\mathrm{~V}^{\mathrm{IV}} \mathrm{O}_{2} \text { (cetoglut) }\right)_{2}\right]$ observaram-se diferenças significativas quanto à forma e ao número de linhas hiperfinas. Essas diferenças foram atribuídas a interações mais fortes entre íons de vanádio, no caso do $2^{\circ}$ composto, através de pontes feitas pelos íons amônio e os ligantes carboxilatos. 
Com o auxílio da técnica de FT/IR pode-se comprovar que os átomos de nitrogênio, além dos de oxigênio, são prováveis pontos de coordenação ao metal nos complexos contendo ligantes imínicos, devido aos deslocamentos observados das bandas de estiramento $v(\mathrm{C}=\mathrm{N})$ no ligante livre e no metal. Através desta técnica também foi possível confirmar os diversos grupos funcionais $(\mathrm{C}=\mathrm{O}, \mathrm{C}=\mathrm{N}, \mathrm{N}-\mathrm{H}$, etc.) existentes tanto nas iminas não-metaladas, quanto nos correspondentes complexos de vanádio(IV).

Através da análise termogravimétrica, pode-se confirmar a proporção estequiométrica ligante:metal no complexo $\left[\mathrm{V}^{\mathrm{IV}} \mathrm{O}(\mathrm{dbhab})\right]_{2}$, podendo-se inferir que este é uma espécie dimérica, como inicialmente proposto e corroborado pelas medidas de condutividade.

Através de medidas de condutividade molar foi possível também verificar que os compostos $\left[\mathrm{V}^{\mathrm{IV}} \mathrm{O}(\mathrm{dbhbal})_{2}\right]$ e $\left[\mathrm{V}^{\mathrm{IV}} \mathrm{O}(\mathrm{dbhab})\right]_{2}$ são neutros, enquanto os complexos $\mathrm{NH}_{4}\left[\mathrm{~V}^{\mathrm{IV}} \mathrm{O}_{2}\right.$ (dbhab)], $\left.\mathrm{Na}_{2}\left[\mathrm{~V}^{\mathrm{IV}} \mathrm{O} \text { (cetoglut) }\right)_{2}\right] \cdot 2 \mathrm{H}_{2} \mathrm{O}$ e $\left.\left(\mathrm{NH}_{4}\right)_{3}\left[\mathrm{~V}^{\mathrm{IV}} \mathrm{O}_{2} \text { (cetoglut) }\right)_{2}\right]$ são eletrólitos $1: 1,2: 1$ e 3:1, respectivamente, em solução.

Os novos complexos de vanádio aqui estudados constituem exemplos de compostos que provavelmente apresentam alguma atividade catalítica. No meio científico há um grande interesse pela síntese e caracterização de complexos deste tipo, tanto no estado de oxidação(IV) quanto (V), devido às suas variadas aplicações como catalisadores de oxidação ou como miméticos de haloperoxidases. 


\section{REFERÊNCIAS}

[1] N. N. Greenwood, A. Earnshaw, Chemistry of the Elements, $2^{\text {nd }}$ ed., Elsevier, 1997.

[2] F. A. Cotton, G. Wilkinson, C. A. Murillo, M. Bochmann, Advanced Inorganic Chemistry, $6^{\text {th }}$ ed., New York, Jonh Wiley, 1999.

[3] N. Winbereg, A. F. Holleman, Inorganic Chemistry, $34^{\text {th }}$ ed., New York, Academic Press, 1995.

[4] D. Rehder, The Biochemistry of Vanadium. Angew. Chem. Int. Ed. Engl., 30 (1991) 148.

[5] B. R. Nechay, L. B. Naninga, P. S. E. Nechay, R. L. Post, J. J. Grantham, I. G. Macara, L. F. Kubena, D. P. Timothy, F. H. Nielson, Role of vanadium in Biology. Fed. Proc., 45 (1986) 123.

[6] H. Kneifel, E. Bayer, Determination of structure of vanadium compound, amavadine, from fly agaric. Angew. Chem. Int. Ed. Engl., 129 (1973) 508.

[7] E. J. Baran, Oxovanadium(IV) and Oxovanadium(V) complexes relevant to biological systems. J. Inorg. Biochem., 80 (2000) 1.

[8] C. K. Dash, Chemistry of vanadium and molybdenum complexes some results and future prospects. J. Indian Chem. Soc., 72 (1995) 359.

[9] P. Poucheret, S. Verma, M. D. Grynpas, J. H. McNeil, Vanadium and diabetes. Mol. Cel. Biochem., 188 (1998) 73. 
[10] Y. Shechter, I. Goldwaser, M. Mironchhik, M. Frickin, D. Gefel, Historic perspective and recent developments on the insulin-like actions of vanadium; toward developing vanadium based drugs for diabetes. Coord. Chem. Rev., 237 (2003) 3.

[11] D. Rehder, Biological and medicinal aspects of vanadium. Inorg. Chem. Commun., 6 (2003) 604.

[12] D. Rehder, J. C. Pessoa, et. al., In vitro of the insulin-mimetic behavior of vanadium(IV, V) coordination compounds. J. Biol. Inorg. Chem., 7 (2002) 384.

[13] D. C. Crans, Chemistry and insulin-like properties of vanadium(IV) and vanadium(V) compounds. J. Inorg. Biochem., 80 (2000) 123.

[14] Y. Dong, R. K. Narla, E. Sudbeck, F. M. Uckun, Synthesis, X-ray structure, and antileukemic activity oxovanadium(IV) complexes. J. Inorg. Biochem., 78 (2000) 321.

[15] C. Hiort, J. Goodisman, J. C. Dabrowiok, Cleavage of DNA by the insulinum-mimetic compound, $\mathrm{NH}_{4}\left[\mathrm{VO}\left(\mathrm{O}_{2}\right)_{2}\right.$ (phen)]. Biochem., 35 (1996) 12354.

[16] G. Verquin, et. al. DNA modification by oxovanadium(IV) complexes of salen derivatives. J. Biol. Inorg. Chem., 9 (2004) 345.

[17] A. G. J. Ligtenbarg, R. Hage, B. L. Feringa, Catalytic oxidations by vanadium complexes. Coord. Chem., 237 (2003) 89.

[18] A. Butler, Mechanist considerations of the vanadium haloperoxidases. Coord. Chem. Rev., 187 (1999) 17.

[19] R. R. Everett, J. R. Everett, A. Knofsky, A. Butler, Mechanist investigations of the novel non-heme vanadium haloperoxidases. Evidence for singlet oxygen production. J. Biol. Chem., 265 (1990) 4908. 
[20] A. Messerschmidt, R. Wever, X-ray structure of a vanadium-containing enzyme: chloroperoxidase from fungus Curvularia. Acad. Sci., 93 (1996) 392.

[21] A. Butler, Vanadium haloperoxidases, Curr. Op. Chem. Biol. 2 (1998) 279.

[22] A. Messerschmidt, L. Prade, R. Wever, Implications for the catalytic mechanism of the vanadium-containing enzyme choloperoxidase from the fungus Curvularia inaequalis by $\mathrm{x}$-ray structures of the native and peroxide form. Biol. Chem., 378 (1997) 309.

[23] N. Mizuno, Y. Nakagawa, K. Yamaguchi, Bis( $\mu$-hidroxo) bridged di-vanadiumcatalyzed selective epoxidation ol alkenes with $\mathrm{H}_{2} \mathrm{O}_{2}$. J. Mol. Catal. A: Chem. 251 (2006) 286.

[24] S. Bunce, R. J. Cross, et al., Chiral Schiff base complexes of copper(II), vanadium(IV) and nickel(II) as oxidation catalysts. X-ray crystal structures of $[\mathrm{Cu}(\mathrm{R}-$ salpn] and [Cu(土-busalcx)]. Polyhedron, 17 (1998) 4179.

[25] T. K. Si, K. Chowdhury, M. Mukherjee, D. C. Ber, Homogeneous selective peroxidic oxidation of hydrocarbons using an oxovanadium based catalyst. J. Mol. Catal. A: Chem. 219 (2004) 241.

[26] R. Ando, T. Yagyu, M. Maeda, Characterization of oxovanadium (IV)-Schiff-base complexes and those bound on resin, and their use in sulfide oxidation. Inorg. Chem., 357 (2004) 2237.

[27] G. Franz, R. U. Sheldon, Encyclopedia of Industrial Chemistry, Elvers, VCH, vol. A Weiheim, 1991.

[28] D. F. Shriver, P.W. Atkins, Inorganic Chemistry, $3^{\text {rd }}$ ed., Oxford, 1999. 
[29] L. V. Boasand, J. C. Pessoa, Comprehensive Coordination Chemistry, eds. G. Wilkinson, R. D. Gillard, J. A. McCLEVERTY, vol. 3, Oxford, Pergamon, 1987.

[30] J. Selbin, Chemistry of oxovanadium. Chem. Rev., 65 (1965) 153.

[31] S. B. Etcheverry, P. A. M. Williams, E. J. Baran, Synthesis and Characterization of a solid vanadyl((IV) complexes of D-glucuronic acid. J. Inorg. Biochem., 63 (1996) 285.

[32] G. Asgedom, A. Sreedhara, J. KiviKoski, C. P. Rao, Synthesis and characterization of vanady|(IV) complexes of Schiff bases derived from anthranilic acid and salicylaldehyde (or its derivatives) or acetylacetone. Single crystal X-ray structures of the oxidized products. Polyhedron, 16 (1997) 643.

[33] C. J. Carrano, C. M. Nunn, R. Quan, J. A. Bonadies, V. L. Pecoraro, Monomeric and dimeric vanadium(IV) and -(IV)complexes of $\mathrm{N}$-(hydroxyalkyl)salicylideneamines: structures magnetochemistry and reactivity. Inorg. Chem., 29 (1990) 944.

[34] M. Kojima, H. Taguchi, M. Tsuchimoto, K. Nakajima, Tetradentate Schiff baseoxovanadium(IV) complexes: Strucuture and reactivities in the solid state. Coord. Chem. Rev., 237 (2003) 183.

[35] Y. H. Xing, K. Aoki, F. Y. Bai, A new insulin-like vanadyl complex: synthesis and structure of $\left[\mathrm{V}(\mathrm{IV}) \mathrm{O}\left(\mathrm{H}_{2} \mathrm{O}\right)_{2}\left(2,6\right.\right.$-pyridinedicarboxylate) $\left.\cdot 2 \mathrm{H}_{2} \mathrm{O}\right]$. J. Coord. Chem., 57 (2004) 157.

[36] M. R. Maurya, Development of the coordination chemistry of vanadium through bis(acetylacetonato)oxovanadium(IV): synthesis, reactivity and structural aspects. Coord. Chem. Rev., 237 (2003) 163. 
[37] D. Rehder, G. Santoni, Structural models for the reduced form of vanadatedependent preoxidases: vanadyl complexes with bidentate chiral Schiff base ligands, J. Inorg. Biochem., 98 (2004) 758.

[38] R. Ando M. Nagai, T. Yagyu, M. Maeda, Composition and geometry of oxovanadium (IV) and (V)-aminoethanol-Schiff base complexes and stability of their peroxo complexes in solution, Inorg. Chimica Acta, 351 (2003) 107.

[39] R. Ando, T. Yagyu, M. Maeda, Characterization of oxovanadium(IV) Schiff base complexes and those bound on resin, and their use in sulfide oxidation, Inorg. Chimica Acta, 357 (2004) 2237.

[40] C. Djordjevic, M. Lee, E. Sinn, Oxo peroxo(citrato)- and Dioxocitrate(vanadates(V): Synthesis, spectra and structure of a Hidroxyl Oxigen Bridged Dimer, $\mathrm{K}_{2}\left[\mathrm{VO}(\mathrm{O})_{2}\left(\mathrm{C}_{6} \mathrm{H}_{6} \mathrm{O}_{7}\right)\right]_{2} \cdot 2 \mathrm{H}_{2} \mathrm{O}$. Inorg. Chem., 28 (1989) 719.

[41] G. J. Colpas, B. J. Hamastra, J. W. Kanpff, V.L. Pecoraro, The preparation of VO ${ }^{3+}$ and $\mathrm{VO}^{2+}$ complexes using hydrolytically stable, asymmetric ligands derived from Schiff base precursors, Inorg. Chem., 33 (1994) 4669.

[42] D. C. Crans, A. D. Keramidas, M. Mohroff-Tahir O. P. Anderson, M. M. Miller, Factors affecting solutions of vanadium( $V)$ compounds $X$-ray structure of $\beta$-cis $\mathrm{NH}_{4}\left(\mathrm{VO}_{2}(\mathrm{EDDA})\right]$, Inorg. Chem., 35 (1996) 3599.

[43] D. C. Crans et. al., Chemistry and Insulin-Mimetic Properties of Bis(acetylacetona)oxovanadium(IV) and Derivatives. Inorg. Chem., 39 (2000) 406.

[44] T. W. G. Solomons, Organic chemistry, $6^{\text {th }}$ ed. Vol. 1 and 2, New York, John Wiley, 1996.

[45] L. Stryer, The molecules of visual excitation. Sci. Am. , 257 (1987) 42. 
[46] M. B. Yim, H. S. Yim, C. Lee, S. O. Kang, P. B. Chock, Protein glycation - Creation of catalytic sites of catalytic sites for free radical generation. Ann. N. Y. Acad. Sci., 928 (2001) 48.

[47] W. L. F. Armarego, D. D. Perrin, Purification of Laboratory Chemicals, $3^{\text {rd }}$ ed., Australia, Pergamon Press, 1998.

[48] P. Guerriero, S. Tamburini, P. A. Vigato, From mononuclear to polynuclear macrocyclic or macroacylic complexes. Coord. Chem. Rev., 139 (1995) 17.

[49] P. A. Vigato, S. Tamburini, The challenge of cyclic and acyclic Schiff bases and related derivatives. Coord. Chem. Rev., 248 (2004) 1717.

[50] R. A. Rowe, M. M. Jones, Preparation from vanadium(V) oxid through prior reduction to oxovanadium(IV) ion. Inorg. Synth., 5 (1957) 114.

[51] R. Ando, H. Ono, T. Yagyu, M. Maeda, Spectroscopic and structural characterization of monuclear, binuclear and insoluble polynuclear oxovanadium(IV)-Schiff base complexes and their oxidation catalysis. Inorg. Chim. Acta, 357 (2004) 817.

[52] W. Wei, Z. Fu-li, W. Xin, T. Min-Yu, A study of oxovanadium(V) complex with a tridentate Schiff base ligands. Polyhedron, 15 (1996) 1699.

[53] E. R. Dockal, J. R. Zamian, Tetradentate Schiff base oxovanadium(IV) complexes, Transition Met. Chem., 21 (1996) 370.

[54] R. J. Hill, E. F. Rickard, Complexes of thorium(IV) and uranium(IV) with some Schiff base, J. Inorg. Nucl. Chem., 40 (1978) 793. 
[55] W. Linert, E. Herhinger, P. Margl, Spectroscopic electrochemical and quantum mechanical investigations of vanady|(IV)-acetylacetonate in non-aqueous solutions. J. Coord. Chem., 28 (1993) 1.

[56] C. J. Ballhausen, H. B. Gray, The Electronic Structure of the Vanadyl Ion, Inorg. Chem., 1 (1962) 111.

[57] D. M. Boghaei, S. Mohebi, Synthesis, Characterization and study of vanadyl tetradentate Schiff base complexes as catalyst in aerobic selective oxidation of olefins, J. Mol. Catal.: A: Chemical, 179 (2002) 41.

[58] R. M. Silverstain, G. C. Bassler, T. C. Morril, Spectrometry identification of organic compounds, $6^{\text {th }}$ ed., John Wiley, New York, 1998.

[59] J. A. Faniran, K. S. Patel, J. C. Bailar Jr, Infrared-spectra of N, N-Bis(salicylidene)1,1-dimethyl)ethylene-diimine and its metal complexes, J. Inorg. NuCl. Chem., 36 (1974) 1547.

[60] E. J. Baran, P. A. M. Williams, D. A. Barrio, S. B. Etcheverry, Characterization of oxovanadium(IV) complexes of D-gluconic and D-saccharic acids and their bioactivity on osteoblast-like cells in culture, J. Inorg. Biochem., 98 (2004) 333.

[61] R. Ando, H. Inden, M. Sugino, H. Ono, D. Sakaeda, T. Yagyu, M. Maeda, Spectroscopic characterization of amino acid and amino acid ester-Schiff-base complexes of oxovanadium and their catalysis in sulfide oxidation, Inorg. Chim. Acta, 357 (2004) 1337.

[62] S. B. Etcheverry, P. A. M. Williams, E. J. Baran, Synthesis and characterization of a solid vanadyl(IV) complex of D-Glucuronic Acid, J. Inorg,. Biochem., 63 (1996) 285.

[63] Wendlandt, W. W. Thermal Analysis, $3^{\text {rd }}$ ed., John Wiley, New York, 1986. 
[64] H. L. David, M. Ionashiro, A. V. Benedettí, J. R. Zamian, E. R. Dockal, Thermal decomposition of vanadyl Schiff-base compounds, Thermochim. Acta, 2002 (1992) 45.

[65] G. H. Jeffery, J. Bassett, J. Mendham, R. C. Denney, Análise Química Quantitativa Vogel, Guanabara Koogan, $5^{\mathrm{a}}$ ed., 1992.

[66] W. J. Geary, The use of conductivity measurements in organic solvents for the characterization of coordination compounds, Coord. Chem. Rev., 7 (1971) 81.

[67] A. S. Orabi, M. I. Ayad, A. E. M. Ramadan, Synthesis, characterization and oxidase catalytic activity of vanadium(IV) and oxovanadium(IV) complexes with Schiff base ligands derived from $\beta$-diketones, Transition Met. Chem., 23 (1998) 391.

[68] X. Zhang, X. You, Synthesis, characterization and crystal structure of a binuclear cis-dioxovanadium(V) Schiff base complex, Polyhedron, 15 (1996) 1793.

[69] P. W. Atkins, Físico-Química, Vol. 2, 6ª ed., Livros Técnicos e Científicos, 1997.

[70] F. E. Mabbs, D. Collinson, Electron Paramagnetic resonance of $d$ transition Metal compounds, N. Y., 1992.

[71] W.A. Alves, I.A. Bagatin \& A.M.D.C. FERREIRA*- Equilibria and tyrosinase activity of a dinuclear and its analogous tetranuclear imidazolate-bridged copper(II) complexes. Inorg. Chim. Acta, 321 (2001) 11.

[72] V. L. Pecoraro, R. LoBrutto, T. S. Smith II, Paramagnetic spectroscopy of vanadyl complexes and its applications to biological systems, Coord. Chem. Rev., 228 (2002) 1. 
[73] R. Öztürk, A. Gül, Construction of nanonuclear supramolecular structures from simple modular units, Tetrahedron Letters, 45 (2004) 947.

[74] E. Garribba, G. Micera, E. Lodyga-Chruscinska, D. Sanna, Oxovanadium(IV) Complexes with Pyrazinecarboxylic Acids: The coordinating Properties of Ligands with the $\left(\mathrm{N}_{\text {aromatic, }} \mathrm{COO}^{-}\right)$donor Set, Eur. J. Inorg. Chem., 13 (2006) 2690. 